The Institut français des relations internationales (Ifri) is a research center and a forum for debate on major international political and economic issues.

Headed by Thierry de Montbrial since its founding in 1979, Ifri is a nongovernmental and a non-profit organization.

As an independent think tank, Ifri sets its own research agenda, publishing its findings regularly for a global audience.

Using an interdisciplinary approach, Ifri brings together political and economic decision-makers, researchers and internationally renowned experts to animate its debate and research activities.

With offices in Paris and Brussels, Ifri stands out as one of the rare French think tanks to have positioned itself at the very heart of European debate.

The opinions expressed in this text are the responsibility of the authors alone.

This collective book was produced within the framework of a three-year research program focused on the governance of the geostationary orbits and associated radio frequencies. For its most part, it is based on the extensive discussion and stimulating exchanges that took place during a closed seminar organized in Paris by Ifri's Space Policy Program in April 2013. In 2014, a one-day conference open to all will be held to take stock of the situation. These three steps aim at placing the issue of the orbit/frequency governance at the heart of the European political agenda, by including decision-makers, relevant stakeholders within the space sector, and recognized experts and researchers.

ISBN: 978-2-36567-238-2

(c) All rights reserved, Ifri, 2014

IFRI

27, RUE DE LA PROCESSION 75740 PARIS CEDEX 15 - FRANCE

Tel: +33 (0)140616000

Fax: +33 (0)140616060

Email: accueil@ifri.org
IFRI-BRUXELLES

RUE MARIE-THERESE, 21 1000 - BRUSSELS - BELGIUM

Tel: +32 (0)2 2385110

Fax: +32 (0)2 2385115

Email: bruxelles@ifri.org

WEBSITE: Ifri.org 


\section{Ce qu'il faut retenir}

Un nombre sans cesse croissant d'acteurs ont accès à l'espace et bénéficient des avantages induits par son utilisation, notamment dans le secteur des télécommunications. Mais cette tendance confirme aussi une réalité qui se fait jour après jour de plus en plus pressante : il ne saurait y avoir de développement significatif des activités spatiales sans un environnement maîtrisé et exempt de brouillages, seul à même de garantir un accès durable aux fréquences radioélectriques et aux positions sur l'orbite géostationnaire dont dépendent les satellites pour leur exploitation.

Or la multiplication ces dernières années des cas de brouillages préjudiciables, notamment des interférences délibérées dont le but explicite est d'empêcher la diffusion d'une certaine information et contre lesquelles aucune solution technique efficace n'est encore connue à ce jour, est précisément en train de remettre en cause cette nécessité physique. L'Union internationale des télécommunications (UIT) qui est chargée d'assurer l'utilisation rationnelle, équitable, efficace et économique des fréquences et positions orbitales est ainsi, malgré elle, devenue un terrain de confrontation permanent entre intérêts opposés. Cette agence spécialisée des Nations Unies a désormais de plus en plus de difficultés à se soustraire aux questions politiques de portée plus générale qui l'assaillent quasiquotidiennement.

Face à cette évolution préoccupante, l'inaction ne peut être que coupable comme le note dans la préface de cet ouvrage Frank Asbeck, conseiller spécial en matière de sécurité et de politique spatiale auprès du Service européen pour l'action extérieure (SEAE). Tout en saluant les efforts qui visent à renforcer la sensibilisation aux enjeux posés par le brouillage illégal des transmissions par satellite, M. Asbeck souligne combien ce sujet est important pour l'Union européenne du point de vue des droits de l'Homme et de la sécurité de l'espace.

Le présent ouvrage a pour but de mettre la question de la gouvernance de l'orbite géostationnaire et du spectre radioélectrique au cœur de l'agenda politique européen. II est le fruit d'un séminaire fermé d'une demi-journée qui s'est tenu en avril 2013 à l'Ifri, à Paris (France), sur la base du constat de la nécessité d'établir un diagnostic précis de la situation. Les discussions ont à cet effet porté sur le mode de fonctionnement du système de gouvernance actuel, ainsi que sur les raisons et les modalités de sa dégradation. II a permis de réunir autour de la table divers experts et universitaires reconnus, de même que des représentants d'agences spatiales, d'autorités de régulation nationales et internationale et de grands opérateurs satellitaires.

Comme l'indiquent à plusieurs reprises les contributions contenues dans cette étude, trois zones d'intérêts majeurs justifient l'attention accordée : 1) la nécessité d'améliorer la compréhension et la prise en compte de la problématique des brouillages préjudiciables et, notamment, d'obtenir une meilleure connaissance des différentes catégories d'interférence, qu'elles soient internes ou externes au réseau satellitaire, volontaires ou accidentelles ; 2) la nécessité sinon de clarifier ou de modifier les règles et procédures de I'UIT au moins d'en renforcer l'application en 
accordant à l'organisation la capacité de confirmer la source et la nature exactes d'un brouillage signalé et de prendre des actions et des décisions précises et étayées afin d'inciter les acteurs coupables à changer de comportement ; 3) la nécessité de prendre en compte le régime juridique général, de même que tous les autres instruments pertinents.

L'étude elle-même se décompose en trois parties. Faisant suite à un exposé introductif sur le régime de l'UIT et son évolution au fil des ans en lien avec la gestion et l'utilisation des fréquences radioélectriques et des positions orbitales, la première partie s'organise autour de trois réflexions, l'une juridique et les deux autres plus politiques, sur les télécommunications par satellite. Autant de contextes différents pour mieux saisir la nature des enjeux posés par les brouillages préjudiciables.

Alors que Xavier Pasco identifie les tendances historiques majeures à l'œuvre derrière la transformation des activités de télécommunications par satellite depuis les années 1960 et leurs conséquences sur la gouvernance, Tanja MassonZwaan explore en détails le régime de I'UIT et celui de l'espace et conclut que ce dernier est sans doute plus approprié pour résoudre le problème actuel des interférences intentionnelles à caractère politique. Celles-ci sont également au cœur de la réflexion que propose Guilhem Penent dans l'article suivant sur le débat historique autour du droit des Etats à entraver la libre circulation de l'information sans considération de frontière.

La deuxième partie entre dans le vif du sujet; et, tout en jetant les bases d'une conversation éclairée entre les principaux acteurs concernés, elle aborde les questions de définition qui surgissent derrière la notion plurielle de «brouillage préjudiciable ». Elle établit notamment un lien entre cette problématique et les différents domaines d'application du régime des satellites de télécommunication. Elle met également l'accent sur quelques initiatives récentes qui ont été proposées au plan politique et règlementaire pour renforcer le système de I'UIT.

Les deux premières contributions sont dans cette perspective les bienvenues. Claire Jolly et l'European Satellite Operator's Association (ESOA) explorent tour à tour la complexité du brouillage des transmissions satellite en analysant et discutant à la fois le contexte, les différentes catégories et sources possibles des interférences, et la question difficile mais cruciale de l'évaluation de l'intention qui se dissimule ou non derrière le «préjudice». Les interférences involontaires représentent la majorité des interférences enregistrées à l'échelle mondiale et constituent pour cette raison une dimension essentielle et nonnégligeable du débat. Mais la multiplication ces derniers temps des brouillages volontaires ou délibérés, y compris les transmissions pirates, soulève des défis uniques contre lesquels l'UIT n'est pas nécessairement préparée.

Comme le rappelle Philippe Achilleas, la raison principale à cela est que les interférences volontaires évoluent à l'intersection entre le droit des télécommunications, défini par le droit des réseaux, et la liberté d'expression, qui appartient au droit des contenus. Mais même s'il est tout à fait possible voire indiqué pour les victimes de telles pratiques de s'appuyer sur les conventions internationales régissant le secteur des télécommunications en lien avec les droits de l'Homme, l'option de I'UIT n'est pas à écarter. En effet, selon Laurence Ravillon, deux séries d'initiatives sont menées de front au sein de l'organisation pour renforcer l'efficacité des mécanismes actuels de règlement des différends. Ces efforts concernent aussi bien le recours en aval à des méthodes de règlement des différends beaucoup plus formels que la mise en œuvre en amont d'un système autonome de géolocalisation qui soit propre à I'UIT. 
Sans doute convient-il d'aborder la question du point de vue des principaux acteurs, qu'il s'agisse de l'autorité réglementaire chargée de faire respecter le droit d'exploiter une fréquence sans interférence ou des trois grands fournisseurs de services fixes par satellite. La réaction de I'UIT à l'augmentation massive des cas de brouillage est ainsi présentée par Yvon Henri, du Bureau des radiocommunications $(\mathrm{BR})$, dans le contexte notamment de la dernière Conférence mondiale des radiocommunications. Du côté des opérateurs satellitaires, Eutelsat a subi depuis 2009 des brouillages répétés, qui empêchent la réception de nombreuses chaînes diffusées à partir de satellites dans toute la région Golfe Moyen-Orient. Tout comme son voisin luxembourgeois, Intelsat, SES est davantage préoccupé par les interférences involontaires. C'est à ce titre qu'une initiative comme la Satellite Data Association (SDA), créée par les opérateurs eux-mêmes pour améliorer la sécurité et l'efficacité des opérations spatiales, peut être évoquée.

Tout aussi important pour l'avenir de la communauté spatiale est l'augmentation des interférences entre les réseaux terrestres et les transmissions satellite au détriment de ces dernières. Avec pour ambition de brosser une vue d'ensemble de la situation qui soit aussi ouverte que complète, Alain Austruy propose plusieurs pistes de réflexion sur l'allocation et la coordination dans la gamme des fréquences inférieures à $6 \mathrm{GHz}$ dans le contexte européen.

La troisième partie de cet ouvrage contribue à replacer le phénomène du brouillage dans son contexte plus large. Les trois dernières contributions sont ainsi consacrées au thème de la gouvernance et cherchent à aboutir à une meilleure compréhension du rôle et de la place de I'UIT en son sein. Victor Strelets, par ailleurs membre élu du Comité du Règlement des radiocommunications (RRB) de l'organisation, s'exprime à titre personnel sur le cadre règlementaire actuel dont il défend les mérites et la grande flexibilité. Sergio Marchisio sert ici d'intermédiaire et rappelle que dans le domaine du droit des télécommunications spatiales il ne saurait y avoir de régime autonome tant « tout se tient » et entretient un lien étroit avec les principes généraux du droit spatial et du droit international. Gérard Brachet saisit cette opportunité pour proposer une discussion sur les enjeux d'un développement durable des activités spatiales en relation avec quelques initiatives diplomatiques récentes, toutes pertinentes du point de vue des brouillages préjudiciables.

La conclusion revient sur les différents éléments discutés tout au long de l'ouvrage et illustre son propos par une tentative de réinterprétation des logiques qui sous-tendent le brouillage des fréquences utilisées par les satellites géostationnaires. 


\section{Executive Summary}

Outer space, particularly in the telecommunication sector, is benefiting and becoming accessible to more and more actors. But with this trend comes also a reality that is every day more compelling: no meaningful development can be achieved without a clear, stable and predictable interference-free environment for the use and control of all satellites that depend upon ready access to radio frequencies and appropriate geostationary orbital slots to function properly.

The increasing incidence of harmful interference these recent years, including intentional ones implying a deliberate purpose to obstruct reception of specific information against which no technical efficient counter measure exists, is putting in danger this capacity to continue operating safely. Despite itself, the International Telecommunication Union (ITU) in charge of the rational, equitable, efficient and economical management of the orbit spectrum resource is increasingly becoming a permanent battlefield between opposing interests. And the ability of this specialized agency of the United Nations to remain aloof from broader political issues is now being challenged on a regular basis.

In the face of such a worrying development, the costs of non-action can only be but prohibitively high as noted by Frank Asbeck, Special Adviser for Space and Security Policy to the European External Action Service (EEAS), in the preface to the topic of the book. While paying tribute to efforts that aimed at elevating public awareness concerning the illegal jamming of satellite transmissions, Mr. Asbeck insists on the importance this issue has for the European Union from a human rights as well as space security point of view.

The present book aims at placing the issue of the orbit/frequency governance at the heart of the European political agenda. It is the main outcome of a one halfday workshop on "Orbital Slots and Spectrum Use: a Governance Outlook" held in Paris (France) in April 2013 whose objective was to establish a precise diagnostic of the situation. To this end, both the functioning of the current system of governance and the reasons and processes explaining why the system might be deteriorating were discussed by recognized academics and experts, as well as representatives from space agencies, national and international regulatory entities and satellite fleet operators.

As manifested repeatedly in the contributions contained in this study, at least three main areas of interests require further focus: 1) the need for a large understanding and awareness of the issue of harmful interference with, notably, a better knowledge of the difference between the different types of interference, be they internal to the satellite network or external, deliberate or unintentional; 2) the need to improve the ITU process by giving it some ability to confirm the source and nature of frequency jamming and take informed actions and decisions that would be more compulsory in nature; 3 ) the need to consider the broader legal regime and the relevance of other instruments.

The study itself is divided into three parts. Following some preliminary comments on the ITU regime and its evolution over the years with regards to the use of radio frequencies and orbits, the first section on "Getting into the Picture: Satellite 
Communications Today" captures the basic debate on satellite communications from a legal and political point of view. It is opened by three authors focusing on the different contexts surrounding the issue of harmful interference.

While Xavier Pasco identifies the key historical trends behind the transformation of the satellite communications activity from the early days and their consequences on the whole collective governance issue, Tanja Masson-Zwann investigates in details the ITU regime and the space law regime and finds the latter better suited for solving today's politically-motivated cases of intentional harmful interference. These are also the subject of the next article by Guilhem Penent on the historical debate of whether states should be given the right to interfere deliberately with the flow of information coming across their borders.

The second section, entitled "Increasing Harmful Interference, a Rationale for Action?," gets to the heart of the topic and highlights the different definitional issues at stake, while laying at the same time the foundations of an informed conversation between some of the main concerned actors. In particular, it establishes the relevant issue areas for harmful interference in respect to satellite communications and draws attention to some recent initiatives proposed to better enforce existing provisions at the ITU.

In a welcome move, the two first contributions, by Claire Jolly and the European Satellite Operator's Association (ESOA), explore the complexity of satellite signals interferences by analyzing and discussing both the context, different types and possible sources, and the difficult but vital question of the assessment of the intent in the "harm." Although unintentional interference is the most frequent and must not be overlooked, intentional or targeted interference, including pirate transmissions, is on the rise and raises special and unique challenges for which the ITU is not necessarily well equipped.

The main reason, as recalled by Philippe Achilleas, is that intentional interference hovers at the interface between telecommunications law, defined as the law of networks, and freedom of expression, presented as the law of content. Though victims of such practices can choose to act by means of the mechanisms related to human rights, should they bring the case before the ITU, they will witness several initiatives taking form to improve the efficiency of current mechanisms of dispute resolution. According to Laurence Ravillon, these efforts involve both the downstream recourse to more formal dispute resolution methods, and the upstream implementation of an independent monitoring system.

What has been lacking until now is a genuine perspective coming from the main actors, including the relevant regulatory body having jurisdiction over satellite interferences and the three larger fixed satellite service operators. ITU's response to the increasing number of cases of harmful interference is thus discussed by Yvon Henri of the Radiocommunication Bureau (BR) in the context notably of the last World Radiocommunication Conference. As for the fleet operators, Paris-based Eutelsat naturally places emphasis on deliberate jamming for which it has suffered greatly since 2009 in its home territory of Europe, the Middle East and Africa. Like its slightly larger Luxembourg neighbor, Intelsat, SES concern is much more focused on unintentional interference and current initiatives created to mitigate its effect as in the case of the Satellite Data Association (SDA).

One issue that has started to draw the worried attention of the entire space community has been the growing interference between terrestrial networks and satellite signals. In a useful attempt to effectively explore the hidden dimensions of the issue, Alain Austruy suggests several avenues for reflection with regards to the 
allocation and coordination in the frequency bands below $6 \mathrm{GHz}$ within the European context.

The third and final section helps put the topic into perspective by offering three opinions on "Satellite Communications and Space Governance in the Coming Years," three steps toward a better understanding of ITU's role. Victor Strelets, one of the twelve members of the Radio Regulations Board (RRB) of the ITU, provides a defense of the current international regulatory framework and its merits, including its adaptability. Sergio Marchisio acts as a bridge by reminding us that the ITU regime is not self-contained, but should be interpreted in close connection with the general principles of space law and international law. Gérard Brachet takes this opportunity to discuss a series of converging international initiatives for the safety and sustainability of space activities, all relevant to harmful interference.

Finally, the conclusion outlines the essence of the different issues discussed in the book and attempts to make explicit the different logics behind harmful interference in space telecommunications on the basis of a power-oriented approach. 


\section{Contents}

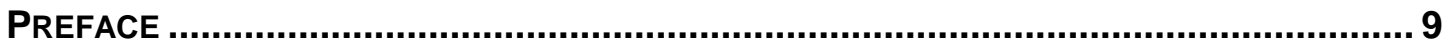

Frank Asbeck, Special Adviser for Space and Security Policy, European External Action Service (EEAS), Brussels (Belgium)........................................................ 9

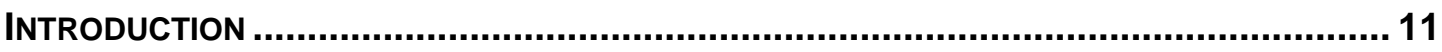

Guilhem Penent, Research Associate at Institut Français des Relations Internationales (IFRI), Paris (France) ................................................................... 11

1/ Getting Into the Picture: Satellite Communications Today ......................... 18

1.1/ Political Issues of Satellite Telecommunications ................................................. 18

Xavier Pasco, Senior Research Fellow at Fondation pour la recherche

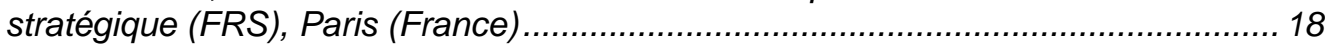

1.2/ Orbits and Frequencies: The Legal Context ....................................................... 23

Tanja Masson-Zwaan, Deputy Director of the International Institute of Air and Space Law, Leiden University (The Netherlands) .............................................. 23

1.3/ Controlling Information Flow: a Political History of Jamming ............................30 Guilhem Penent, Research Associate at Institut Français des Relations Internationales (IFRI), Paris (France) .................................................................. 30

2/ INCREASING HARMFUL INTERFERENCE, A RATIONALE FOR ACTION? ........................ 36

2.1/ Interferences of Satellite Signals: Not a New Issue... but More Complex .......... 36

Claire Jolly, Policy Analyst at the OECD Space Forum, Organisation for Economic Co-operation and Development, Directorate for Science, Technology

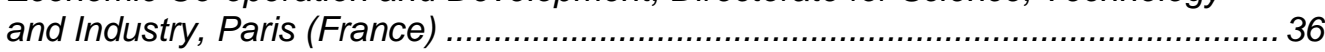

2.2/ What Is Harmful Interference: Qualifying Intentions .......................................... 39

Ethan Lavan, Director of Orbital Resources at Eutelsat representing ESOA ............. 39

2.3/ Telecommunications Law and Freedom of expression ....................................... 42

Philippe Achilleas, Director of the Institute of Space and Telecommunications Law (IDEST) and the Master's Degree in Law of Space Activities and Telecommunications at the University Paris-Sud 1 (France).................................. 42

2.4/ A Transforming Role for ITU: Monitoring as the Way Forward? ..........................47 Laurence Ravillon, Professor of Private Law, Director of the Research Centre on Investment and International Trade Law (CREDIMI), Dean of the Faculty of Law and Political Science at the University of Burgundy, Dijon (France) ......................... 47

2.5/ Preventing Harmful Interference to Satellite Systems ..........................................50

Yvon Henri, Chief of the Space Services Department (SSD) at the Radiocommunication Bureau (BR) of the International Telecommunication Union

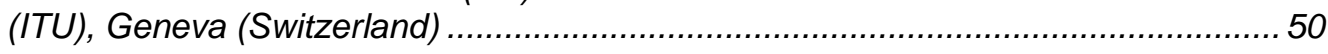

2.6/ Eutelsat: Freedom of Information, "Regardless of Frontiers"............................54 Astrid Bonté, Responsible for Institutional Affairs at Eutelsat, Paris (France)............54 
2.7/ Intelsat: Interview with Ron Busch 58

Ron Busch, Intelsat's Vice President, Network Engineering and the Space Data Association's Chairman 58

2.8/ SES: A Perspective on Interference. 60

2.9/ Orbit-spectrum resources allocations for space and terrestrial radiocommunications in the frequency bands below $6 \mathrm{GHz}$

Alain Austruy, Frequency Office at Centre national d'études spatiales (CNES), Toulouse (France).

3/ Satellite Communications and Space Governance in the Coming Years .... 69

3.1/ International Regulation of Frequencies and Satellite Orbits: Improving Rather than Revising ITU's Procedures

Victor Strelets, Member of the Radio Regulations Board (RRB) of the International Telecommunication Union (ITU), Counselor to the General Director of FSUE "Morsvyazsputnik," Moscow (Russia) .

3.2/ The ITU Regulatory System: a Self-Contained Regime or a Part of International Law?.

Sergio Marchisio, Professor of International Law, University Sapienza of Rome (Italia), Chairman of the European Centre for Space law (ECSL/ESA), Paris (France).

3.3/ From GEO and Spectrum Crowding to the Threat of Space Debris: Is our Present Use of Outer Space Sustainable?

Gérard Brachet, Space Policy Consultant, former Chairman of the UN Committee on the Peaceful Uses of Outer Space (2006-2008), French expert on the UN Group of Governmental Experts on Outer Space TCBMs (2012-2013).

Conclusion: Governance Without Politics?

Guilhem Penent, Research Associate at Institut Français des Relations Internationales (IFRI), Paris (France)

List of AUthors AND CONTRIBUting ENTITIES 
Frank Asbeck, Special Adviser for Space and Security Policy, European External Action Service (EEAS), Brussels (Belgium).

Satellite communications technologies, accompanied by large performance improvements by other IT and telecommunications systems, have become remarkably efficient in facilitating worldwide connectivity. As is now abundantly clear, satellite communications play a pivotal role as they transport critical information concerning socio-economic and political-military developments worldwide. These technologies support a wide variety of data, telephone, TV, radio and various networking services at the national, regional and global levels, including in remote, and otherwise inaccessible, regions, enabling anytime/anywhere communications.

In addition, all forms of satellite activities, whether for remote sensing, space navigation, satellite meteorology, radio astronomy, time synchronization, space research or space operations, need to operate active communications links to convey information to Earth and receive information and commands from Earth locations. In short, communications systems today are critical enablers of the connectivity among societies, economies, and people globally, overcoming physical boundaries.

Radio frequencies and orbital positions are vital tools for satellite communications. Once radio frequencies and orbital positions are secured by a satellite operator under a national licence, the international coordination and registration processes of the International Telecommunication Union (ITU) are required to ensure interference-free use of radio frequencies and orbits. The main purpose of the ITU's international regulatory regime for satellite communications, spelled out in Article 45 of the ITU Constitution, is to avoid harmful interference and to ensure equitable access to radiofrequencies and satellite orbital slots.

Despite the international ITU regime, however, "harmful interference," as defined in Article 1.169 of the ITU Radio Regulations, is a rapidly growing problem. Deliberate disruption of radio and TV broadcasts through frequency jamming - an intentionally caused interference - in order to deny access to information, is on the rise in several parts of the world. While frequency jamming is clearly illegal, unequivocal attribution is often difficult, and existing tools for neutralizing such interference are limited, if not non-existent.

Political systems that are not legitimised by democratic consent of their population may have reason to fear free access to information and freedom of expression.

The jamming of direct-broadcast satellites deprives citizens of their freedom of expression and free access to information. It thus constitutes another means of censorship. Recent experience has shown that jamming activities often coincide with political unrest, such as has occurred in Iran and Syria. A stark example of jamming is that emanating from Iranian territory directed toward foreign TV and radio station 
broadcasts via satellite. The jamming efforts have intensified during sensitive periods, such as prior to the February 2010 anniversary of the 1979 Revolution, when almost seventy foreign radio and television programmes transmitted via satellites operated by the European direct broadcast provider Eutelsat were interrupted. In fact, Eutelsat has been one of the principal victims of these incessant jamming incidents. The negative effect on the company's operations doubled between 2010 and 2011, and tripled from 2011 to 2012. Eutelsat has recorded 340 jamming incidents from January to November 2012, a high percentage of which originated from Iran. This is but one example of the jamming threat in today's globally networked world.

The EU is highly concerned about such practices, which constrain citizens from accessing information freely. The EU also believes that states which interfere with direct broadcast satellite transmissions violate the universal right to free expression, including the right of any individual to seek, receive and share information, irrespective of borders or locations. This universal right constitutes an international commitment which most of these states themselves subscribed to under the UN Covenant of Civil and Political Rights. Moreover such activities contravene Article 19 of the Universal Declaration of Human Rights, Article 10 the European Convention for the Protection of Human Rights and Fundamental Freedoms, and Article 11 of the Charter of Fundamental Rights of the European Union.

Accordingly, the European Union supports the efforts of the ITU to ensure that radio services of its Member States are not affected by harmful interference. This is a political, rather than technical, issue. Its resolution has remained complicated. There exists no compulsory international dispute settlement mechanism within the ITU with respect to this issue, although dispute resolution is addressed in Article 56 of the ITU Constitution, Article 41 of the ITU Convention, and the Optional Protocol. Nonetheless, these provisions have never been tested. Accordingly, all such incidents to date have been addressed through the provisions of Article 15 of the ITU Radio Regulations, where all cases are to be resolved through negotiations among the concerned parties. The ITU, however, does not possess any enforcement measures, or sanctions mechanisms to deter violators.

The EU has suggested addressing the issue of harmful interference with space objects, notably satellites, in its proposal for an International Code of Conduct for Outer Space Activities. This initiative, which is currently under discussion in the international community, proposes a political commitment by subscribing states to minimise the possibility of any forms of harmful interference, including radiofrequency interference. It also makes explicit reference to the need to make progress toward adherence to, and implementation of, ITU regulations.

To conclude, the complexity of this abusive practice and its more frequent use have outstripped the capacity of the existing legal regime and require additional measures to be brought to bear, particularly in the area of enforcement. A coordinated political push is needed to identify jamming perpetrators and ensure that they are adequately penalized. The geopolitical costs of non-action are prohibitively high. This publication will most certainly help elevate public awareness concerning this security-related challenge, including among European decision-makers who must grapple with this troubling new space reality. 


\author{
Guilhem Penent, Research Associate at Institut Français des Relations \\ Internationales (IFRI), Paris (France).
}

Mention of natural resources usually evokes images of physical things being subject to consumption and exclusion, such as ocean fisheries, minerals or fossil fuels. This note focuses on two natural resources that are an exception to this general rule: radio frequencies which allow information to be transmitted over large distances by radio waves, and the geostationary-satellite orbit (GSO) in space which is the preferred location for most communication satellites.

These resources are not consumed or extracted so it is (almost) impossible to deplete or damage either of them on a permanent basis; and their primary value is access to the very specific domain to which they belong rather than to any resource flow. However, despite being "boundless," they are limited in their availability because overcrowding and lack of coordination can quickly reduce or eliminate their usefulness. If these two are not properly used and managed, harmful interference could occur which, in turn, might impede the use and control of all satellites that depend upon ready access to interference-free radio frequencies and appropriate orbital slots to function. Thus, to maintain the full potential of the orbit/spectrum resource $(\mathrm{OSR})^{1}$ for transmitting information which is vital for all nations, it is essential to regulate the number and types of uses that are made of it. It is also important that entities that do not fully comply with negotiated policies and protocols be sanctioned. All these indicate the strong need to keep order in the geostationaryorbit arc and related spectrum.

Europe is particularly concerned as the home of the four largest operators in the world in Fixed Satellite Services (FSS) and Mobile Satellite Services (MSS) whose critical business in enabling communications services and the delivery of information and entertainment regionally and globally relies on an expanding fleet of more than 150 satellites in orbit. Satellite communications have proven to be the only example of a mature commercial use of space that generates huge revenue stream and profitable returns and benefits billions of consumers in almost all nations of the world while serving as an engine for the whole space industry, including satellite manufacturing and launch services. ${ }^{2}$ Although economics drive many aspects of

\footnotetext{
${ }^{1}$ Although outer space and the electromagnetic environment can be considered as separate global commons, for present purposes, it is necessary to consider them together as the twin orbit/spectrum resource. On this point see John Vogler, The Global Commons. Environmental and Technological Governance (Chichester: John Wiley, $2^{\text {nd }}$ ed., 2000), 97, 112. See also Marvin S. Soroos, "The commons In the sky: the radio spectrum and geosynchronous orbit as issues in global policy," International Organization, Vol. 36, No. 3 (June 1982), 665-677; and Susan Beck, The Global Commons. An Introduction (Washington, D.C.: Island Press, 1998), 153-163. See also the following boxes for details.

${ }^{2}$ For further information on satellite communications, see notably Joseph N. Pelton, Scott Madry and Sergio Camacho-Lara (eds.), Handbook of Satellite Applications (New York: Springer, 2013), 1-557.
} 
satellite communications, it would be profoundly misguided and historically wrong to lessen its socio-political importance. Space telecommunications, being by nature global with the ability to broadcast information simultaneously from one point to many points on Earth irrespective of political borders, in cooperative or noncooperative context, address issues of relationships between geopolitical entities in a much more encompassing and insistent way than terrestrial networks do. Allocating OSR for communication purposes is thus an international and diplomatic exercise besides being an economic one.

International policy on use and management of the radio frequencies and geostationary locations is almost exclusively made at conferences of the International Telecommunications Union (ITU). The ITU is unique in many ways, including its flexibility and responsiveness to changing demands. It is one of the oldest international organizations, founded in 1865 at the initiative of Napoleon III as the International Telegraph Union. Created at a time when there was no prototype to emulate, the ITU was forced to create its own structure and method of functioning in order to regulate a very dynamic, rapidly expanding technology at the global level. As delays for sending telegrams decreased, it was quickly celebrated as a model of international cooperation. No one could be forced to join it. Yet the benefits of membership were self-evident. ${ }^{3}$ They still are today as witnessed by a membership of 193 countries; maybe the nearest one can get to global plebiscite. Its one-country, one-vote process has helped to define most international organizations, thus planting the seeds of today's world governance. Most of all, the ITU has not been static. Over the years, it has modified its structure and operating procedures to meet new world economic conditions and international politics, never showing any real sign of strain. For almost one hundred and fifty years the International Telecommunication Union has worked to guarantee that telecommunications are used in the most efficient manner. ${ }^{4}$

While it has a permanent constitution encapsulating its most basic principles, the ITU is mainly governed by a series of conventions that are reviewed at Plenipotentiary Conferences every four years or so to determine the general policies of the Union; hence the importance of such events in the evolution of the organization. The present-day ITU formed in 1932 and became part of the United Nations family of specialized agencies in 1947. Over its lifetime, its primary task has been to facilitate cooperation by taking actions involving the planning of networks, standardization of procedures and equipment, and allocation of radio frequencies. As such, the ITU began regulating radio communication shortly after 1906 when it became obvious that Italian physicist Guglielmo Marconi's company was trying to create a monopoly over maritime radio by banning all intercommunications with any radio station employing non-Marconi equipment irrespective of the general safety of the shipping routes. ${ }^{5}$ It has been making frequency allocations since 1912.

Allocation of the electromagnetic spectrum is not permanent. Users receive usufructuary rights rather than full proprietary rights. This was confirmed in 1965 when the ITU Plenipotentiary Conference described the International Frequency Registration Board (IFRB), which registers frequency assignments, "as custodians of

\footnotetext{
${ }^{3}$ Mark Mazower, Governing the World. The History of an Idea (London: Penguin Press, 2012), 102.

${ }^{4}$ For a useful account of the history of the ITU, besides the references made in the previous footnotes, see George A. Codding, "The International Telecommunications Union: 130 years of telecommunication regulation," Denver Journal of International Law and Policy, Vol. 23, No. 3, 501-511.

${ }^{5}$ On the beginnings of radio, see Daniel R. Headrick, The Invisible Weapon: Telecommunications and International Politics, 1851-1945 (New York: Oxford University Press, 1991), 116-137.
} 
an international public trust." ${ }^{6}$ But when requests for new allocations or expansion of old ones are received, consideration is given in priority to the impact on previously established users under the so-called "first-come, first-served" practice or "a fortiori planning;" thus theoretically enabling the technologically advanced countries to gain a permanent hold over the resources. In effect, one of the more interesting aspects of the evolution of the ITU has been the emergence of a bloc of developing country and its increasing willingness to use its voting power during ITU conferences.

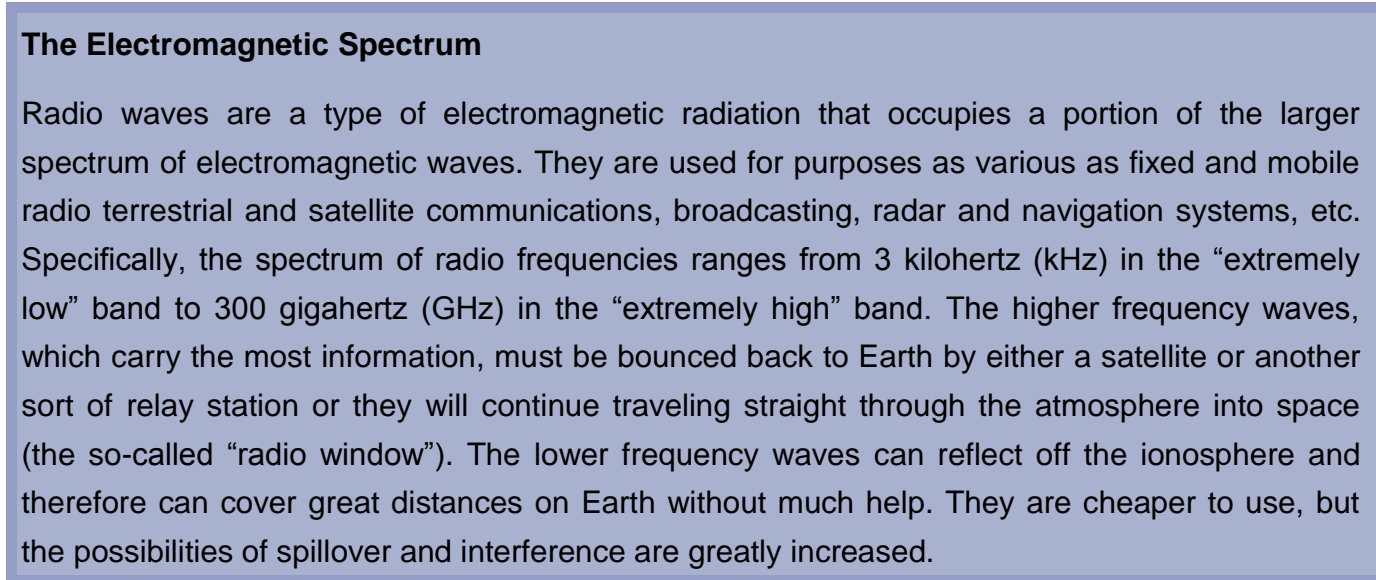

Although the potential of the use of geostationary orbit for telecommunications services was first seriously considered during the mid-1940s by Arthur C. Clarke, it was not until the late 1950s that launch technology that could place satellites into GSO came into being. The ITU was a neutral observer of the space race that defined these early years of satellite development. But the Union clearly recognized the need to reserve some portion of the spectrum for satellite use, feeling in a sense that its involvement was a logical extension of its telecommunications missions. As a result, its initial response was to create a regime which merely reflected the norms and principles of the existing spectrum arrangements. However, the development of principles and norms related to GSO was not an issue confined to the ITU. Being a part of outer space, the geostationary orbits are also subject to treaties negotiated in the Committee on the Peaceful Uses of Outer Space (COPUOS) of the UN General Assembly, notably the Outer Space Treaty which states that space is "the province of all mankind." Therefore, if the 1971 World Administrative Radio Conference on Space Telecommunications (WARC-ST) formally brought the matter under ITU control, it had no choice but to do so by stating that all countries were given equal access to the use of space radio communication service frequencies and to the related geostationary orbits in accordance with "a priori planning." A more definitive statement recognized in 1973 the right of equitable access as well as the special needs of the developing countries. Another confirmation was provided in 1979. By 1989, an "arc allotment plan" had been created and adopted in order to ensure that each nation would receive at least one orbital slot.

${ }^{6}$ ITU Constitution, Art. 14, No. 98. See also Beck (fn. 1), 154. 


\section{Geostationary Orbits}

Geostationary orbits are located approximately 35,786 kilometers above Earth's surface; a satellite maintaining an orbit at these altitudes travels at a velocity that takes it around the planet once every twenty-four hours. If it is on an equatorial path in the direction of the Earth's rotation, it will remain above the same point on the surface of the planet, hence appearing to be stationary. Some 400 satellites are currently in operation in GSO, but as few as three satellites each covering $40 \%$ of the surface could serve the entire inhabited parts of the globe. To be exact, scarcity in GSO is not so much a matter of physical congestion. Rather, it turns upon the occupancy of certain highly favored positions that reach a vast or wealthy population or a politically important one, and very complex engineering questions of the spacing - commonly referred to as a satellite slot - required between satellites in order to avoid harmful interference. ${ }^{7}$

As new trends related to globalization and the privatization of telecommunications seemed also to require a serious reorganization, ITU structure was finally revised by the Geneva Plenipotentiary Conference of December 1992 in order to better respond to the new international telecommunications environment. Three sectors, still in place today, were created. The telecommunication development sector (ITU-D) facilitates and enhances telecommunications development by offering and coordinating technical assistance activities. The telecommunication standardization sector (ITU-T) studies technical, operating, and tariff questions and adopts recommendations on them with a view to standardizing telecommunications on a worldwide basis. The radiocommunication sector (ITU-R) is the main unit within the ITU. It adopts the detailed rules, procedures, and standards for ensuring interference-free use of radio frequencies and orbital positions and their routine implementation. As such, it is responsible for the regulatory activities formerly conducted by the IFRB, now replaced by the Radio Regulations Board (RRB) with the Radiocommunication Bureau (BR) acting as its executive arm.

Historically, telecommunications have been regarded as a perfect example of rational policy making in which decisions are taken on technical rather than political grounds. Underlying this is the assumption that the ITU, while having great social responsibilities, has an essentially "functional" if not "scientific" character. Managing the OSR is an entirely objective undertaking to which there are only rational and consensual engineering solutions. ${ }^{8}$ From a general perspective, in the light of history, it looks as though the ITU has been proved right. If deficiencies or abuses are discovered, they can and will be addressed and fixed.

Notwithstanding this continued success, it remains to be seen whether the system will be flexible enough as well as sufficiently robust to deal with the break neck speed of ever expanding and complex needs for radio frequencies and geostationary orbital positions. ${ }^{9}$ It is true that the voluntary compliance approach worked well in the past and that member states have largely been following the ITU

\footnotetext{
7 See for example Peter B. de Selding, "Orbital Slotting Issues Resolved, Ukraine's Lybid Satellite Gets a Launch Date," Space News, Nov. 21, 2013 ; and Editorial, "Conciliation over Protracted Conflict," Space News, Sept. 9, 2013.

${ }^{8}$ Vogler (fn. 1), 113. See also James G. Savage, The Politics of International Telecommunications Regulations (Boulder: Co, Westview Press, 1989), Index "Politics." For a broader historical perspective, see Mazower (fn. 3), 94-115.

9 Ram Jakhu and Karan Singh, "Space Security and Competition for Radio Frequencies and Geostationary Slots," ZLW, Vol. 58, No. 1 (2009), 74-93
} 
rules mainly because it is in their best interest to do so. It is uncertain whether this practice based on consensus will work in the future as the number of players is increasing and the competition for scarce resources is becoming very severe. The ITU does not possess any power of enforcement or imposition of sanctions against the violators of its rules, regulations and processes. In the words of one official from Nilesat, coordination is just not enough in today's context: "the ITU's regulations are very idealistic; however we are not an ideal world." ${ }^{10}$ As outer space is becoming more and more contested, congested and competitive, failure to appreciate the political saliency inherent in the dissemination of communication and information technologies might eventually be problematic.

Just as the developing countries began asking, much to the alarm of the ITU personal, for equity to be introduced into deliberations on equal foot with the "rational use" of telecommunications and encouragement of efficiency after they had come to realize that decision made behind the technical veil of the organization were not necessarily in their own best interests. Some member states might appear today more than willing to remind the ITU that it does not operate in a political vacuum. If it were to be confirmed, such a development would certainly be a test case calling into question the Union's credibility to govern the OSR and its will to reform and to act.

Some could argue that we are getting there fast as witnessed by several worrying trends. It is always difficult to assess the situation without the benefit of hindsight. However, it is now obvious that, in recent years, an ever-increasing number of instances of harmful interference, including intentional ones implying harmful intent and a deliberate purpose to obstruct reception of specific content, have emerged which particularly affect telecommunication satellites and those depending on them. Involuntary accidental interference is of course not uncommon. In such cases, operators generally know what is needed and are working on effective tools and procedures both on an informal ad hoc level and official regulatory basis to identify its likely cause and mitigate its impact. Intentional jamming of radio signals of satellite is more surprising, if only because until recently it was statistically less significant representing usually around $5 \%$ of all the instances of harmful interference experienced worldwide. Its occurrence is now so widespread that, in some cases, notably in the region over the Middle East and North Africa (MENA), it has reached a point to where it is having a significant effect on revenue. Collateral damage of jamming is very high indeed; up to 10 TV and 50 radio channels can be taken out by the jammer even though its intent is to target only one of them. For the 21-nation Arabsat consortium of Saudi Arabia, intentional jamming represented almost $10 \%$ of all interference events in 2011; this number reached $26 \%$ in 2012. Nilesat of Egypt witnessed a similar escalation over the years after it was introduced to this phenomenon for the first time back in 2008. The World Cup in 2010 marked a major milestone with not a single day without jamming to the very annoyance of the viewers and customers whose football games were interrupted each time a goal was scored. But the real watershed came in the aftermath of the Arab Spring in 2011 when the cause of the jamming was clearly political. Both satellite fleet operators have tried to take measures about it, including geolocation of the sources of interference and complaints to national and international frequency regulators, to no real effect, as have Turksat of Turkey and Eutelsat of Paris and broadcasters such

\footnotetext{
${ }^{10}$ Quoted from the international satellite communication workshop "The ITU - challenges in the 21st century: Preventing harmful interference to satellite systems," which was organized in Geneva in June 2013. See http://www.itu.int/en/ITU-R/space/workshops/2013-interference-geneva/Pages/default.aspx
} 
as BBC, Deutsche Welle, CNN, Voice of America and others which are also dramatically affected. ${ }^{11}$

\begin{abstract}
Intentional jamming and the ITU process
Usually, to resolve cases of harmful interference, the first step is to pinpoint the source of the jamming through satellite geolocation (triangulation). ${ }^{12}$ Once these measurements are carried out, the notifying national administration of the interfered satellite can send a formal complaint of harmful interference to the ITU and the administration on the territory of which the jamming earth station was geolocalised. Even though this procedure works most of the time, its main weakness is that it relies on the assumptions that all national administrations are able to control emissions originating from their territories, and eager to exercise the utmost goodwill and to provide mutual assistance as recommended by Article 45 of the ITU Constitution and Article 15 of the Radio Regulations.
\end{abstract}

The spectrum we use is a finite resource that should neither be poorly managed nor unlawfully polluted. The fact is that there can be no future for radio communications if one cannot protect its investments from interference for the environment needs to be clear, stable and predictable. In April 2013, the Ifri's Space Policy Program held within its walls a closed seminar on this specific topic of the governance of orbital slots and associated spectrum, which gathered academics and experts as well as representatives from space agencies, national and international regulatory entities and satellite fleet operators. ${ }^{13}$ Three main points of interest were discussed: 1) the need for a large understanding and awareness of the issue of harmful interference through, notably, a better knowledge of the difference between the different types of interference, be they internal to the satellite network or external, deliberate or unintentional; 2) the need to improve the ITU process by giving the BR the ability to confirm the source and nature of the jamming and take informed actions and decisions that would be less advisory in nature; 3) the need to consider the broader legal regime and the relevance of other instruments with regard to the topic of harmful interference with satellite systems. For the most part, this collective work is the fruit of the extensive discussion and stimulating exchanges that took place during the seminar under the Chatham House rule. I would like to thank all the individual present this day as well as the contributors who accepted to give their time to make this project a reality.

What follows is divided into three main parts. The introductory section captures the basic debate on satellite communications as well as its evolution over the years from a legal and political point of view. The second section highlights the different definitional issues at stake and lays the foundations for an informed conversation. In particular, it establishes the relevant issue areas for harmful interference with respect to satellite communications and draws attention to some

\footnotetext{
${ }^{11}$ See for example Peter B. de Selding, "Broadcasters Call for ITU Action on Satellite Jamming," Dec. 9, 2011; "Jamming No Mere Nuisance for Middle East Satellite Operators," Space News, Mar. 23, 2012; and "Eutelsat To Field Test New Anti-jamming Capability," Space News, Jan. 28, 2013. For a whole range of perspectives coming from national administrations, the satellite communications industry, user community, and other ICT stakeholders, see also fn. 10.

${ }^{12}$ It may be noted that geolocation by various satellite fleet operators serving users over the MENA region has helped to detect the uplink location of interferences coming in majority from countries such as Iran, Bahrain, Syria, Ethiopia, Eretria or Libya. Considering jamming in general, many other cases, most often very specific, can be found in other areas (North/South Koreas, the United States/Cuba, etc.).

${ }^{13}$ See http://www.ifri.org/?page=detail-contribution\&id=7648.
} 
iffi Governing the Geostationary Orbit

recent initiatives proposed to better enforce existing provisions at the ITU. The third part helps put the whole topic into perspective by offering various opinions centered on the Union and its relative position with regard to the broader space governance. Finally, the conclusion outlines the essence of the different issues discussed in the book and attempts to make explicit the different logics behind harmful interference. 


\section{1/ Getting Into the Picture: Satellite Communications Today}

\section{1/ Political Issues of Satellite Telecommunications}

Xavier Pasco, Senior Research Fellow at Fondation pour la recherche stratégique (FRS), Paris (France).

The role played by Satellite Communications (Satcoms) development has often been underestimated in the construction of national space policies before Satcoms transformed into successful commercial applications over the years. Indeed, high political stakes have been apparent from the start as testified by the relatively heavy involvement of the UN in the international regulation of this activity (through ITU in Geneva).

Precisely, the evolution of the political status of the Satcom activity, as well as a brief assessment of current and future issues will be the main subject of this paper.

\section{Some remarkable features of Satcom history}

A look at space telecommunications history shows how much this technique has largely contributed to structuring the regulation (and the universalization) of space applications and has prompted the crafting of national space policies by the main space faring nations, namely the US and USSR first, with very different choices and consequences.

\section{A political landscape shaped by technical competences very early on}

As soon as the 1960s, the development of Satcom techniques has had a strong political imprint on the development of international organizations. The U.S. Comsat Act $(26 / 07 / 1962)$ can be considered as the first attempt for designing a global governance of Satcoms under U.S. guidance. The specific balance of power of the day meant that this initiative (also based on a quasi unique mastery of Satcoms satellites in the "western block" at that time) quickly gained some political legitimacy in the UN arena via a largely admitted principle of non-discriminatory access to Satcom (Res. 1721-XVI)

In this context, Intelsat, as a uniquely organized technical-oriented organization but also as a U.S. commercially-oriented structure (Comsat), became in charge of ensuring a world-wide public service. As an illustration of its normative power during these years, Intelsat had eventually gathered 143 States by 2000.

However, orbital systems have been treated in a manner that was remaining very specific in this respect, while, by construction, ground stations have remained under sovereign leadership. Additionally, USSR did not adhere and built its own network, providing additional evidence of the highly political character of the wordwide development of Satcom networks. 


\section{ifri Governing the Geostationary Orbit}

It remains that the Satcom industry quickly developed dependency upon a unique source, with unavoidable political and industrial consequences.

Nascent alternate views in the 1970s

The common objective of a nascent European community in the 1970s to gain more political weight and visibility in the international scene prompted new political perceptions and postures in the old continent in many domains. Satcoms didn't escape these general trends. Following a few years of almost unique technical and regulatory dependency on a U.S.-led commercial endeavour almost transformed into a "global commons" as it may be labeled today, European States progressively looked for an increased political presence in this field. On the technical level, this took the form of the Symphonie Satellite mainly promoted by France. The political significance of this programme was also made apparent in the controversy that surrounded the launching of the satellite on the basis of existing rules dominated by U.S. interests. It must be recalled incidentally that this episode was also used to legitimate the development in Europe of an autonomous launching capability that would pave the way for the Ariane launchers family. But this more assertive European posture also led to the creation of two levels of responsibilities in Intelsat (State parties), materializing a first step before creating a fully autonomous capability.

Parallel rising concerns appeared in developing countries, both increasingly dependent on Intelsat and fearing some sort of cultural dominance, that some feared to see reinforced by the advent of direct broadcast satcom technologies. The autonomy acquired for domestic political development for many countries freshly relieved from past colonial links with dominant western countries made them very reluctant towards any system that shall be considered as infringing on their hardly gained national sovereignty. In some more specific cases, models of political development were to become a very sensitive issue as many countries saw rising domestic conflicts for the gain of power, sometimes (but not always) leading to regimes that did not promote liberal democracy but rather authoritarian regimes. Leaving domestic access to cultural values coming from abroad, and in this particular case broadcasted from abroad, was not accepted.

In this context, as soon as early 1972, a number of Asian, African and South American nations opposed the cross-borders principle of freedom of information. This movement quickly gained legitimacy and transformed into a 1972 UNESCO "Declaration of Principles" supporting this view. It is notable that this Declaration of principle was clearly opposed by the U.S. while the USSR abstained. In one way or another the political dimension of direct broadcast satcoms had indeed been clearly established by the two superpowers in their respective spheres of influence.

"O tempora, O mores"...

Following this initial founding period marked by the traditional cold war style, but also showing the premises of deep international transformations, the 1980s and the 1990s would give birth to a large deregulation movement that would clearly act as a game changer.

Initial impulse and enduring energy for this changing perspective for the satcom policies and industry was found in large politically-inspired projects, again under the very energetic leadership of the U.S. (and most notably at the time from the Clinton administration, with Vice-President Al Gore as a very proactive proponent of projects such as National Information Infrastructure - NII - or Global Information 
Infrastructure/Grid - GII) with parallel industrial new organizations and moving alliances. This change of perspective, a by-product of a careful reconsideration of the U.S. industrial, economic and even military ${ }^{1}$ policy in the post cold-war new balance, was both prompted by a need to prepare for a more opened and competitive world following the transitional post cold war years, with a view to benefit in this new context from the initial investments made by powerful actors with the hope of commercial and political gains. The National Economic Council in the U.S. acted here as a key strategic executive institution.

As a consequence, starting from 2000 (year of the U.S. "Orbit Act"), Intelsat, but also Inmarsat and Eutelsat, non U.S. large semi-public operators, had to adapt to the announced international competition and transform into private structures (Intelsat, Eutelsat, 2001). This can be considered as another key step in the worldwide evolution of the Satcom activity. The mainly political nature of this move can even lead to compare it with president Kennedy July 1961 engagement behind the initial Intelsat endeavour, but obviously in a very different environment. Here again, Satcoms are not considered for themselves anymore but more as elements of a larger vision involving the use of information systems in proactive foreign policies.

Obviously, these evolutions have also reflected over the recent years an increasing diversification of the techniques used allowing the Satcoms transmission of more and more diverse types of data and information.

\section{Today's main characteristics and trends}

The rising role of private operators as structuring new international relations However, a second key trend must be taken into account in the general balance that is characterizing the satcom activity today. The Satcom industry and services have been dominating the economy of the space sector by far for many years. This simple fact of life has induced a slow change in the way such systems (sometimes huge, with 50 to 70 satellites composing the fleet of the main private players today) have been gradually perceived by governments today who have often become some of the main customers of these private operators. This evolution has materialized more as an obligation given a sky-rocketing consumption of bandwidth by state actors, rather than as a deliberate political decision by governments. Both this increasing role of private operators in the global satcom economy and the "modernized" cultural approach they adopted to better suit their respective markets (diversification of broadcasted local channels, radios, etc.) have allowed private regional de facto networks being more widely and more easily accepted by local actors, whether they are state actors or nascent private TV industry. Pioneering examples of success in this respect in areas initially often reluctant to endorse international broadcasting systems can be illustrated by projects such as AFRISTAR by Worldspace (providing local Radio broadcast); then CNN (with for example United Tribes of Africa News); Asiasat for Saudi Arabia early 2002 or New Skies in Bangladesh.

Again, the improvements in precise broadcasting techniques allowed by more and more precise beams and footprints configurations have played a key role in improving the relationship between "western" private satcoms providers and their local customers on a world-wide basis. Additionally, over the recent years, an explosion in the quantity and diversity of information services (along with the use of the Internet) has consolidated the key role played by private satellite operators in

\footnotetext{
${ }^{1}$ The military version of this large reconsideration was well-known at the time under the generic label of RMA standing for "Revolution in Military Affairs."
} 
global communication policies. As a result, the demand for satcom services has been stirred up, constituting a key trend today that has in turn reinforced again the role of these private operators.

\section{Redefinition of public-private balance}

Given this "new deal" in the satcom activity, public and private users appear to be more and more intertwined. An increasing military demand (the most striking - and often quoted - figure of $80 \%$ of U.S. milsatcom representing 1.2 \$B of revenues in 2012 for the satcom industry can be quoted here) has been forming a new very active market segment. It has offered opportunities to induce new public-private relationships, or sometimes partnerships. The number of communicating systems in the field of security and defense as well as the "weight" of the content (despite improved compression techniques) has transformed the demand for world-wide instant connectivity, giving a boost to the satcom services industry.

Of course, while this tendency has defined a market for private operators, (sometimes representing a very significant two-digit part of their revenues), it has also given birth to new specific constraints for those actors. Constant availability, ability to satisfy unpredictable so-called "surge" market, "new security" demands (protection of space and ground segments) are among the most common requirements that have implied new responsibilities of the private operators.

This redefinition of the public-private relationship has been currently going on and is far from being stabilized yet. Still, should such relationships extend, the issue of a de facto "regulatory" come back via "normative styled" State users can legitimately be raised when confronted the raise of private companies.

Whatever the fate of this relationship, one can already witness a side effect of this new pressure in self-private collective organizations which tend to answer, and sometimes even anticipate, regulatory demands or the pressure of new requirements. In this respect, the example of the Space Data Association (SDA) with the goal to generate better orbital management coordination as well as non interference policy between space operators is very typical. The parallel emergence of national space laws, leading to national obligations, precisely taking into account the emergence of the private actors in the space activities, has indeed formalized, or reformatted, the role of national States in regulating national private operators activities in this new era.

Whether the increased public users weight on the Satcom market (especially in the field of security and defense) or the new format given to the public-private relationship on a world-wide basis, especially in the field of satcom services, are likely to lead in the mid-term to increased complexity for collective governance is the key question.

\section{Future policy/international governance challenges}

Whatever the answer, the current evolutions may appear as a key challenge for the collective principles inherited from an international public regulation-dominated era. To summarize the findings evoked in this paper, a number of possibly deep changes will result of:

- A quickly evolving balance between public and private operators/stakeholders/users with possible effects on international regulation and public service; 
- New issues related to spectrum management; to national policies about Satcom protection, all this implying a possible evolution of the International Telecommunications Union;

- The development of new reference strategic and policy environments for the Satcom activity worldwide taking into account that:

- Satcoms will become more and more part of integrated IT systems and architectures;

- New technological environment will also be based on non space systems evolution, possibly creating conflicting situations with satellite technology. The key illustration is given by the WI Max development, possibly ousting satellite from the use of C-Band or by other terrestrial developments looking at L-Band (as was the case with the LightSquare issue in the U.S. in 2012);

- An increasing national political "added-value" of Satcoms as they become part of complex national/regional global IT and telecommunication policies, hence involving complex evolutions?

- Satcoms becoming targets from deliberate interferences

The rapidly transforming nature of the Satcoms activity calls for a reinforced/reshaped international governance (e.g. ITU with high political stakes) or may lead to self-organized regulations from the part of the stakeholders with possible differences related to fragmented (sometimes even opposed) corporate or national interests. In this context, reconciling both trends shall certainly be proposed as a major international challenge to be tackled by each actor (Governments, international institutions and private operators) to their mutual benefit and for the best continued service of their respective constituencies. 


\section{2/ Orbits and Frequencies: The Legal Context}

Tanja Masson-Zwaan (t.I.masson@law.leidenuniv.nl), Deputy Director of the International Institute of Air and Space Law, Leiden University (The Netherlands).

This chapter addresses some of the legal themes and challenges relating to the use and management of the radiofrequency spectrum and the geostationary orbit in order to put the growing problem of harmful interference into a broader legal context.

The demand for radio spectrum and orbital slots has grown along with the number of space players. Consequently, harmful interference issues are growing as well and increasingly give rise to disputes. Although some degree of (technical) harmful interference cannot be avoided, it is worrying that cases of intentional harmful interference are emerging as well. The question is whether the current regulatory scheme is able to deal with such cases.

The radio-frequency spectrum is a scarce natural resource. Hence it is of vital importance that this resource is managed in a fair and efficient manner. This management of the use of the radiofrequency spectrum and the geostationary orbit is the task of the International Telecommunication Union (ITU), ${ }^{2}$ the oldest specialized agency of the United Nations (UN). Today the ITU has 193 member states, ${ }^{3}$ thus it is as "international" as an international organization can be. In addition, it welcomes over 700 private-sector entities and academic institutions.

But the ITU regime is not self-contained. International law itself is not fragmented and should be considered as a whole. As such, it is important to consider other legal regimes in addition to the ITU regime, like the UN space law treaties, setting out the principles governing the use of outer space, or human rights instruments, which for instance codify the right to seek, receive and impart information and provide protection against cultural indoctrination.

To address the problem of harmful interference, and more specifically intentional harmful interference, it may be useful to resort to such other legal regimes, which may in fact be better suited to solve it than the ITU regime. In the following, the ITU regime and the space law regime will be discussed and some ingredients for a solution to the growing problem of (intentional) harmful interference will be suggested.

\section{Harmful interference and the ITU}

The ITU is mostly a technical organization, regulating the planning of satellite services and coordinating and registering those services so that they do not interfere with each other. The legal instruments of the ITU address harmful interference and formulate clear obligations for the member states to avoid such interference. A few of the relevant provisions are summarized here.

\footnotetext{
${ }^{2}$ See http://www.itu.int.

3 This includes all UN members except Palau, plus Vatican City.
} 
The main aim of the organization as stated in Article 1 of the ITU Constitution ${ }^{4}$ includes maintaining and extending international cooperation among all Member States, for the improvement and rational use of telecommunications of all kinds. A general obligation of the Union is to promote the use of telecommunication services with the objective of facilitating peaceful relations, harmonize the actions of Member States and promote fruitful and constructive cooperation and partnership between Member States and Sector Members. It must allocate bands, allot radio frequencies and register assignments in order to avoid harmful interference between radio stations of different countries. In addition, it must coordinate efforts to eliminate harmful interference between radio stations of different countries.

Article 44 of the Constitution provides that Member States must limit the number of frequencies and the spectrum used to the minimum essential, and must apply the latest technical advances. Further, Member States must bear in mind that radio frequencies and any associated orbits, including the geostationary-satellite orbit, are limited natural resources and that they must be used rationally, efficiently and economically, in conformity with the provisions of the Radio Regulations.

Harmful interference is addressed in Article 45 of the Constitution. It provides that "all stations, whatever their purpose, must be established and operated in such a manner as not to cause harmful interference to the radio services or communications of other Member States or of recognized operating agencies, or of other duly authorized operating agencies which carry on a radio service, and which operate in accordance with the provisions of the Radio Regulations."

The term "harmful interference" is defined in the ITU Radio Regulations (Article 1) as "Interference which endangers the functioning of a radionavigation service or of other safety services or seriously degrades, obstructs, or repeatedly interrupts a radiocommunication service operating in accordance with Radio Regulations." And Article 15 of the Radio Regulations specifies that "all stations are forbidden to carry out unnecessary transmissions, or the transmissions of superfluous signals, or the transmission of false or misleading signals or the transmission of signals without identification." Stations that cause harmful interference are obliged to immediately eliminate this harmful interference.

The fact is that these provisions are geared to deal with cases of "technical" harmful interference but not with intentional harmful interference for political or economic reasons. The ITU as an international intergovernmental organisation can do little to enforce obligations under its rules vis-à-vis sovereign member states or to impose sanctions. Compliance with international law is mostly a matter of political goodwill of states. So far this has not led to problems, but the increasing occurrence of (intentional) harmful interference is putting the system to the test.

The Radiocommunication Bureau (BR) and the Radio Regulations Board (RRB) have certain powers with regard to harmful interference. The BR (Article 12 of the Convention), which records and registers frequency assignments and keeps up to date the Master International Frequency Register (MIFR), assists in the resolution of cases of harmful interference at the request of one or more of the interested administrations, and where necessary makes investigations and prepares a report including draft recommendations to the administrations concerned for the RRB. The RRB (Article 14 of the Constitution and Article 10 of the Convention) addresses matters referred to it by the BR that cannot be resolved through application of the

\footnotetext{
${ }^{4}$ See for the basic texts of the ITU: http://www.itu.int/net/about/basic-texts/.
} 
rules, considers reports of unresolved interference investigations carried out by the $\mathrm{BR}$ at the request of one or more administrations and formulates Recommendations. It also considers appeals against decisions made by the BR regarding frequency assignments. Both the $B R$ and the RRB can only intervene if a state requires its service and that influences their efficiency in cases of intentional harmful interference.

In case of disputes, for instance about harmful interference, the Constitution provides in Article 56 that member states may settle them by negotiation, through diplomatic channels, or according to procedures established by bilateral or multilateral treaties concluded between them for the settlement of international disputes, or by any other method mutually agreed upon. If none of these means is adopted, recourse may be had to arbitration, in accordance with Article 41 of the ITU Convention. The ITU basic instruments also include an Optional Protocol on the Compulsory Settlement of Disputes, which makes the abovementioned arbitration procedure compulsory. However, neither Article 41 nor the Optional Protocol have ever been used in practice.

The latest World Radio Conference of $2012^{5}$ achieved some results in improving the ITU's capability to solve harmful interference. It reaffirmed that recent and repeated cases of intended harmful interference represent infringements and that member states under the jurisdiction of which the signals causing this harmful interference are transmitted have the obligation to take the necessary actions. The BR may also conclude Memoranda of Cooperation, such as with the International Monitoring System (IMS), a worldwide network of observational technology to help verify compliance with and detect and confirm violations of the Comprehensive Nuclear Test-Ban Treaty (CTBT), ${ }^{6}$ to measure harmful interference and to verify compliance of space stations with the characteristics recorded in the MIFR.

\section{Harmful interference and the UN Space Treaties}

As seen above, the use and management of the orbit/spectrum resource must be seen in the wider context of the legal principles governing the use of outer space as contained in the UN outer space treaties, especially the 1967 Outer Space Treaty.

Since 1961, issues relating to the use of outer space have been dealt with through the United Nations Committee on the Peaceful Uses of Outer Space (COPUOS). The Scientific and Technical Subcommittee of COPUOS addresses related technical issues, whereas the Legal Subcommittee deals with legal matters. Five UN treaties were adopted between 1967 and 1979, which set the scene for the activities of man in outer space. ${ }^{7}$

\footnotetext{
${ }^{5}$ See http://www.itu.int/net/newsroom/wrc/2012/. See also Yvon Henri, "Preventing harmful interference to satellite systems," below in this volume.

${ }^{6}$ See http://www.ctbto.org/verification-regime/background/overview-of-the-verification-regime/.

7 They are: (1) the "Treaty on principles governing the activities of states in the exploration and use of Outer Space, including the moon and other celestial bodies" of 1967 (Outer Space Treaty); (2) the "Agreement on the Rescue of Astronauts, the Return of Astronauts, and the Return of Objects launched into Outer Space" of 1968; (3) the "Convention on international liability for damage caused by space objects" of 1972; (4) the "Convention on Registration of Objects launched into Outer Space" of 1976; and (5) the "Agreement Governing the Activities of States on the Moon and Other Celestial Bodies" of 1979. All texts, official titles and sources of the five UN space treaties can be consulted on the website of the Office for Outer Space Affairs in Vienna, the UN office supporting the work of the UN Committee on the Peaceful Uses of Outer Space (UN COPUOS). See http://www.oosa.unvienna.org, especially under "Space law."
} 
Many of the provisions of the Outer Space Treaty are of direct or indirect relevance to the issue of harmful interference, and hence it is possible to rely on them to solve potential disputes in case the ITU rules and procedures are unable to do so.

For instance, the first and most important principle of space law is contained in Article I of the Outer Space Treaty. It states that the exploration and use of outer space must be carried out for the benefit and in the interests of all countries and are the province of all mankind. Outer space is free for exploration and use without discrimination, on a basis of equality and in accordance with international law. The concepts are not clearly defined and can be subject to varying interpretations - but the general idea is clear: the use of space should somehow benefit mankind. The freedom to use space is of course not absolute, but subject to respect for the freedom of other users - including commercial satellite operators.

The second-most important principle of space law is contained in Article II, which declares that outer space and celestial bodies cannot be subject to appropriation by any means. This means that there is no "territorial jurisdiction" in outer space, unlike on earth or in the airspace above the territory of a state. It is forbidden to claim ownership of any part of outer space, and this applies not only to states but also to private entities. Again, this principle can be relevant for the case of harmful interference, as it confirms that the right to use a certain orbit/frequency does not confer a right of ownership.

Another important feature is that activities must be carried out in accordance with international law, including the UN Charter, in the interest of maintaining international peace and security and promoting international co-operation and understanding (Article III of the Outer Space Treaty). This includes Articles 2.4 and 51 of the UN Charter, prohibiting the threat or use of force on the one hand, and recognizing the individual and collective right of self-defense on the other. Furthermore, international cooperation is an obligation under the UN Charter, which ipso facto also applies to space activities. Again, this Article could help to solve a case of harmful interference.

The treaties also contain important rules concerning responsibility and liability (Articles VI and VII of the Outer Space Treaty, further elaborated in the Liability Convention). A state is internationally responsible for "national activities" in space, and a launching state is liable for damage caused by its space object to another state or its natural or juridical persons, whether that damage occurs in space, in the air or on the ground. A very specific characteristic of space law is that it only has a system of state liability, i.e. a private entity or a natural person cannot present a claim based on the Treaty against another state directly under the Treaties, but must be represented by its state; nor can a private entity be held directly liable. A state could be held responsible for harmful interference under Article VI, and if damage occurs, it could be held liable for damage under Article VII. So far these articles have never been put to the test before an international tribunal, but it is not inconceivable that harmful interference would cause actual damage that gives rise to a claim under international law.

Lastly, it is important to mention Article IX, the only article that mentions "harmful interference." It provides that states must conduct their activities in outer space with due regard to the corresponding interests of other states parties. If a state believes that an activity planned by it, or its nationals, would cause potentially harmful interference with activities of other states, it must undertake international consultations before proceeding with it. And if a state party believes that an activity of another state could cause potentially harmful interference, it may request such 
consultation. Thus, if potentially harmful interference is expected, international consultations are required; however, such consultations are bilateral and focused on the actor, not on the affected state.

\section{Harmful interference and recent initiatives}

It has been said that the ITU is no longer the "gentlemen's club" it used to be, but the problem is rather that harmful interference sometimes occurs with intent, often for political or economic reasons. The means available to the ITU to address nonavoidable technical harmful interference are of little use in such cases. In the current scenario of growing dependence on satellite communications and increasing needs by a multitude of players, this is a worrying scenario. It is virtually impossible to qualify or quantify interference objectively; only a few states have such capability, the ITU does not. The recent cooperation plans with existing monitoring systems are a positive development. Further measures to empower the ITU may however be needed.

The law-making process for outer space activities has slowed down since the adoption of the Moon Agreement in 1979. Since then, UNCOPUOS has adopted non-binding sets of guidelines, for instance addressing the mitigation of space debris, the concept of the launching state or the issue of registration. ${ }^{8}$ This is not necessarily a bad thing. The current geopolitical climate is not propitious for the adoption of new treaties. States are not willing to give up more of their sovereignty. But other forms of law-making are emerging, and although some are of the view that only hard rules contained in treaties merit to be called law, it should be recognised that these legal principles can find their way into national law, as is the case for instance in some countries for the debris mitigation guidelines. This in turn may lead to state practice. After time, non-binding guidelines and principles could become binding under customary international law.

In this context, three different initiatives currently being developed are relevant for the topic of harmful interference. They can be considered as three pillars to increase the safety, security, and sustainability of space activities. ${ }^{9}$

Firstly, UN COPUOS added the Long-Term Sustainability of Outer Space Activities (LTSSA) as a new agenda item of its Scientific and Technical SubCommittee (STSC) in 2010. A formal Working Group was created, and as part of its work four Expert Groups were set up, addressing different aspects of the sustainability issue and drawing up Guidelines. They deal with (a) Sustainable Space Utilization Supporting Sustainable Development on Earth, (b) Space Debris, Space Operations and Tools to Support Collaborative Space Situational Awareness, (c) Space Weather and (d) Regulatory Regimes and Guidance for Actors in the Space Arena. $^{10}$

\footnotetext{
${ }^{8}$ The "Space Debris Mitigation Guidelines of the Committee on the Peaceful Uses of Outer Space" (2007, http://www.unoosa.org/pdf/bst/COPUOS_SPACE_DEBRIS_MITIGATION_GUIDELINES.pdf), the Resolution on "Application of the concept of the "launching State" (A/RES/62/101 of 17/12/2007, "Recommendations on enhancing the practice of States and international intergovernmental organizations in registering space objects."

9 For a discussion of the three initiatives, see Gérard Brachet, "From GEO and spectrum crowding to the threat of space debris: Is our present use of outer space sustainable?," below in this volume.

${ }^{10}$ See http://www.oosa.unvienna.org/pdf/reports/ac105/AC105_1041Rev01E.pdf. See also a useful fact Sheet by the Secure World Foundation (SWF), http://swfound.org/media/84709/SWF\%20\%20UNCOPUOS\%20LTSSA\%20Fact\%20Sheet\%20-\%20June\%202012.pdf.
} 
Expert Group D drafted a guideline to encourage and promote activities of non-governmental entities that will enhance LTSSA, as these can help increase awareness about compliance with ITU Radio Regulations related to space services, and development of open, transparent standards for exchange of data necessary to avoid radio frequency interference. Furthermore the group recommends for future consideration:

\begin{abstract}
"Definitions, e.g. of "space activity," because earth-based activities, such as radio frequency interference, has significant potential to affect the sustainability of space-based activities. Therefore regulation of "space activities" will need to encompass both Earth-based and outer-spacebased activities if it is to be effective in ensuring the sustainability of outer space activities."
\end{abstract}

The expected outcome of the Working Group is a set of "Best practice" guidelines for space operations and recommendations to establish new data exchange mechanisms, both aimed at improving the safety of launch and in-orbit operations, to be presented to the Scientific and Technical Subcommittee of UNCOPUOS in February 2014.

Secondly, the Council of the European Union took an initiative in 2007 to propose an "International Code of Conduct" for Outer Space Activities, a first version of which was approved in December 2008. A new version was circulated in 2010 and since then, two multilateral meetings took place, one in June 2012 in Vienna, and a second in Kiev in May 2013, with sixty states participating. ${ }^{11}$ Eventually a Conference of Adhesion may be held to finalize and sign this International Code of Conduct - but this might take a while. The Code is a political, dynamic document with an allencompassing scope, covering both military and civil uses of outer space. The governing principles mention "the responsibility of states to take all appropriate measures and cooperate in good faith to prevent harmful interference," as well as the compliance with and promotion of treaties, including the ITU Constitution, Convention, and Radio Regulations.

Lastly, a Governmental Group of Experts (GGE) was set up by the United Nations in 2012 to conduct a study on outer space transparency and confidence measures (TCBMs), with a report due by the end of 2013. ${ }^{12}$ The GGE argues that timely and routine consultations through bilateral and multilateral diplomatic exchanges and other government-to-government mechanisms can inter alia be useful in preventing or minimizing potential risks of physical damage or harmful interference, and recommends States to consider using existing consultative mechanisms, for example as provided for in Article IX of the Outer Space Treaty and the relevant provisions of the ITU Constitution and the Radio Regulations.

\title{
Conclusion
}

Today's world is confronted with problems that were not conceived at the time when the regulatory framework for the management of the radio-frequency spectrum and satellite orbits was created. The rules and procedures of the ITU are not well suited to deal with modern-day issues such as (intentional) harmful interference. There may be ways to enhance the efficiency of the organization, but there might be a limit to what can be achieved because the issues are more political and economic in nature, than technical.

\footnotetext{
${ }^{11}$ See http://eeas.europa.eu/non-proliferation-and-disarmament/outer-space-activities/index_en.htm.

${ }^{12}$ See http://www.un.org/disarmament/topics/outerspace/.
} 
In the current context of multiple actors and increasing demand for a scarce natural resource, regulation and settlement of disputes must be seen in a wider context of international law, encompassing space law and other fields of law. The UN outer space treaties may provide the legal basis for solving cases of harmful interference. Solutions may also be found in non-legally binding instruments such as Guidelines or Codes of Conduct that address the safe, secure and sustainable use of outer space in a comprehensive manner, with due regard for the long-established rules and instruments of the ITU. If successful, these instruments can support existing legal instruments and mechanisms to maintain the use of outer space safe, secure and sustainable. Some synergy between the current initiatives will hopefully emerge to provide a basis for solving harmful interference, which is at the core of future successful use and exploration of space for the benefit of all countries. The challenge will be to bring progress in a consistent manner. In that context it is worth mentioning that a new "single item/issue for discussion" was adopted by the UN COPUOS Legal Subcommittee, named "General exchange of information on nonlegally binding United Nations instruments on outer space". ${ }^{13}$

If all else fails, it may be necessary for parties to a dispute to have recourse to alternative means of dispute resolution, and the Optional Rules for Arbitration of Disputes Relating to Outer Space Activities, adopted in 2011 by the Permanent Court of Arbitration (PCA), may well be an interesting option in that regard. ${ }^{14}$

\footnotetext{
13 See http://www.oosa.unvienna.org/pdf/limited///AC105_2013_CRP06E.pdf. See also http://www.oosa.unvienna.org/pdf/gadocs/A_68_20E.pdf, paragraph $25 \overline{1}$.

${ }_{14}$ See http://www.pca-cpa.org/showpage.asp?pag_id=1188.
} 


\title{
1.3/ Controlling Information Flow: a Political History of Jamming
}

\author{
Guilhem Penent, Research Associate at Institut Français des Relations \\ Internationales (IFRI), Paris (France).
}

However unprecedented the situation may look, this is not the first time that the International Telecommunication Union (ITU) has found itself confronting the controversial topic of the "jamming" of international transmissions. ${ }^{15}$ One might actually say that of all the issues arising from the explosion of telecommunications in the twentieth and early twenty-first centuries, one of the most pervasive has been whether states should be given the right to block or interfere deliberately with the flow of information coming across borders. The fact that direct regulation (and even sometimes recognition and awareness) of deliberate interference remains a concern today is an indicator of the difficulty with which the technically-focused Union has regarded this very politicized issue. And yet, intentional restrictions against the flow of news and information constitute a practice which explicitly contravenes Articles of the ITU Constitution and Radio Regulations. This is all the more the case in the context of satellite jamming which can irreparably damage the transponder carried on the satellite.

The objective of this brief study is to address this so-called discrepancy by asking how international regulation actors and specifically the Union have historically involved themselves in the resolution of the jamming of communications between sovereign entities. While being contextual to the evolution of international relations notably during the Cold War and for that reason mainly focused on the extensive debate in the United Nations (UN) and elsewhere to design a system of international regulation accepted by all, it is believed that the answer will contain valuable information for the present situation.

\section{Background: to jam or not to jam?}

There is a large variety of methods by which a state can seek to obstruct unwanted international transmissions from other states. Some are more subtle than others if not as efficient. For instance, one is simply to forbid listening to "unauthorized" foreign signals like Germany did without much success during World War II in all occupied territories. Another is to attempt to discredit and undermine the credibility of foreign broadcasters by presenting them as subversive and not to be trusted. New technologies generate new tools of deliberate interference, but domestic means of obstructing foreign broadcasts has remained an option worth considering given the fact that they are not affecting listeners outside one's borders. Even though these methods limit the flow of information, they do not cause harmful interference to any third parties; they merely try to control reception of a particular signal within a specific sovereign territory in accordance with the Preamble of the Constitution of the ITU. This is the reason why one still popular technique of unilaterally limiting signals

\footnotetext{
${ }^{15}$ See James G. Savage, The Politics of International Telecommunications Regulations (Boulder: Co, Westview Press, 1989), Index: "Jamming" thereafter defined as intentional interference with radio, television, or other electronic communications.
} 
involves state control over the distribution and use of community and/or personal receivers, be they transistor radios, wired networks or satellite dishes.

However, the most obvious as well as the best known illustration of deliberate interference remains the jamming of international transmissions. Basically, shortwave jamming involves the transmission of a disruptive signal on the same frequency as the unwanted broadcast. Generally, it is just static or irritating noise-like signals. On other occasions, it is a distorted voice or music. In both cases, the principle is the same; the interference is imposed with greater power so as to prevent reception or at least render a broadcast unintelligible for all its potential audience. To obtain such a large and widespread impact, most jamming uses powerful transmitters that radiate signals into the ionosphere and make them bounce back to Earth across the path of the broadcast "sky-wave," hence affecting population over large areas without paying attention to political boundaries. Usually, mainly in cities, a complementary "ground-wave" jamming signal is also radiated directly at the targeted audience with the result of providing saturation in the local area only.

This two-tier logic has not changed much in the satellite communications era. Uplink orbital jamming of a satellite transponder targets the signal directly at its origin, resulting in the capture and complete overriding of the downlink power for everyone, everywhere. Impact is large and pervasive, affecting both the viewers and the neighboring channels which are using the same frequency irrespective of their nationalities, contents or footprints. Downlink terrestrial jamming takes place in a more specific rural or urban area, and involves cheaper and smaller equipment. It attempts to inject contradictory signals into ground terminal receivers rather than into the satellite itself. Since the jammer has a range advantage over the satellite-based emitters, it can be very low-powered. But it has also the disadvantage of allowing only a few terminals to be jammed, especially if the audience is geographically dispersed.

In the use of jamming, Austria is usually presented as an early example. Austria used this technique in 1934 under the Dollfuss government in order to decrease the effect of German propaganda calling for the union of the two countries. A very common phenomenon during the inter-war and war periods, jamming received a new lease of life as a result of the partitioning of Europe and the escalation of Cold War tensions, and the subsequent establishment of the Voice of America (VOA) services and other international broadcasts intended at Russian and East European audiences. As a consequence, while operating jamming transmitters has proven very expensive, ${ }^{16}$ this method of control remained quite popular during the entire Cold War as a spin-off of the whole East-West issue. Incidentally, the first incident of jamming in the western hemisphere occurred in the early 1960s when Cuba started interfering with broadcasts originated from the US. The potential for Cuba to bring chaos to the airwaves of the United States "as far away as Salt Lake City" has been of concern ever since. ${ }^{17}$ But because jamming is by nature political something that became even clearer following the ascendency of the Third World

${ }^{16}$ By 1988, the Soviet Union's total effort had grown approximately to 1700 local and "sky wave" jamming transmitters. "Operating these transmitters 24 hours per day at an estimated electrical cost of $\$ 0,06$ per kilowatt-hour amounted to an operational cost of $\$ 48$ million per year for electricity alone (assuming 50\% transmitter efficiency), not including operational and maintenance labor costs, or capital costs", George W. Woodard, "Cold War Radio Jamming," in A. Ross Johnson and R. Eugene Parta (eds.), Cold War Broadcasting: Impact on the Soviet Union and Eastern Europe (Budapest and New York: Central European University Press, 2010), 53.

17 Stephen D. Bayer, "The Legal Aspects of TV Marti in Relation to the Law of Direct Broadcasting Satellites," Emory Law Journal, Vol. 41 (1992), 574. 
and the advent of direct broadcast satellite communications -, the ITU has naturally expressed difficulty if not reluctance in addressing the issue.

\section{The challenge of telecommunication regulation in a world of sovereign states}

Understandably, the problem at the heart of any discussion of the issue is related to the ambivalent nature of deliberate interference. What one country calls jamming another may call "defense against psychological warfare" or "protection of the state sovereignty from external interference." What one deplores as a denial of the right to all persons to be fully informed another may define as a self-help tactic used for defensive purposes only. It is these complexities that historically have prevented any resolution to emerge, notably within the ITU.

\section{The free flow of information vs. the sovereign right \\ to control its telecommunications}

The issue of deliberate interference - in this case the destruction of telegraph lines during the Franco-Prussian War of 1870 - was first raised at the International Telegraph Conference held in Rome in 1871 with well-known Samuel Morse expressing the hope "that the conference will not adjourn without adopting a resolution asking the universal protection of all nations for this powerful agent of civilization." ${ }^{18}$ The use of jamming as a specific method of interfering with unwanted transmissions, for its part, was touched upon at the 1932 Madrid Conference when the radio convention was being merged with the telegraph convention to form a single entity, the actual International Telecommunication Union. A draft article was even submitted but it was successfully opposed notably by the American delegation. ${ }^{19}$ Under the aegis of "The League of Nations Convention to Formulate an International Convention Concerning the Causes of Peace," a new conference convened four years later to discuss political guidelines for the character and control of international broadcasting but failed in its turn to tackle the question, mainly because it was unable to secure an agreement from Germany. ${ }^{20}$

When nations gathered again in the immediate postwar in Atlantic City in 1947 to reformulate the convention of the ITU and discuss its future relationship with the new United Nations organization, they mostly ignored the issue of jamming. Article 44 of the then convention asked states to avoid unintentional harmful interference with the broadcasts of other countries but made no reference to intentional interference, thus conveying "the notion that all future problems of this nature would be the unintentional product of new technologies and innovations." 21 The ITU succeeded only in creating a major contradiction. Namely, that the Union defends both the right to international protection from "harmful interference" to all frequencies registered, and the right of a country to suspend incoming communications if it deems it appropriate (the so-called "stoppage of telecommunications" and "suspension of services" also mentioned in the currently effective Constitution) by employing measures that in practice might be deliberately causing "harmful interference."

\footnotetext{
${ }^{18}$ Savage (fn. 15), 29.

${ }^{19}$ George A. Codding, "Jamming and the Protection of Frequency Assignments," The American Journal of International Law, Vol. 49, No. 3 (Jul., 1955), 386.

${ }^{20}$ George A. Codding, Broadcasting without Barriers (Paris: UNESCO, 1959), 74.

${ }^{21}$ Savage (fn. 15), 140.

${ }^{22}$ Codding (fn. 19), 384-388.
} 
In effect, the Union is torn between two urges; what many have called the "free flow versus prior consent or national sovereignty" debate. ${ }^{23}$ On the one hand, the ITU's raison d'être is to coordinate and facilitate international telecommunications. As such, any kind of control is clearly at odds if not in direct contravention with the purpose of the ITU as an international organization promoting interference-free telecommunication operations. On the other hand, the ITU explicitly recognizes each country's sovereign right to determine its own destiny - as shown in the Preamble - and act accordingly. Hence nations have on occasion reported that resort to jamming was a remedy against outside interference with their internal affairs. Fearful of the rapid development of direct broadcasting by satellite (DBS), they have also tried to promote the idea that transmissions over the territory of other countries should be prohibited or at least limited to the maximum unless said otherwise. Even if attempts to block signals have an impact on the efficient collective use of the radio frequency spectrum thus forcing ITU to act, resolution of deliberate harmful interference disputes is doomed to occur infrequently: the country at fault needs only to refuse to admit anything, benefiting from the fact that a sovereign nation's word cannot be challenged.

As early as 1957, the United States notified the ITU that Soviet jamming operations directed against VOA were interfering with European aeromobile radio services. In response, the Soviet Union went as far as announcing that it was willing to stop jamming if the US ceased all radio transmissions directed to the USSR. But the American administration rejected the notion that Soviet interference with European utility services was somewhat connected to the content of Voice of America Russian-language signals. ${ }^{24}$ Since the ITU is traditionally concerned by the means of telecommunication and not the actual message or content encapsulated within the media, the topic was too political for the Union to be of any assistance. This certainly did not stop attempts to convince the Soviets that jamming was in no one's interest for many efforts focused hereafter on the UN. But the fact is that neither the UN nor the ITU could claim any credit in the decreasing or worsening of the level of jamming. To put it simply, "The extent to which jamming ceased or declined was determined by the general state of relations between the USSR and the United States." 25

Jamming regulation, prior consent and the advent of satellite broadcast

Clearly, deliberate interference with broadcasts has been for the most part of the Cold War an East-West issue. Third World states have not been particularly interested with jamming operations, not least because its cost has tended to deter most states from trying. Also, foreign transmissions have not been openly hostile toward their governments. Things began to change with the emergence of satellite broadcasting technology potentially capable of transmitting television signals to all. Unlike shortwave radio broadcasting, satellite television is not international by nature. While it is regionally contained, it is however impossible for a DBS signal "footprint" to conform exactly to national political boundaries. With this development, spillover naturally moved onto a different scale and so did the concerns of many countries fearful that if DBS receiving dishes become pervasive their domestic telecommunication administrations will suffer a significant loss of control over the

\footnotetext{
${ }^{23}$ See for example Savage (fn.15), chap. 3; see also Colby C. Nuttall, "Defining International Satellite Communications as Weapons of Mass Destruction: The First Step in a Compromise Between National Sovereignty and the Free Flow of Ideas," Houston Journal of International Law, Vol. 27, No. 2 (2005), 389-428.

${ }^{24}$ Savage, (fn. 15), 143.

25 lbid., 145.
} 
social, cultural and political destiny of their citizenry rendered accustomed to foreign signals. Understandably, television broadcasting was perceived as having an even greater impact than radio.

Therefore, even before the technology of satellite television become actually mature, the Soviet Union and many developing countries tried to make sure that acceptance of the principle of sovereignty won the day against the free flow of information. By 1972, not only the ITU had established two norms for the operation of DBS television: the obligation to limit the signal spillover of any transmission in one's own territory to a maximum, and the doctrine of prior consent for international programming operations destined to other countries. Also, the $17^{\text {th }}$ United Nations Educational, Scientific and Cultural Organization (UNESCO) General Assembly passed by a vote of 100-1 (the United States) a resolution supporting the principle of prior consent regarding DBS signals. And the UN General Assembly Resolution 2916, which promoted the need to ensure the free flow of information on a basis of "strict respect for the sovereign rights of states" including the right to deliberately interfere with the incoming signal in case of non prior agreement from the target country, was approved by a vote of 102-1 (the United States) with only seven abstentions. ${ }^{26}$

The Soviet motivation was two-fold. First, the objective largely unchanged from the start was to exclude any opinion seen as subversive and a threat to the prosperity of the State and the Party. On the other hand, international cooperation was also worth supporting provided that it did not compromise domestic control of information flows and the existence of jamming transmitters. As for the South, it was not until the late 1970s that it started to have a significant influence in the debate after several developing countries began actively pursuing a genuine policy regarding the control of information flows. Arguments over direct broadcast satellites, on which the focus was placed primarily, were then closely linked to demonstration for the New World Information and Communication Order (NWICO) which sought to free the Third World from economic dependence on the North as a corollary of the New International Economic Order. Assumption was that the then state of affairs allowed the perpetuation of the domination of the North over the production of information and communications and, indeed, the emergence of new forms of neocolonial dependence, which provoked in response a strong desire for "balanced flow" against "free flow."

The result of this contradiction of interests and strategies was failure to adopt a binding international treaty on the regulation of direct broadcast satellites. Instead, by a vote of 108 to 13 (with 13 abstentions), the UN General Assembly passed Resolution 37/92 in 1982 on the "Principles Governing the Use by States of Artificial Earth Satellites for International Direct Television Broadcasting," that tried to balance the different interests at play. The principle of requiring prior agreement of the receiving countries was abandoned, but the non-binding document provides in paragraph 8 that "States should bear international responsibility for activities in the field of international direct television broadcasting by satellite carried out by them or under their jurisdiction." Also, as put by paragraph 13 and 14 that frame the requirement of prior consultation and agreement, remains the notion that a state should at least have some say over the reception of satellite signals within its sovereign territory.

\footnotetext{
${ }^{26}$ Also known as the "jammer's charter." See ibid., 150. Regarding those different initiatives, see also Stephen Gorove, "International Direct Television Broadcasting by Satellite: "Prior Consent" Revisited," Columbia Journal of Transnational Law, Vol. 24 (1985), 1-11.
} 


\section{Back to the future}

There is therefore no information regime for the space commons that involves the prior consent principle. But its absence has not prevented states from adopting versions of it where they consider it important. In effect, neither the end of the Cold War nor the advent of globalization and deregulation in telecommunications and broadcasting have changed the desire governments have to control signals coming into their respective territories or have an influence on the functioning and distribution of satellite services. They have merely provided a new environment in which efforts to control or manage the flow of information are more informal and pragmatic. Accordingly, the nature and content of the "toolbox" available to be put at the disposal of states have also evolved with the emergence of a mix of practices. ${ }^{27}$ In this context, jamming can still be considered a viable "self-help" option in the hand of states in need of some desperate political leverage in bringing pressure to bear on other states to alter their modes of diffusion. In 1995, for example, MED-TV, a Kurdish satellite channel, was intentionally jammed. And yet, the case is atypical because of the formality of the proceedings which culminated with the license being eventually revoked by the British government itself. ${ }^{28}$ Far more recent and emblematic is the case of intentional interference with radio and TV broadcasts directed at Iran which runs in parallel with other commercial and political disputes. ${ }^{29}$

To the extent that the ITU has been able to achieve successful outcomes in the past in the area of deliberate interference, that success has been heavily dependent not to the force of any international legal constraints, but to the costs and own inconvenience of jamming and its possible damage to reputation. Today, as technology allows jamming to be both cheaper and more effective, it remains to be seen whether the risk of being exposed will suffice to deter such initiatives or if more regulatory measures need to be taken in complement at the national, regional or global level, and in the telecommunication sector or beyond. The shape of a more formal governance of satellite may hang in the balance.

\footnotetext{
${ }^{27}$ See, for example, Mei Ning Yan, "China and the Prior Consent Requirement: A Decade of Invasion and Counter Invasion by Transfrontier Satellite Television," Hastings Communications and Entertainment Law Journal, Vol. 25, No. 2 (2003), 265-305.

${ }^{28}$ On this case and others, see Monroe E. Price, "Satellite Transponders and Free Expression," Cardozo Arts \& Entertainment Law Journal, Vol. 27, No. 1 (2009-2010), 11-26.

${ }^{29}$ See Peter B. de Selding, "Satellite Fleet Operators Push ITU To Act," Space News, Sep. 26, 2011; Editorial, "Iran's WRC-12 Agenda," Space News, Feb. 7, 2012.
} 


\title{
2/ Increasing Harmful Interference, a Rationale for Action?
}

\section{1/ Interferences of Satellite Signals: Not a New Issue... but More Complex}

\author{
Claire Jolly, Policy Analyst at the OECD Space Forum, Organisation for Economic \\ Co-operation and Development, Directorate for Science, Technology and Industry, Paris \\ (France).
}

As part of its mission to explore possible sources of economic growth, the Organisation for Economic Co-operation and Development (OECD) launched in 2006 a Space Forum in co-operation with the space community. The Forum aims to assist governments, space-related agencies, and the private sector to better delineate the statistical contours of the growing space sector worldwide, while investigating the space infrastructure's economic significance and potential impacts for the larger economy.

Over the years, while examining the role of space activities and their wider impacts in both OECD and non-OECD countries, the OECD Space Forum has seen several threats to the global space infrastructure become more significant: they include the increasing amount of harmful space debris in useful orbit and the interferences of satellite signals.

In that context, IFRl's April 2013 workshop on "Orbital Slots and Spectrum Use: a Governance Outlook" is timely. Space applications have the potential to make significant contributions in the management of major $21^{\text {st }}$-century challenges (e.g., environmental and natural resources monitoring, the digital divide). However a stable space infrastructure is essential to serve our societies' needs and this includes a sound governance of spectrum uses. This paper provides a brief overview of selected issues regarding interferences of satellite services.

\section{Satellite services are suffering from their growing popularity}

As satellites services are increasingly integrated into a wider information and communication infrastructure, they are engaged in fierce competition for radiofrequency spectrum. In parallel, as the use of satellite signals become ever more popular in numerous commercial applications (e.g. in-car navigation tools, major

\footnotetext{
1 See OECD, The Space Economy at a Glance 2011 (Paris: OECD Publishing, 2011); OECD, Space technologies and Major Threats (Paris: OECD Publishing, 2013 forthcoming); and Claire Jolly, "Space Security in 2013: An Overall Assessment," in The Space Security Index 2013, http://www.spacesecurity.org/, Oct. 2013.
} 
sporting events accessed via satellite television broadcasting), these signals also suffer from more interference threats.

Signal interference is not a new phenomenon though. As early as the 1980s when commercial satellite broadcasts became available, already some intentional and often unintentional interferences took place. What is different today is that interferences can affect the functioning and reliability of services from many different segments of the orbital infrastructure (i.e., broadcasting, communications links, navigation, and positioning).

\section{Selected sources of signal interferences}

The sources of satellite signal interferences are various and can be unintentional or malicious, as presented by selected telecommunications operators and regulators during the IFRI workshop: "Orbital Slots and Spectrum Use: a Governance Outlook." Few statistics are shared by governmental and private operators, but overall the unintentional interferences seem to be the most frequent. Follow a selection of signal interferences, which should not be overlooked.

More devices creating interferences...

Unintentional interferences are due in a large part to the growing range of information technologies' products and services available in both OECD and nonOECD economies, which all require spectrum (e.g. multiplication of Wi-Fi emitters, Wi-MAX devices). To avoid interloping from other devices, a "band jumping" effect has already occurred for a number of $900 \mathrm{MHz}$ devices (e.g. selected industrial, scientific and medical equipment, near field communication devices, and wireless computer networks), which are now being operated in $2.4 \mathrm{GHz}$ to avoid interferences from competitors... but creating new problems for incumbent devices active in the $2.4 \mathrm{GHz}$ bands. Overtime, the "band jumping" effect is starting to include some $2.4 \mathrm{GHz}$ devices moving to $5 \mathrm{GHz}$, and so on, affecting increasingly bands dedicated originally to satellite uses. As more terrestrial communication networks are being put in place in many parts of the world, their interference with satellite signal reception will tend to increase (e.g. the aborted LightSquared development in the United States in 2012).

\section{Jamming of signals... resulting in the distortion of GPS signals and satellite communications links.}

Commercial satellite communications broadcasts have suffered from diverse types of jamming over the years. But this affects also increasingly Global Navigation Satellite Systems (GNSS) signals. Today, GPS information is provided free by the United States, and signals are used in countless products, from smartphones to automobiles. There are different signal failures types, often not confirmed until much later after the event. The causes may vary: software glitches, natural obstructions blocking signals and GPS jamming (deliberate or not). In 2007, the unintentional jamming of GPS in the San Diego Harbour affected for several hours light civilian aircraft traffic, telephone switches, cellular phone operations, and the US Naval Hospital's mobile paging system was shut down. It took several weeks to find out the cause: two US Navy ships were conducting for two hours a scheduled communications jamming training exercise with no intention to intrude in the GPS signals spectrum. But intentional jamming can also increasingly cause problems. In 2009, satellite-positioning receivers using a new air-navigation aid at Newark airport in New Jersey were suffering brief daily reception breaks. The culprit was a driver who passed by on the nearby New Jersey Turnpike each day, who had a cheap GPS jammer in his truck to avoid being tracked by his company. It took several months for FAA investigators to track down the problem and find the guilty party. 
These examples of unintentional and intentional jamming demonstrate that the legal context for GNSS devices is moving from theory to practical problems, as the democratisation and globalisation of these devices is provoking new uses, new dependences and new criminal activities to be dealt with at national level.

\section{Dealing with satellite signal interferences}

In 2003, the United States and the European Union disagreed over the radiofrequency allocation for the navigation satellite Galileo. This conflict was then seen as an example of potentially enduring competition for a scarce space resource. Since then, more actors have become involved in space activities, new competition for spectrum use has arisen from ground-based telecommunications services and new types of jamming have occurred. The way forward includes technical development to make better use of scarce spectrum and improved governance mechanisms at national and international levels.

\section{Technical developments}

In the past decade, technical developments to alleviate conflicts over bandwidth allocation have taken place. They include shielding, frequency hopping, lower power output, digital signal processing, frequency-agile transceivers, and softwaremanaged spectrum. To circumvent intentional and unintentional interference from third parties, satellites operators and ground-based equipment providers are looking at possible technical solutions with their networks of customers. Such solutions do not resolve all problems (parallel policy, legal, and regulatory approaches are also needed), but contribute to better awareness of the risks by users and providers of space applications.

\section{Spectrum governance}

Negotiations at both national and international levels remain essential to improve the coexistence of very different systems. As the scope for wireless communications increases, efficient spectrum allocation will become increasingly important policy and economic issues. In 2012, approximately 3,000 delegates attended the ITU World Radiocommunication Conference. They made some key revisions to the Radio Regulations, the international treaty governing the use of the radio-frequency spectrum and satellite orbits. The ITU continues to play a major political and regulatory role in arbitrating conflicts about radio signal interference (as demonstrated by the 2012 satellite communications disputes in the Arabo-Persian Gulf). Although governments cannot be forced to strictly apply ITU regulations, most countries do abide by the rules that they set themselves. Without resolving all interferences issues, regular improvements of the international regulatory process should contribute to a more efficient use of the spectrum overall. On a more national level, the same issues apply, as competition from different systems rises. But in addition, recent examples from GPS signal failures and disruption demonstrate that innovative legal responses will need to be ironed out in many countries to deal with new forms of jamming. 


\section{2/ What Is Harmful Interference: Qualifying Intentions}

Ethan Lavan, Director of Orbital Resources at Eutelsat representing ESOA, the European Satellite Operator's Association, a non-profit European organisation established with the objective of serving and promoting the common interests of European satellite operators. $^{2}$

\section{Interference vs. harmful interference}

As long as there are radio services there will always be some level of interference this is the nature of physics. The challenge is to manage this interference so that the multitude of services sharing the radio waves today can co-exist in an efficient and effectively interference-free environment.

In common language (including as often used throughout the present paper), when one speaks of interference, one is referring to what should more precisely be labelled as harmful interference - that is interference that has a measurable and/or observable negative effect on the desired service.

This harmful interference can vary in level of unacceptability - whether this be in terms of degradation to image or sound quality, reduction of data throughput, or in many cases, complete loss of service. Given the nature of today's digital satellite transmissions, harmful interference, particularly those of an intentional nature, very often do result in a complete loss of service.

\section{Uplink interference - specificity of broadcast services}

Given its particular nature, it will be useful to look at the mechanics of interference in a broadcast service environment, especially as many of the issues being considered in this paper concern the satellite broadcast of television services.

Harmful interference to a satellite broadcast service can occur to the uplink and/or the downlink. In the case of interference to the downlink, only a subset of users is generally affected. Downlink interference may be caused locally by a nonsatellite source, in which case only receivers located in the region or vicinity of the interferer are potentially affected. If the origin of interference is a neighbouring satellite with overlapping downlink coverage, it may be only those receivers in the overlap zone which are inadequately dimensioned (e.g. too small an antenna size) or which are improperly setup (e.g. badly pointed) which are affected.

However if the interference is affecting the uplink transmission, then the broadcast satellite, which acts as a repeater, retransmits the degraded signal to all receivers in the coverage area. This is generally much more serious, as the harmful interference is applied in a non-discriminatory manner in a way which generally allows the receiver little or no recourse to mitigate the effects.

\section{Usual cases of interference are accidental or otherwise unintentional in nature}

With the increase in number and density of satellites providing service over a limited resource - i.e. orbital spectrum - it is inevitable that cases of interference will arise.

\footnotetext{
${ }^{2}$ http://www.esoa.net/
} 
The most common cause of satellite interference is human error in the technical set up and operation of the networks. This can be due to wrong time, frequency, polarisation or power settings - or even mistakenly accessing the wrong satellite. Other causes are faulty or poor quality equipment, bad wiring, or particularly in the case of smaller receive terminals, mispointed antennas.

In short, the large majority of cases of harmful interference are an unintended consequence of the increased occupation of the geostationary arc, for which accommodations must be increasingly made between closely neighbouring satellites and services.

Fortunately in the case of unintentional interference, there is nearly always a common will amongst operators to find a solution to solve the problem and end the interference. To this end there are a number of industry organizations and consortium effectively addressing the subject with results which are both effective and encouraging.

\section{Intentional or targeted interference - qualitative criteria}

While there can never be a fully objective basis on which to categorise a given case of harmful interference, through the analysis and experience of past events, there are a number of qualitative and technical characteristics which might suggest that a given interference is of an intentional nature.

Here we are speaking of an action which implies a harmful intention and a deliberate purpose, such as preventing the diffusion of certain content at a certain time.

Perhaps the single most determining qualitative characteristic of intentional interference to television broadcast services is the link to content, where more precisely there is a high correlation of the interference event to the broadcast of specific content which might be politically objectionable to a potential interferer. Often a politically sensitive channel, transmitted in a language to target a specific audience is involved. The likelihood of specific episodes of interference may be associated with political situations of social unrest related to a target content or audience.

Not only does the interference in such cases often take on an episodic nature according to the airing of the objectionable material, but one sometimes even observes the intentional interference following the same content and/or program when the broadcast frequency, and even the satellite itself, are changed during attempted mitigation actions by the satellite operator.

\section{Technical characterization of intentional or targeted interference}

There are also a number of elements of a technical basis which strongly suggest that a given interference is likely to be of an intentional nature. For example, the interfering signal may appear as a high power, unmodulated carrier containing no content or identification. An interfering uplink might point with great directional precision, and hence with little chance of an unintentional mistake, only at the victim satellite, with a carrier centred at a precise frequency related to a particular television multiplex carrying the targeted content or program. The interfering carrier might track the interference mitigation attempts of the victim carrier, for example with the power of the interfering signal increasing in reaction to each increase in power of the targeted carrier. 
Of note is that the technical characteristics of the interfering carrier typically require very substantial ground infrastructure, requiring large earth station diameters and/or high power amplifiers. As such, another factor is that the geographical origin of recurring intentional interference tends to be limited to a very small number of fixed and precisely located sites.

\section{Pirate transmissions}

Pirate transmissions are another specific type of illegal transmission with a very different intent than that of targeted, intentional interference. Specifically, the pirate transmitter has as its primary objective to successfully transmit its unauthorized, illegal signal for as long as possible. Of course common to both is the intentional nature, which for a pirate transmission is almost always without any doubt.

A key differentiator is that the pirate carrier usually makes every effort to coexist with, rather than cause harm to other existing services on the satellite. To achieve this, the pirate transmission may select a transmission channel which is in the so-called guard band separating two nominal transmission channels, or may select a part of a frequency band which may appear to be unused at the moment of the pirate transmission.

Despite the difference in intent, pirate transmissions usually do cause real damage and interference, and can thus can be considered, and in many cases similar treated, as any other intentional interference to satellite services.

\section{Consequences of intentional uplink interference to satellite TV broadcasts}

Whether as targeted interference, or as a result of illegal pirate transmissions, the damaging effects of uplink interference in satellite television broadcast are the same, generally being both international and multi-channel in nature:

The entire downlink coverage area of the satellite is denied service when the uplink is interfered with, even where the intent of the interference may be limited to a specific region, or even a single country.

Also, due to the nature of the way digital television signals are broadcast today, 10 or more television programs are typically broadcast in a single digital television multiplex. If this multiplex signal is damaged by uplink interference, the entire multiplex is made unavailable to the receiving decoder. Thus even if only a single program is targeted by the interferer, the entire multiplex of channels is destroyed as collateral damage.

\section{Qualifying and defining harmful interference - Conclusions}

Although there are no absolute certainties in the categorizing and identifying of the different types of interference to satellite services, there is in practice a great number of cases where the preponderance of evidence leaves no real doubt as to an intentional, targeted nature of the interference.

Once identified as intentional, however, understanding the exact motivations, identifying the underlying responsible parties, and finding the means to end the interference, remain, in increasing order of difficulty, very real challenges. 


\section{3/ Telecommunications Law and Freedom of expression}

Philippe Achilleas, Director of the Institute of Space and Telecommunications Law (IDEST) and the Master's Degree in Law of Space Activities and Telecommunications at the University Paris-Sud 1 (France).

Since 2009, Eutelsat Communications, the French satellite communications company is victim of massive interferences. The origin of the interferences is clearly established. They are generated from Iran, who did not deny that they are caused from its territory. Repeated interferences target several international services including BBC Persian, Voice of America in Farsi and Radio Free Europe / Radio Liberty's Radio Farda, which broadcast their programs on three Eutelsat satellites. These intentional interferences that impede satellite reception represent a serious offence under international conventions of the Union International Telecommunication Union (ITU). They also represent a violation of the freedom protected by the major human rights international texts. Telecommunications law and human rights separately each represent two branches of law. Yet there are many interactions between these two branches of law. The principal interaction is based on the direct link between telecommunications law and freedom of expression. Therefore, the issue of interference can be treated in terms of human rights.

Telecommunications Law is defined as the law of networks whereas information law is presented as the law of content. This dichotomy between the two sides of communications law is based on the legal definitions of telecommunications. According to the ITU, the term "Telecommunication" represents: "Any transmission, emission or reception of signs, signals, writing, images and sounds or intelligence of any nature by wire, radio, optical or other electromagnetic systems." ${ }^{3}$ The distinction between networks and content is more significant in European Union Law where the legal term "telecommunications" is replaced by the terms "electronic communications." Based on the 2002 "Framework Directive," "electronic communications network" means "transmission systems" which permit the conveyance of signals at distance "irrespective of the type of information." 4 The definition expressly includes "networks used for radio and television broadcasting, and cable television networks." Thus all networks are included in the scope of the definition. The text also defines "electronic communications service" as "a service normally provided for remuneration which consists wholly or mainly in the conveyance of signals on electronic communications networks [...]." The definition expressly excludes "services providing, or exercising editorial control over, content transmitted using electronic communications networks and services; it does not include information society services [...] which do not consist wholly or mainly in the conveyance of signals on electronic communications networks?"5 Therefore content does not fall within the scope of the definition.

\footnotetext{
${ }^{3}$ Constitution of the International Telecommunications Union, 1992, Annex, $n^{\circ} 1012$, ITU, Collection of the basic texts of the International Telecommunications Union adopted by the Plenipotentiary Conference, Edition 2011, ITU, Geneva, 2011, 56.

${ }^{4}$ Directive 2002/21/EC of the European Parliament and of the Council of 7 March 2002 on a common regulatory framework for electronic communications networks and services (Framework Directive), Article 2 (a) EUOJ L 108 , 24 April 2002 p. 0033.

${ }^{5}$ Directive 2002/21/EC, Article 2 (c).
} 
In a converging world, it is however irrelevant to argue that telecommunications law has no influence on content and applications and as a consequence that telecommunications regulations and freedom of expression have no interaction. Both international law and national law confirm the interconnection between telecommunications law and freedom of expression (I). Therefore regulation of spectrum and orbits has to be in line with freedom of expression, in particular its corollary, freedom of information (II).

\section{Interconnection between telecommunications law and freedom of expression}

Freedom of expression is enshrined in all human rights instruments. At the universal level, this principle is proclaimed at Articles 19 of both the 1948 Universal Declaration of Human Rights ${ }^{6}$ and the 1966 International Covenant on Civil and Political Rights. ${ }^{7}$ Freedom of expression is contained in all the regional conventions on human rights: the 1950 European Convention for the Protection of Human Rights and Fundamental Freedoms, Article $10 ;^{8}$ the 1969 American Convention on Human Rights, Article $13 ;^{9}$ and the 1981 African Charter on Human and Peoples' Rights, Article $9 .{ }^{10}$ Almost all national constitutions recall the fundamental right of freedom of expression.

Freedom of expression includes freedom of information defined as the freedom to seek, receive and impart information and ideas of all kinds, regardless of frontiers and governmental interference, either orally, in writing or in print, in the form of art, or through any other chosen media. Freedom of information covers content as well as telecommunications networks. This interpretation is in line with the methods of interpretation of international treaties as codified in Article 31 the 1969 Vienna convention on the law of treaties. ${ }^{11}$

As a consequence, everyone has the right to use telecommunications networks to express their opinion or to seek access or distribute information. The European Court of Human Rights (ECHR) considers, for example, that the distribution of programs over the air and via cable is covered by the right of expression and information. ${ }^{12}$ From this point of view the right of the public to use the international telecommunications service stated in Article 33 of the ITU Constitution represents a perfect combination with freedom of expression. The right to universal service, as expressed by European $^{13}$ and domestic telecommunications legislations, ${ }^{14}$ also supports implicitly freedom of information by imposing an obligation for operators to provide basic telecommunications networks and services to all individuals within the territory at an affordable price regardless of geographical location. Generally, any regulation or policy encouraging development of

\footnotetext{
${ }^{6}$ UNGA, Resolution 217A (III), 10 December 1948.

7 UNTS, Vol. 999, 171.

${ }^{8}$ ETS, No. 005.

9 OAS Treaty Series, No. 36

${ }_{11}^{10} \mathrm{OAU}$ Doc. CAB/LEG/67/3 rev.

${ }^{11}$ UNTS, vol. $1155,331$.

12 ECHR, Case of Groppera radio AG and others v. Switzerland, Application No. 10890/84, Judgment, 28 March 1990.

${ }^{13}$ Directive 2002/22/EC of the European Parliament and of the Council of 7 March 2002 on universal service and users' rights relating to electronic communications networks and services, EUOJ L 108 of 24 April 2002, 51.

${ }^{14}$ French Posts and Electronic Communications Code, Article L. 35-1; US 1996 Telecommunications Act, Section 254.
} 
telecommunications such as those aimed at bridging the digital divide contribute directly to strengthening freedom of expression. On the other hand, any strengthening of freedom of information contributes to the building of the information society and thus to the development of the telecommunications market. This reciprocal influence between freedom of expression and information society was confirmed by the participants of the World Summit on Information Society organized in Geneva in 2003 and in Tunis in 2005. ${ }^{15}$

Second, any restriction on telecommunications networks, services and equipment represents a violation of the freedom of expression. In the case Autronic $A G v$. Switzerland the ECHR concluded that a restriction on satellite reception equipment represents a direct violation of freedom of information. ${ }^{16}$

Freedom of expression and freedom of information, however, are not absolute. Restrictions may be imposed under certain conditions. An analysis of the texts cited above reveals the following three conditions. First, restrictions must meet a legitimate aim stated in the texts relating to human rights. Then they must be prescribed by the law of the State applying the limitation. Finally, they must be proportionate. Regarding the legitimate aims, Article $19 \S 3$ of the International Covenant on Civil and Political Rights states: the respect of the rights or reputations of others; and the protection of national security or of public order, or of public health or morals. Article $10 \S 2$ of the European Convention on Human Rights provides six legitimate aims. ${ }^{17}$ Again, from this point of view, the stoppage of telecommunications authorized by Article 34 of the ITU Constitution is in line with human rights instruments. Based on this article, Member States of ITU reserve the right to cut off, in accordance with their national law, any other private telecommunications which may appear dangerous to the security of the State or contrary to its laws, to public order or to decency.

\section{"Spectrum/orbit" resource management from a freedom of information perspective}

The use of the "spectrum/orbit" resource is subject to national administrative authorizations called "assignations" in the vocabulary of the ITU. The number 18.1 of the ITU Radio Regulations states that: "No transmitting station may be established or operated by a private person or by any enterprise without a license issued in an appropriate form and in conformity with the provisions of these Regulations by the Government of the country to which the station in question is subject."18 Such a procedure is not contrary to freedom of information. The European Convention on Human Rights expressly states in the third sentence of Article $10 \S 1$ that freedom of information shall not prevent States from requiring the licensing of broadcasting, television or cinema enterprises. In the Case of Groppera radio AG and others $v$. Switzerland, the ECHR considers that "national licensing systems are required [...] in large part to give effect to international rules, including in particular number 2020

15 Declaration of Principles on Building the Information Society: a global challenge in the new Millennium , 12 December 2012, par. 4 and 55 (Document WSIS-03/GENEVA/DOC/4-E); Plan of Action, 12 December 2012, Action Line C.9 (Document WSIS-03/GENEVA/DOC/5-E).

${ }_{16}$ ECHR, 22 May 1990, judgment $n^{\circ}$ A 178.

17 The interests of national security, territorial integrity or public safety; the prevention of disorder or crime; the protection of health or morals; the protection of the reputation or rights of others; the prevention of the disclosure of information received in confidence; and the maintaining of the authority and impartiality of the judiciary.

${ }_{18}$ ITU, Radio Regulations, Part I, ITU, Geneva, 2012. 
[now number 18.1] of the Radio Regulations." 19 The negotiating history of Article 19 of the 1966 International Covenant on Civil and Political Rights shows that the inclusion of such a provision in that article had been proposed with a view to the licensing to prevent chaos in the use of frequencies. However, its inclusion was opposed on the ground that it might be utilized to hamper free expression, and it was decided that such a provision was not necessary because licensing in the sense intended was deemed to be covered by the reference to "public order" in paragraph 3 of the Article. ${ }^{20}$ States also have the right to limit the number licenses available in particular to implement the Article 44 of the ITU Constitution according to which: "radio frequencies and any associated orbits, including the geostationary-satellite orbit, are limited natural resources and that they must be used rationally, efficiently and economically." Once again, this practice is not as such a violation of freedom of information. In the field of broadcasting any selection procedure must meet the general objective of respect for pluralism. ${ }^{21}$ However, the ECHR has held that the refusal to grant a broadcasting license constitutes interference with the exercise of the rights guaranteed by Article $10 \S 1$ of the European Convention on Human Rights that could represent a violation of freedom of information when the conditions for limiting this freedom prescribed by this convention are not met. ${ }^{22}$

The use of the "spectrum/orbit" resource is also subject to the prevention of harmful interference principle. According to Article 44.1 of the ITU Constitution, all stations must be established and operated in such a manner as not to cause harmful interference to the radio services or communications of other Member States or of recognized operating agencies, or of other duly authorized operating agencies which carry on a radio service, and which operate in accordance with the provisions of the Radio Regulations. The Resolution 424 (V) on Freedom of information: interference with radio signals, adopted by the General Assembly of the United Nations on the December 14, 1950 expressly refers to Article 44.1 of the ITU Constitution. This text creates a direct link between telecommunications law and human rights in terms of harmful interference. Indeed, the General Assembly considers that the freedom of information principle stated at Article 19 of the Universal Declaration of Human Rights is violated when a duly authorized radio operating agency in a country is deliberately interfering with the reception by the people of this country of certain radio signals originating beyond their territories. ${ }^{23}$ As a consequence, the General Assembly of United Nations condemns harmful interferences of this nature as a denial of the rights of all persons to be fully informed concerning news, opinions and ideas regardless of frontiers. ${ }^{24}$

Since the deliberate jamming of foreign signals represents a violation of freedom of information, States and persons ${ }^{25}$ affected by such a practice have access to the international mechanisms of human rights protection in addition to the

\footnotetext{
${ }^{19}$ Paragraph 60.

${ }^{20}$ UN Document, A/5000 of the sixteenth session of the United Nations General Assembly, 5 December 1961 , par. 23.

${ }^{21}$ ECHR, case of Informationsverein Lentia and Others V. Austria, judgement, 24 November 1993, par. 38.

${ }^{22}$ See, among other authorities, Informationsverein Lentia and Others v. Austria, cited above, § 27; Radio ABC v. Austria, 20 October 1997, § 27, Reports 1997-VI; Leveque v. France (dec.), no. 35591/97, 23 November 1999; United Christian Broadcasters Ltd v. the United Kingdom (dec.), no. 44802/98, 7 November 2000; and Demuth v. Switzerland, no. 38743/97, § 30, ECHR 2002-IX.

${ }^{23}$ Paragraph 1.

${ }^{24}$ Paragraph 2.

25 Physical persons as well as judicial persons such as private companies may benefit from these mechanisms.
} 
ITU procedures. First States and individuals have access to legal remedies through regional institutions: the European Court of Human Rights, the Inter-American Court of Human Rights and the African Court on Human and People's Rights. States may refer to these Courts any alleged breach of the freedom of information (Inter-State cases). In the European and the African systems, the Court may also receive applications from any natural of legal person claiming to be the victim of a violation by one of the Contracting Parties of the freedom of information (Individual applications). Second, at the universal level, States and individuals may use the mechanisms of the human rights which mission is to monitor the implementation of the International Covenant on Civil and Political Rights including the freedoms of expression and information by its State parties. The Covenant provides for the Committee to consider inter-state complaints. Furthermore, the first optional Protocol to the Covenant gives the Committee competence to examine individual complaints with regard to alleged violations of the Covenant by States parties to the Protocol. ${ }^{26}$ All these procedures are subject to prior acceptance by States parties to the conventions or protocols that have established them. ${ }^{27}$ Non-governmental entities may also benefit from the complaint procedure established under the United Nations Human Rights Council. This procedure addresses communications submitted by individuals, groups, or non-governmental organizations that claim to be victims of human rights violations or that have direct, reliable knowledge of such violations. Finally, on a political level, the states affected by the voluntary interference may bring the violation of freedom of information to the the attention of the Council of Human Rights or the General Assembly of the UN. The General Assembly may discuss any questions concerning human rights and, after a long process, adopt a new recommendation to recall the protection of freedom of expression and freedom of information against harmful interferences.

In October 2012, ${ }^{28}$ Eutelsat Communications announced bringing the case to ITU bodies to put an end to end to the repeated acts of intentional interference from Iran caused to their services. But it is, as we have seen, also possible to act by the mean of the mechanisms related to human rights.

\footnotetext{
${ }^{26}$ Optional Protocol to the International Covenant on Civil and Political Rights of 16 December 1966 (UNGA resolution 2200A (XXI)).

27 Since the adoption of Protocol No. 11 (ETS n' 155) to the European Convention on Human Rights, recognizing the right of individual application is mandatory in Europe.

${ }^{28}$ Eutelsat, CP/62/12, 4 October 2012.
} 


\section{4/ A Transforming Role for ITU: Monitoring as the Way Forward?}

Laurence Ravillon, Professor of Private Law, Director of the Research Centre on Investment and International Trade Law (CREDIMI), Dean of the Faculty of Law and Political Science at the University of Burgundy, Dijon, (France).

International regulations are an essential element in the satellite telecommunications sector, considering the scarcity of natural resources in outer space (frequencies and orbital positions) and the obligation to try and avoid interference, in compliance with Article 45 of ITU Constitution.

In the past few years, frequencies and orbital positions have been at the heart of disputes between states, particularly because of harmful interference. Such was the case in the durable dispute between France, Qatar and Eutelsat on one side, and Iran, Saudi Arabia and Arabsat on the other. ${ }^{29}$ Or, in cases of repeated intentional interference by several countries such as Iran contrary to ITU regulations.

Other conflicts can be mentioned, in particular those related to the lack of exploitation of the frequencies and orbital positions allocated by the ITU within the time limits defined by the latter, which can sometimes lead to the submission of the case - by national regulators ${ }^{30}$ or satellite operators - to the ITU ${ }^{31}$ as well as to state or arbitral jurisdictions. The dispute between Eutelsat and SES, ${ }^{32}$ heard in October 2012 by an ICC arbitral tribunal, regarding the infringement of the Intersystem Coordination Agreement (whose object is to coordinate Eutelsat's and SES's respective operations at several orbital positions to avoid interference which was entered into by both operators in 1999) is another relevant illustration. Disputes can also arise from the supposed under-utilization of orbital positions allocated by ITU to some communications satellite operators. ${ }^{33}$

Disagreements regarding frequencies and orbital positions can be settled through the ITU, notably by the Radiocommunications Bureau - ITU-R, whose role is to advise member states on the proper use of the radio-frequency spectrum, register frequency allocation at an international level and assist states in case of harmful interference. It is however obvious that this role is more an incentive than a coercion, as ITU does not dispose of a specific body in charge of settling disputes ${ }^{34}$ (although the Study Groups, Working Groups and Radiocommunications Advisory Group assist and contribute to the reflection on the matter).

\footnotetext{
${ }^{29}$ Peter B. de Selding, "ITU Board Fails to Resolve Dispute over Iranian Service," Space News, Nov. 4, 2011, 4, and "Dispute over Iranian Satellite System Gets More Complicated," Space News, Jun. 18, 2012, 7.

${ }^{30}$ In Great Britain, cf. http://www.bailii.org/ew/cases/EWCA/Civ/2011/1121.html.

${ }^{31}$ Peter B. de Selding, "Britain Petitions ITU to Evict Stalled ICO-P Satellite Project," Space News, Oct. 31, 2011, 4; Peter B. de Selding, "China and Europe Taking Their Navigation Dispute to ITU," Space News, Oct. 8, 2012, 5.

${ }^{32}$ Peter B. de Selding, "Eutelsat-SES Frequency Dispute Escalates," Space News, Oct. 22, 2012, 14.

${ }^{33}$ Peter B. de Selding, "FCC Investigating Satellite Fleet Management Practices for Abuse," Space News, Jun. 17, 2013, 4

${ }^{34}$ Contrary to some national regulators who have set up guidelines and procedures regarding the settlement of disputes (for example, in the UK, "Ofcom Guidelines and Dispute Resolution Procedures," and the appointment of an Ombudsman).
} 
Yet, increasing tensions about orbital positions ${ }^{35}$ reveal an inadequacy in the systematic search for consensus - even though ITU has taken a stand in several cases $^{36}$ - and the acute need for rules of conduct implemented by the International Telecommunication Union.

In a document dated $2004,{ }^{37}$ the ITU and the World Bank both pointed out the necessity to reduce delays and improve the efficiency of mechanisms of dispute resolution in the space sector, insofar as disputes in that sector can have major consequences, given that they affect the development of the telecommunications market and slow down the introduction of new services. The Report underlines the deficiencies of current mechanisms of dispute resolution regarding telecommunications, whether they might be competition conflicts, investment law, consumption law, interconnection issues or frequencies and orbital positions, all the more as those disputes definitely have a complex, technical but also political character.

Several suggestions have been considered, within the ITU, to improve the efficiency of the mechanisms of dispute resolution in order to boost investments, develop competition, expand the space industry and optimize the use of limited resources including radio spectrum or geostationary orbit.

Therefore, beyond the incentives for the actors of the sector to resolve their disputes themselves on a self-regulatory basis - hence informally -, the recourse to alternative dispute resolution methods is clearly encouraged, in the same way as is, as a last resort solution, the submission of the case to state or arbitral jurisdictions depending on the agreement between the parties - or, as is sometimes considered, the creation of an independent body in charge of settling disputes within ITU. Those proposals would enable to avoid a certain compartmentalization of litigation: mediation and arbitration are traditionally used for commercial disputes only whereas disputes involving states are resolved differently.

As far as states are concerned, the development of exchanges between regulators concerning their experiences of dispute resolution is, at an international level, encouraged as part of the G-REX (Global Regulators Exchange) which gives the opportunity to share experiences, to establish precedents and gain from the experience of other regulators.

This is the downstream side... which would not exist without the upstream implementation of a monitoring system concerning the absence of interference and the respect of the frequencies allocated by the ITU as well as the respect of time limits and the follow-up of filings. The monitoring of the spectrum would enable to observe the use of frequencies and to update it, which would make dispute resolutions easier in case of jamming.

Thus, Document RRB 13-1/1 states that the Radiocommunication Bureau should draw up Memoranda of Cooperation with administrations that would have the capacity to monitor the use of spectrum allocated to satellite services (following the memorandum signed by ITU and the International Civil Aviation Organization (ICAO)

\footnotetext{
${ }^{35}$ The Report of the 62nd meetings of the Radio Regulations Board which took place dated 27 May 2013 (CR/350) states that "there had been an increase in the number of harmful interference cases for which the Bureau's assistance was requested." (4.10).

${ }^{36}$ Peter B. de Selding, "ITU Rules for Avanti in Frequency Dispute with SES," Space News, Nov. 19, $2013,3$.

37 ITU - Dispute Resolution in the Telecommunications Sector - Current Practices and Future Directions, ITU - The World Bank, 2004.
} 
regarding cases of interference involving the global navigation satellite system (GNSS) on board civil aircraft ${ }^{38}$ ). Administrations are therefore urged to conclude sharing agreements hence to collaborate with the Bureau in order to ensure an optimal management of the spectrum and orbits (for example in case of obsolete registrations, application of the due diligence principle ...).

Still on the upstream side, in addition to this cooperation, the technical aspects can also be emphasized, and more particularly the possibility to implement a database which would facilitate the observation of events of intentional harmful interference as well as their evolution and would develop an international monitoring system that could identify the geographical position of jamming base stations ${ }^{39}-a$ proposal which is backed by France. Indeed, the resolution of disputes is complicated by the difficulties of identifying harmful interference. Establishing proof and finding proper means to investigate remain major issues. Yet, numerous administrations and satellite operators have created monitoring stations which could be used as part of an international space radio monitoring system. It would imply the collection and dissemination of information, achievable on the basis of Recommendation ITU-R-SM.1267 entitled "Collection and publication of monitoring data to assist frequency assignment for geostationary satellite systems."

Those notions of monitoring and supervision (or periodic tests) have been used in areas such as environmental law (finding inspiration in human rights), in order to support the implementation of international obligations defined for member states and increase transparency, on the basis of a cooperation between states. They consist, within a specific monitoring system, in collecting data and exchanging information, which are then treated by states in a mixture of reactions, sanctions (whether they are moral, disciplinary or economic) and incentives.

The technical aspects would also contribute to a transparent and efficient spectrum management, which requires the implementation of a collaborative approach from the states, within the ITU in transformation. ${ }^{40}$

\footnotetext{
${ }^{38}$ Memorandum of Cooperation between ICAO and the International Telecommunication Union (ITU) for Providing a Framework for Enhanced Cooperation Regarding the Protection of the Global Navigation Satellite System from Harmful Interference with a Potential Impact on Aviation Safety, ACP WG-F/28 IP05, 2013-03-12.

39 Document RRB 13-1/1, 33.

${ }^{40}$ See our article, "Les orbites et les fréquences dans une UIT mutante," in Mireille Couston (ed.), Orbites et fréquences - Statut, répartition et régime juridique (Paris : Pedone, 2006), 17-48.
} 


\section{5/ Preventing Harmful Interference to Satellite Systems}

Yvon Henri (yvon.henri@itu.int), Chief of the Space Services Department (SSD) at the Radiocommunication Bureau (BR) of the International Telecommunication Union (ITU), Geneva (Switzerland).

Satellite systems are key communication tools that are increasingly in demand from a large and growing number of requirements, such as fixed, mobile, broadcasting, amateur, space research, emergency telecommunications, meteorology, global positioning systems, environmental monitoring and a host of other communication services. However, no meaningful development of space services would be achieved without a proper and stable interference-free environment for the use of radio frequencies and geostationary satellite orbital positions.

In recent years an increasing number of cases of harmful interference ${ }^{41}$ have emerged, including deliberate ones with the intention of disturbing or preventing the reception of signals, which particularly affect telecommunication satellites. In some cases, instances of harmful interference have targeted radio navigation-satellite service (RNSS) signals used by civil aviation, threatening international air traffic with dire consequences including potential loss of life.

A primary objective of ITU ${ }^{42}$ is to ensure interference-free operations of radiocommunication systems. This has been emphasized at the last ITU World Radiocommunication Conference held in Geneva from 23 January to 17 February 2012 (see below), as citizens of every country around the world depend on terrestrial and space Radiocommunication systems for the provision of reliable telecommunication and broadcast services.

\footnotetext{
${ }^{41}$ ITU Radio Regulations No. 1.169: Interference which endangers the functioning of a radionavigation service or of other safety services or seriously degrades, obstructs, or repeatedly interrupts a radiocommunication service operating in accordance with Radio Regulations.

42 http://www.itu.int/en/Pages/default.aspx
} 


\section{WRC-12 output on harmful interference issues}

Over 3000 participants, representing 165 out of ITU's 193 Member States attended the fourweek World Radiocommunication Conference from 23 January to 17 February 2012 (WRC-12). Over 100 Observers from among ITU's 700 private sector members along with international organizations also attended WRC-12. WRC-12 addressed some 30 agenda items related to frequency allocation and frequency sharing for the efficient use of spectrum and orbital resources, thus ensuring high quality radiocommunication services for mobile and satellite communications, maritime and aeronautical transport as well as for scientific purposes related to the environment, meteorology and climatology, disaster prediction, mitigation and relief.

Regarding the interference issue, the point was being made that citizens of every country worldwide depend on terrestrial and space radiocommunication systems for the provision of reliable telecommunication services, but that in recent years there have been an increasing number of cases of deliberate interference intended to disturb or prevent the reception of signals. Also it was underlined that the operation of telecommunication satellites has been especially disrupted by persistent interference.

After considerable debate, an Ad hoc Group of the Plenary, set up to discuss possible modifications to Article 15 (Interferences) of the Radio Regulations, agreed on a text presented and subsequently adopted by WRC-12 Plenary. The agreement was facilitated by the confirmation of two key understandings:

1) first, any transmission which has the intent to cause interference to stations of other administrations is an infringement of the Constitution, Convention or Radio Regulations; and,

2) second, any station operating in the territory of an administration is under the authority of that administration, even if the station is not authorized.

Provision No.15.21 of the Radio Regulations was amended and reads as follows:

$15.21 \S 13$ If an administration has information of an infringement of the Constitution, the Convention or the Radio Regulations (in particular Article 45 of the Constitution and No. 15.1 of the Radio Regulations) committed by a station under its jurisdiction, the administration shall ascertain the facts and take the necessary actions.

As the leading United Nations ${ }^{43}$ agency for management of the radiofrequency spectrum and satellite orbits - and hence responsible for resolving instances of intentional or unintentional harmful inference - ITU is extremely concerned about the growing number of satellite networks which are the targets of deliberate harmful interference.

Although current mechanisms do exist within the ITU Constitution including the Radio regulations to resolve harmful interference between the parties concerned, a resolution of this nature is often an expensive and lengthy process.

ITU's response so far has been limited to appealing to all parties that may be involved to exercise the utmost goodwill and to provide mutual assistance in settling issues of harmful interference. In such cases, ITU applies the provisions enshrined in

\footnotetext{
${ }^{43}$ http://www.un.org/en/
} 
Article 45 of the ITU Constitution ${ }^{44}$ and Section VI of Article 15 of the Radio Regulations. ${ }^{45}$

Indeed, neither does the ITU possess any mechanism nor power of enforcement nor imposition of sanctions against violators of the Radio Regulations. The application and compliance with the ITU regulations are based on the willingness of the ITU Member states to be abided by the regulations and therefore on a volunteer compliance approach.

At its $61^{\text {st }}$ meeting (12-16 November 2012) and subsequent meetings, the Radio Regulations Board (RRB ${ }^{46}$ carefully considered reports of the Director of the Radiocommunication Bureau regarding the severe interference affecting transmissions on EUTELSAT satellites at $7^{\circ} \mathrm{E}$ and $13^{\circ} \mathrm{E}$ notified by the Administration of France as the notifying administration for the intergovernmental satellite organization EUTELSAT. The RRB was extremely concerned to witness a continuing situation in which satellite assignments operating in accordance with the Radio Regulations and duly recorded in the ITU Master International Frequency Register (MIFR) were the targets of harmful interference, and as foreseen in the regulations appealed to the administrations involved to exercise the utmost goodwill and mutual assistance in the application of the provisions of Article 45 of the ITU Constitution and Section VI of Article 15 and No. 0.4 of the Radio Regulations with a view to settling these issues of harmful interference.

The RRB also instructed the Radiocommunication Bureau to assist the Administrations involved in resolving this harmful interference, including having recourse to No. $16.5^{47}$ of the Radio Regulations, concerning international monitoring, as appropriate. In this regard, the RRB requested the Radiocommunication Bureau to invite administrations with the necessary capabilities to provide assistance to the Bureau and the administrations in order to address this matter.

In its Report to WRC-12 under Resolution 80 (Rev. WRC-07), the RRB already considered that monitoring results obtained by recognized international monitoring stations using measurement techniques and technologies documented in the ITU-R Handbook on Spectrum Monitoring ${ }^{48}$ to be a valuable resource for addressing harmful interference and noted with satisfaction the Bureau's activities in this area.

In most instances of requests for assistance on harmful interference cases, the information provided to ITU by an affected administration includes already evidence on the location of the source of harmful interference. However, as the information often comes from a single source, and in the absence of proper means to investigate or corroborate the information, irrefutable evidence cannot be provided to the administration under investigation to assume responsibility for stopping the interference.

Within this context, the ITU Radiocommunication Bureau has developed a draft cooperation agreement which could, as appropriate, be concluded between ITU and Administration and organizations that have the capacity to monitor the use of spectrum allocated to satellite services. This draft cooperation agreement has been

\footnotetext{
${ }^{44} \mathrm{http}: / /$ www.itu.int/en/history/Pages/ConstitutionAndConvention.aspx

${ }^{45} \mathrm{http}: / /$ www.itu.int/pub/R-REG-RR/en

${ }^{46} \mathrm{http}: / /$ www.itu.int/en/ITU-R/conferences/RRB/Pages/default.aspx

47 ITU Radio Regulations No.16.5 Administrations shall, as far as they consider practicable, conduct such monitoring as may be requested of them by other administrations or by the Bureau.

${ }^{48}$ http://www.itu.int/pub/R-HDB/en
} 
conceived as a tool to assist ITU in performing measurements related to cases of harmful interference for which an administration is seeking the assistance of ITU, and in performing measurements to assist ITU in verifying the compliance of the technical characteristics of a space station in operation on the geostationary-satellite orbit (GSO) with the characteristics recorded in the Master International Frequency Register (MIFR) or their conformity, where appropriate, with a plan.

The objective of the proposed draft cooperation agreement would thus be to establish a framework for the assistance that could be provided to ITU by your Administration by means of its space monitoring earth station(s). The scope of the Cooperation Agreement would cover inter alia the provision of data to assist ITU in the resolution of cases of harmful interference pursuant to Article 15 and No. 13.2 of the ITU Radio Regulations, as appropriate, and the provision of monitoring data, at the request of ITU, in cases of reported interference arising from coordination issues (ITU Radio Regulations Article 11, No. 11.41).

The Radiocommunication Bureau is fully conscious of the innovative character of this approach, and comments, suggestions and views on the proposed draft Cooperation Agreement sent in August 2013 to relevant administrations are under review

A memorandum of cooperation has already been signed by ITU and the International Civil Aviation Organization (ICAO) regarding cases of interference involving the global navigation satellite system (GNSS) on board civil aircraft.

Such agreements, along with continued work in improving the technical and regulatory environment, are expected to help in the timely settlement of harmful interference cases, including GNSS, which would have a profound impact on improving aviation safety.

Additional contacts have also been initiated with other organizations, such as the Satellite industry Association (SIA) ${ }^{49}$ the European Satellite Operator's Association (ESOA); ${ }^{50}$ and the Global VSAT Forum (GVF $)^{51}$ for assistance in providing satellite monitoring and helping to determine sources of harmful interference.

The Radiocommunication Bureau is also studying the possibility of making available on its website a database of events of harmful interference, including intentional ones.

The overarching objective of the ITU initiative is to establish a framework that will avoid duplication of efforts, as well as to benefit from potential synergies between the parties acting in their respective fields of responsibility as well as to develop a long-term strategy in solving the issue of harmful interference to satellite systems.

\footnotetext{
${ }^{49} \mathrm{http}: / /$ www.sia.org/

${ }^{50} \mathrm{http}: / /$ www.esoa.net/

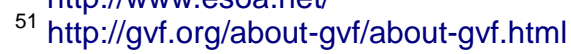




\title{
2.6/ Eutelsat: Freedom of Information, "Regardless of Frontiers"...
}

\author{
Astrid Bonté, Responsible for Institutional Affairs at Eutelsat, Paris (France)
}

As the third telecommunications satellite operator in the world, Eutelsat provides TV and radio channels the satellite capacity they need to be distributed over a large territory, as well as telecommunications and governmental services. The main two advantages of satellites are that they allow to reach out to people located in remote areas where no terrestrial technology could provide a service at an affordable cost, and that they provide services "regardless of frontiers." As a lot of international TV channels are broadcast all over the world, satellites are today key enablers of the right to freedom of expression and information.

In this context, a satellite operator's objectives such as reliability and quality of service are key for the clients, who request the highest standard of continuity of service. This continuity of service is the key word when it comes to satellite operator performance.

Interference is the largest factor affecting technical quality of satellite services. But whereas interferences were mainly from accidental or technical sources in the past, satellite operators have been experiencing increasing deliberate interferences in recent years, thus challenging the continuity of service principle and putting the industry at the heart of a global debate on freedom of information.

\section{Deliberate jamming}

Involuntary interference - that represents the largest majority of cases experienced worldwide - can be distinguished from deliberate jamming, which implies harmful intent and a deliberate purpose to obstruct reception of specific content.

Involuntary interference is not uncommon, due to the increasing number of satellites in orbit sharing a limited resource. They are usually due to a human error, to a lack of coordination between two satellite operators operating adjacent satellites, faulty equipment or poor quality of ground systems. Those problems are usually quickly fixed by a data exchange and cooperation between the operator affected by the interference and the ones at the origin of it.

Unlike involuntary interferences, deliberate ones imply a harmful intent, a deliberate purpose to obstruct the reception of a specific signal: very commonly international news channels such as BBC channels, Voice of America, Deutsche Welle, France 24 and others like Al Jazeera or CCTV (China) are targeted. Jamming signals present specific features very different from those arising from unintentional interferences: it is a clean carrier, i.e. a physical signal with no particular content on it, whereas we always have transmission of content in legitimate transmission activity.

Practically, for the citizens of the world, deliberate jamming means a blank screen and the fact that the information they are looking for does not reach them.

However, as we are living in a $100 \%$ digital environment, it is not just reception of the targeted channel that is damaged, but all the channels in the same 
multiplex. Up to ten to twelve channels can be affected when one channel is targeted, representing huge collateral damage.

Between 2009 and 2012, jamming cases rose dramatically, that can be illustrated precisely with a few figures:

- The total duration of jamming on Eutelsat satellites went from 1975 minutes in 2010 to $142913 \mathrm{mn}$ in 2011 and up to $329826 \mathrm{mn}$ in 2012, showing a $72 \%$ increase from the previous year in 2011 and a 130\% increase in 2012.

- The part of intentional jamming within the total number of interferences experienced by Eutelsat in 2012 reached up to $18 \%$ to be compared with only $5 \%$ in 2009.

The time duration of each jamming incidents has increased significantly and so has the number of incidents detected. Geographical sources have expanded as well: in addition to Iran, which represents the origin of a large part of the identified jamming incidents during this period of time, harmful interferences from Syria, Bahrain, and, to some point, Ethiopia, have also risen.

For satellite operators, it is a big challenge as the quality and continuity of service due by the satellite operator to its customers is severely affected. It is the trust relationship that would be damaged.

Deliberate jamming is perfectly illegal, representing an infringement to Article 45 of the ITU Constitution ${ }^{52}$ as well as to Article 15.1 of the ITU Radio Regulations. ${ }^{53}$

More generally it is also a violation of freedom of expression "regardless of frontiers" as defined in Article 19 of the United Nations Universal Human Rights Declaration, Article 10 of the European Convention of Human Rights and Article 19 of the International Covenant on Civil and Political Rights.

\section{How to fight jamming and strengthen the current regulatory framework}

The ITU is the relevant regulatory body having jurisdiction over satellite interferences.

In order for ITU to address a specific interference problem, an operator victim of such a practice has to first of all provide elements related to the country of origin of the jamming signal. This is obtained through the so-called geolocation, a sophisticated and costly technique of triangulation: requiring the use of 2 adjacent satellites, this process allows an unambiguous identification of the location.

Even though the successful completion of the geolocation process requires several conditions to be met, which is not always possible, geolocation capacity has become more and more successful over the past years, thanks to increased cooperation and data sharing between operators. There is no doubt the more the origin of the interfering signal is identified, the best all the legal and procedural mechanisms will be efficient.

\footnotetext{
52 "All stations, whatever their purpose, must be established and operated in such a manner as not to cause harmful interference"

53 "All stations are forbidden to carry out unnecessary transmissions or the transmission of superfluous signals or the transmission of false or misleading signals, or the transmission of signals without identification..."
} 
When a jamming is noticed and a geolocation completed, then an official complaint can be sent by the State operating jurisdiction over the satellite operator affected both to the ITU and to the State where the jamming is identified as coming from. Then the concerned State is supposed to comply with the Radio Regulations rules that ask the State to "take all necessary action" to put an end to the interference.

And here appear the limits of the current regulatory system. Indeed, under the ITU, all States are given equal status and all of them are supposed to be acting and speaking in good faith. There is a generally agreed principle that the sovereign word of a Member State cannot be challenged within the various instances of the organization.

However, this can present damaging consequences: no matter how precise the geolocation elements provided, the targeted State can refute any responsibility; the ITU is then denied the ability to further investigate the case and contradict governmental statements.

The regular complaint process may achieve its objective with jamming quickly disappearing. Nevertheless, unconditionally accepting the sovereign word of every administration leaves open an option for abusing and allows some suspected States to keep resorting to this illegal practice with perfect impunity.

\section{Ways of improvement with the ITU initiative}

The ITU Bureau current initiative to define an international monitoring system could definitely start to bring a remedy to this weakness.

Instead of always depending on States declarations, which themselves rely on operators data, ITU would be allowed to resort to some Administrations monitoring capabilities and could then endorse identification of the interferences. Several consequences would follow:

- ITU could easily challenge any offending administration trying to ignore complaints or deny responsibilities for wrongful activity, and ask the suspected government to provide evidence of its statements. This would reverse impunity, the jammers clearly facing the risk of being exposed.

- banalizing everyday acceptance of the jamming practice would be dramatically reduced as the ITU monitoring system would act as an effective deterrent.

Jamming is a scourge that is a clear violation of international regulations governing the sector. It has not always gained much attention because it was statistically quite limited but it has become intensely topical, as the phenomenon has recently grown, originating not from a single country.

In addition to reinforcing their cooperation to increase their geolocation process, private satellite operators are also working on long-term ways to mitigate jamming and reduce its effect on customers, such as a new generation of more resilient satellites using smaller uplink beams and electronic antennas. Jamming severely affects the continuity of service due to the customers by the operators and represents significant loss for them. But more importantly, access to information is the right of all citizens.

Operational solutions to mitigate jamming can progress, but no matter how clever they are, they will never replace a more sustainable regulatory framework. 
iffi Governing the Geostationary Orbit

That is where States can play a decisive part in supporting the ITU initiative during the next Plenipotentiary Conference in 2014 as well as during the next World Radio Conference in 2015. 


\section{7/ Intelsat: Interview with Ron Busch}

Ron Busch, Intelsat's Vice President, Network Engineering and the Space Data Association's Chairman.

\section{- Can you share with us some of the motivations for SDA's creation?}

The creation of the Space Data Association was based on enhancing "safety of flight" of satellites. This is achieved by data sharing amongst satellite operators to improve accuracy of collision avoidance predictions, assist in Radio Frequency Interference (RFI) mitigation, improve and expedite communications via a company contacts database, and sharing and adopting best practices. Satellite operators have the best data concerning where their satellites are, therefore, this data should be used in determining collision avoidance predictions. Some of the same data and other additional data can be used in RFI troubleshooting such as information utilized in geo-location. The satellite community has always been able to exchange information usually through people who know each other. A contacts database allows for quick access for anyone. Best practices allow all to work effectively and efficiently to maintain a safer space environment.

- What about the intentional political jamming of signals whose development these past three years have begun to seriously impact the business of several satellite fleet operators and broadcasters? Does it concern you?

From an Intelsat perspective, we have been very fortunate that we have not experienced any intentional jamming in the past few years. Of course, this is concerning from an industry standpoint and from our customers' standpoint. But these are political actions that are not in the realm of what we can solve as satellite operators. In the past, when we have encountered such occurrences, we worked closely with the proper regulatory agencies to address the issue.

- There is a generally agreed principle within the ITU that the sovereign word of a member state cannot be challenged. How do you feel about the current efforts made within the various instances of the organization to adapt the current regulatory system so as to respond more efficiently to this new threat?

From an Intelsat perspective, we encourage ITU member states to solve their political differences in the right forum, and not take actions that can not only affect signals, but also jeopardize the overall health of a space station.

- Does part of SDA's role imply helping members secure or defend frequency rights? How does such an initiative fit within the international regulatory system, notably the ITU that regulates orbital slots and frequency assignments?

The SDA prohibits the use of its data to secure or defend frequency rights.

- How does SDA protect each member sensitive data?

The SDA protects each member's data through secure connectivity between the member and the Space Data Center and, most importantly, through a strong legal framework that has severe penalties for misuse of the data by any of its members. 
ifri Governing the Geostationary Orbit

- What do you intend to do in the future regarding the integration of new members and the building and strengthening of relations with governments and civil operators? Is there any prospect for a kind of global "space traffic control"?

The SDA continues to encourage all members of the space community to join this initiative, including satellite operators from the various orbits, satellite manufacturers, insurance companies, etc. SDA membership is not limited to commercial operators, but can also include governmental bodies. Today, we have 21 contributing operators covering 90 LEO satellites and 267 GEO satellites. We have civil agencies as participants, such as NASA, NOAA and Eumetsat. The SDA continues to have dialogue with different governments around the world to discuss sharing data. We hope to find a way to share amongst us and create the ultimate database of all trackable objects in space. 


\section{8/ SES: A Perspective on Interference}

Within the Fixed Satellite Service (FSS) community, the overwhelming majority of satellite users experience excellent levels of service availability, frequently in excess of design. These high levels of service availability coupled with the inherent reliability of satellites as a delivery platform are a key contributor to the continued high demand for satellite based services and forecast growth across the industry in the coming years.

Radio Frequency Interference, or RFI, is a complex subject area that is very much in vogue and enjoying an increasingly high profile. Satellite operators are cognisant of the potential impact it has to satellite operations, commercial services and to the credibility of the industry. The primary role of any Satellite Payload Management Centre is to preserve the integrity of the satellite system itself and all those services it supports.

When dealing with interference, it's important to catalogue and classify all events such that systems and resources can be targeted appropriately to both prevent but also resolve such incidents. There are many sources of interference to satellite signals however in general terms and from an operational perspective, interference can be categorised as unintentional, intentional and terrestrial.

Unintentional interference remains by far the single highest contributor to the number of events being managed by satellite operators today. These are commonly intra-system and are caused mainly by human error, inadequate training and poor performance or failure of ground systems. Operators such as SES have sophisticated systems and processes in place that allows them to detect, isolate and resolve these types of events as they occur.

The drive for more efficient use of spectrum and smaller aperture ground terminals has resulted in an increasing number of inter-system or Adjacent Satellite Interference (ASI) issues. Operators have historically exchanged information on a somewhat informal and ad hoc basis to manage the RF environment they share however with an increasing number of operators and wider community of users, the industry has sought more formal collaboration across a number of levels.

The Space Data Association (SDA) is a not-for-profit organisation founded by and for satellite operators, to provide reliable and efficient data sharing critical to the safety and integrity of the space environment and RF spectrum. ${ }^{54}$ SDA has key mission areas in collision avoidance and flight safety, RFI mitigation and sharing of contact information by SDA members. Data on payload configuration, frequencies and RFI alerts are shared by members, allowing for faster and more efficient resolution of RFI events and identification of the most likely sources of interference.

Through the efforts of global industry organisations such as the Satellite Interference Reduction Group (SIRG) and the Global VSAT Forum (GVF), the satellite industry works proactively to combat and mitigate RFI. SIRG and GVF work to promote best practice, expand interference awareness, inform and support operators, users and regulatory entities with the ultimate objective of reducing satellite interference. Through these organisations, satellite operators, equipment manufacturers and users are working proactively to reduce the sources of RFI by

\footnotetext{
54 The SDA currently has 17 members: Arabsat, Avanti, EchoStar, Eutelsat, GeoEye, GE Satellite,
} Inmarsat, Intelsat, NASA, NOAA, Optus, Paradigm, SES, Spacecom-Amos, SS/L, StarOne and Telesat. 
establishing industry training and certification programs to reduce for example, the number of inadequate ground installations. An equipment type approvals process is also being adopted to reduce deployment of non-certified and substandard equipment that will also contribute to reducing the number of RFI events.

Reports of Intentional interference are becoming more frequent and although these tend to be isolated to particular regions with specific content being targeted, these events can be highly disruptive with any resolution challenging and often outside of the satellite operator's control. With no direct means of contact with suspected transgressors, the only course of action open to an operator is through regulatory channels and their regional administrator with likely escalation to the ITU for consideration by the RRB.

Another particular concern of the satellite industry is about existing and further potential RFI occurring as a result of high-capacity fixed and mobile terrestrial services (called IMT) deploying in the C-band frequencies. The C-band was allocated to and used by the satellite industry since the first networks were deployed over 40 years ago. The C-band remains of outstanding importance because of some properties of this part of the electromagnetic spectrum, often suitable to fulfill the communication needs of countries in areas near or within tropical or equatorial regions: C-band is very resilient to rain fade. C-band also allows satellite networks to cover large regions, making the use of low-cost receive-only hardware possible in developing countries, where the absence of or inaccessibility to alternative communication infrastructures makes satellite communications the only viable solution to deliver TV content or essential services such as for the Galileo Data Dissemination Network, emergency.lu, UNHCR communications or air navigation services in Africa or in Latin America.

Several issues can be identified when assessing the potential sharing and compatibility between terrestrial and satellite systems using the C-band. Due to the limited power available on board of a spacecraft, satellite terminals on the ground are designed to receive very low-power signals transmitted by space stations located thousands of $\mathrm{km}$ away and are very sensitive to external interference. This inherent system design makes the compatibility with wireless terrestrial systems hard to achieve. Such terrestrial networks normally make use of an extensive distribution of base stations transmitting high powers simultaneously in every horizontal direction, over wide bandwidths.

The requirement to protect ubiquitously deployed FSS earth stations by maintaining large geographical separation distances from IMT systems (from tens to 100s kilometres) leads to large holes in any potential coverage by terrestrial networks. In regions where FSS earth stations are densely deployed, the combined exclusion areas may consist of virtually the entire country, making IMT operations impractical/ impossible. Conversely, implementation of IMT stations would preclude the use of C-band receiving stations within a relatively large area around each IMT station, thus restricting further development/expansion of C-band satellite services.

In many countries of Latin America, Asia and Africa which have authorised terrestrial systems in some parts of the C-band, RFI cases have been reported. ${ }^{55}$

\footnotetext{
${ }^{55}$ Public reports were made in Bolivia, Fiji and Indonesia, and field trials in Hong Kong have confirmed several interference cases. (In the Hong Kong experiments, television signals feeding 300,000,000 households throughout Asia were inadvertently knocked off the air). At the beginning of 2012, the British Broadcasting Corporation (BBC) confirmed that FSS earth stations operating in the C-band and used for their international satellite distribution network of radio and TV content had been affected by harmful
} 
ifri Governing the Geostationary Orbit

This demonstrates the need that the next WRC-15, which has the opening of the Cband to IMT systems on its agenda, addresses this issue adequately.

interference in 12 African countries plus Pakistan, Cambodia, Trinidad and Jamaica. Furthermore, Bangladeshi broadcasting, cable and satellite TV operators, in co-ordination with the international satellite communications industry, have called for the Government of Bangladesh to take rapid action to halt the disruption of TV services suffered by millions of citizens due to the operation of "WiMAX" services in the $3.5 \mathrm{GHz}$ band. 


\title{
2.9/ Orbit-spectrum resources allocations for space and terrestrial radiocommunications in the frequency bands below $6 \mathrm{GHz}$
}

\author{
Alain Austruy, Frequency Office at Centre national d'études spatiales (CNES), \\ Toulouse (France).
}

Before 1990 and still today, the spectrum below $6 \mathrm{GHz}$ has been predominantly allocated to professional uses or to institutional uses, for supplying satellite or terrestrial services such as Radar, Fixed Services (for Telecommunication, Broadcasting...), Radiolocation, Radionavigation, Maritime Mobile, Aeronautical Mobile, Terrestrial Mobile, etc. ${ }^{56}$ The technology and the costs were not accessible to the individual customer market.

\section{The terrestrial mobiles services}

Since then, the developments in technology and the lower costs allowed to provide the general public with new commercial services within the terrestrial mobile services. Now, by the end of 2013 , the terrestrial mobile service has become a mass market with billions of user all over the world.

Their private developers ${ }^{57}$ announced that they would continue to grow ${ }^{58}$ and that they would need large amounts of additional spectrum. The report ITU-R M.2078 ${ }^{59}$ said, in 2006, that the additional spectrum requirements for 2020 would be of $1280 \mathrm{MHz}$ and $1720 \mathrm{MHz}$ for low and high user demand scenarios respectively.

But the forecasts made in 2006 for the 2020 spectrum requirements for land mobiles were based on assumptions of capacity that evolved. For example, from the same amount of spectrum, the current new technology (the $\mathrm{LTE}^{60}$ ) is increasing the possible throughput and the number of simultaneous connections on a same surface on ground. ${ }^{61}$ The proportion of these areas with increased capacity is becoming higher than assumed in the report, in the places that served precisely to justify a high need for spectrum. The additional capacity which is being created meets the market need for the mobiles. And this evolution requires less additional spectrum than

\footnotetext{
${ }^{56}$ See for example:

- for the United Kingdom:

http://stakeholders.ofcom.org.uk/binaries/spectrum/spectrum-information/UKFAT_2013.pdf,

- for the United States:

http://transition.fcc.gov/Bureaus/OPP/working_papers/oppwp38chart.pdf,

- for France :

http://www.anfr.fr/fileadmin/mediatheque/documents/tnrbf/DR-02_13-Mod1__

Version_modifiee_le_21_juin_2013_publique_.pdf

57 The developers of terrestrial mobile services are gathered within the GSM Association (http://www.gsma.com/). The GSMA represents over 218 countries around the world: 850 mobile operators, 200 manufacturers and other industrial sector, and 3.3 billion customers.

${ }^{58}$ The use of a ground transmitter towards mobile allows to develop technological evolutions cheaply and with less risk than the use of a satellite. The mass market of terminals and of base stations will guarantee return on investment. The terrestrial facilities can then extend to the geographical areas where the market is proving to be the most lucrative.

${ }^{59}$ See http://www.itu.int/pub/R-REP-M.2078-2006/en

${ }^{60}$ See http://www.3gpp.org/technologies/keywords-acronyms/97-lte-advanced

${ }^{61}$ See http://en.wikipedia.org/wiki/Spectral_efficiency\#cite_note-furusk.C3.A4r-4
} 
announced in the report because it reuses the spectrum previously used with the previous less efficient technology.

On the one hand, having a bigger amount of spectrum would generate a higher cost of licenses for mobile operators. On the other hand, it would increase the costs and would affect the financial balance of the operators, if we consider the increasing proportion of low cost subscriptions of customers. Today, for example, the $200 \mathrm{MHz}$ released for the mobiles between 3.4 and $3.6 \mathrm{GHz}$ in the European Union (EU) are still not used by the operators.

On February 15, 2013 during a presentation to the GSMA Leadership Summit, Goldman Sachs ${ }^{62}$ asks "Wireless telecoms: The end of growth?"

One graph shows that the Telecoms revenues correlate with GDP

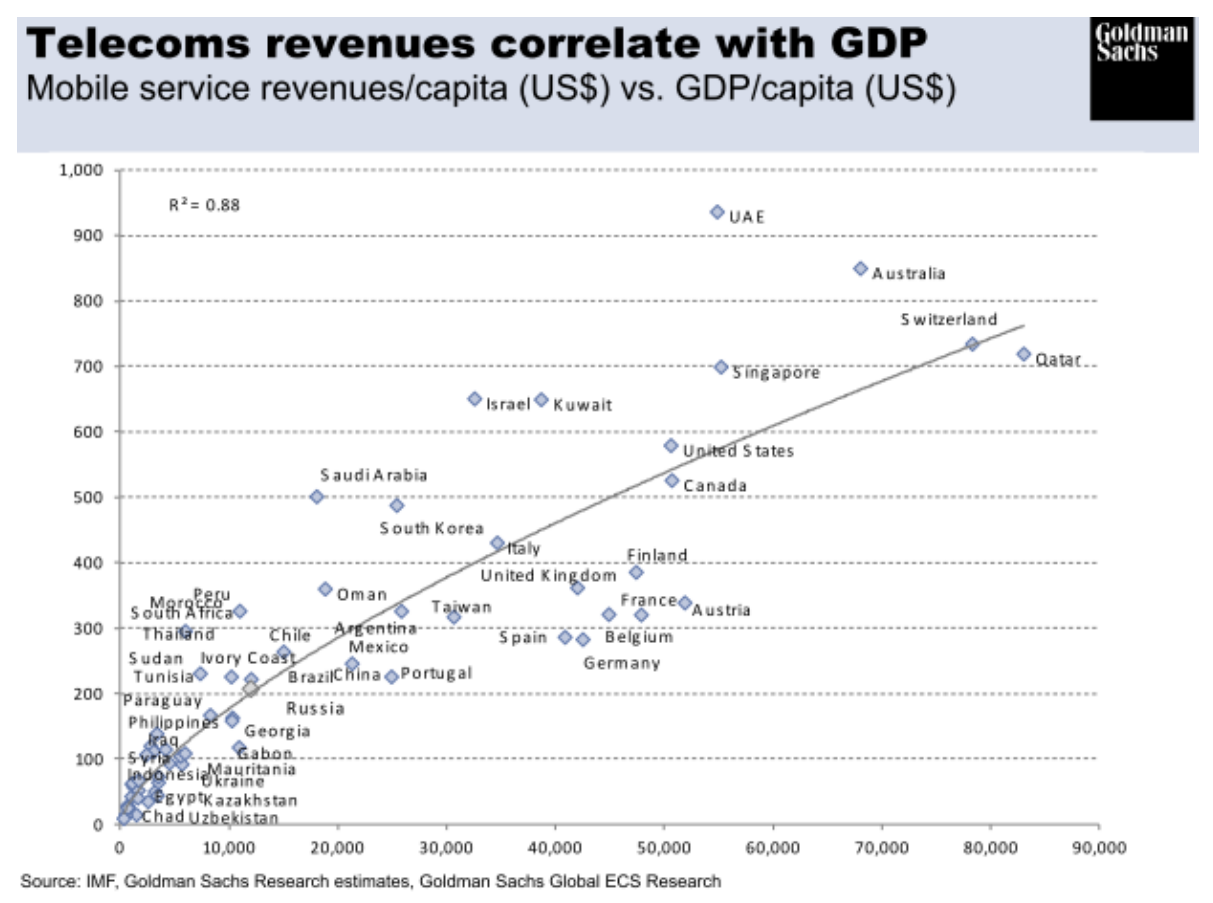

According to this graph, we can conclude that customers seem to spend for land mobile services a constant fraction of GDP/capita, and this regardless of the country.

${ }^{62}$ See http://www.mobileworldcongress.com/wp-content/uploads/GSMA-Leadership-Summit-2013.TimBoddy-Goldman-Sachs.pdf 
Another slide shows that the concentrate market structure increases investment capability:

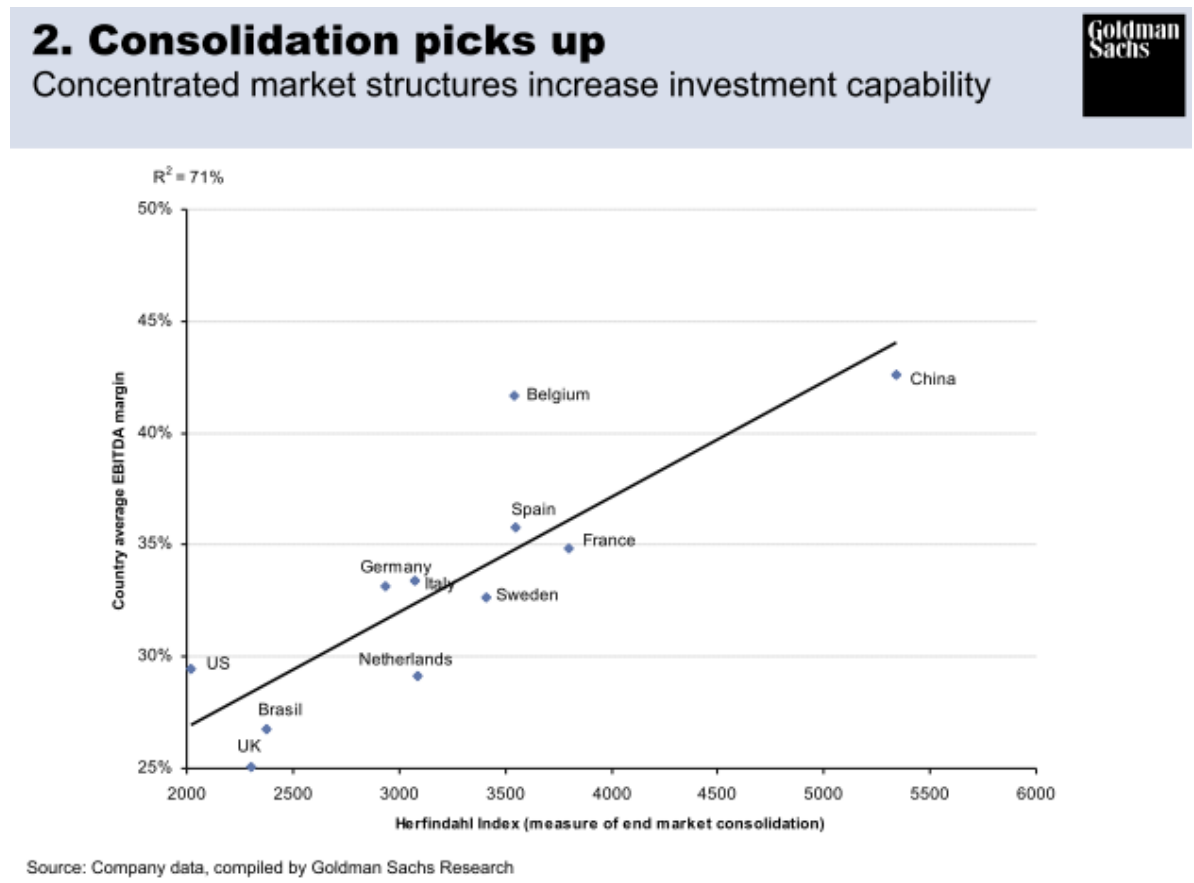

According to this graph, we can also conclude that the strong dispersion of the market (low Herfindahl Index ${ }^{63}$ ) reduces the average profitability per country. One could also conclude that competition pushed to excess between operators could also reduce both innovation (as a consequence of investments) and also compliance with the public interest.

\section{Consequence on the next WRC}

In preparation to the World Radiocommunication Conference (WRC) of November 2015 , the regulatory meetings deal again with sharing allocation of spectrum between terrestrial mobile services and at least 8 different other services (including satellite services). Hence they see an increasing number of spectrum sharing studies $^{64}$ between new terrestrial mobile services and existing satellite services for frequencies above $700 \mathrm{MHz}$ and below $6 \mathrm{GHz}$.

\section{The satellite services}

On their side, after reaching a high occupancy rate in the frequency bands below 6 $\mathrm{GHz}$ where the satellite service is allocated, the GSO satellite operators have kept on using higher frequencies in the $\mathrm{Ku}$ and $\mathrm{Ka}$ bands, enabling a reduction in the size of ground user terminals, and increased data rates.

Then the occupancy of these new frequency bands also became high. Moreover, the technology and the difficulties in the propagation make that there is nearly no satellite usage within the $\mathrm{V}$ band or higher frequencies to date.

\footnotetext{
${ }^{63}$ See http://en.wikipedia.org/wiki/Herfindahl_index

${ }^{64}$ See Resolution 233 (WRC-12) at

http://www.itu.int/dms_pub/itu-r/oth/0c/0a/R0C0A00000A0011PDFE.pdf
} 


\begin{tabular}{|l|l|l|l|l|}
\hline \multirow{2}{*}{$\begin{array}{l}\text { Letter } \\
\text { symbols }\end{array}$} & \multicolumn{2}{|c|}{ Radar (GHz) } & \multicolumn{2}{c|}{ Space radiocommunications } \\
\cline { 2 - 5 } & $\begin{array}{l}\text { Spectrum } \\
\text { regions }\end{array}$ & Examples & $\begin{array}{c}\text { Nominal } \\
\text { designations }\end{array}$ & Examples (GHz) \\
\hline $\mathbf{L}$ & $1-2$ & $1.215-1.4$ & $1.5 \mathrm{GHz}$ band & $1.525-1.710$ \\
\hline $\mathbf{S}$ & $2-4$ & $2.3-2.5$ & $2.5 \mathrm{GHz}$ band & $2.5-2.690$ \\
\hline $\mathbf{C}$ & $4-8$ & $2.7-3.4$ & & $\begin{array}{l}3.4-4.2 \\
\end{array}$ \\
& & $5.25-5.85$ & $4 / 6 \mathrm{GHz}$ band & $5.85-7.075$ \\
\hline $\mathbf{X}$ & $8-12$ & $8.5-10.5$ & - & - \\
\hline Ku & $12-18$ & $13.4-14.0$ & $11 / 14 \mathrm{GHz}$ band & $10.7-13.25$ \\
& $18-27$ & $24.05-$ & $20 \mathrm{GHz}$ band & $17.0-14.5$ \\
\hline $\mathbf{K}(\mathbf{1})$ & $27-40$ & $33.4-36.0$ & $30 \mathrm{GHz}$ band & $27.5-30.0$ \\
\hline Ka (1) & - & - & $40 \mathrm{GHz}$ band & $\begin{array}{l}37.5-42.5 \\
47.2-50.2\end{array}$ \\
\hline $\mathbf{V}$ & & & & \\
\hline
\end{tabular}

(1) For space radiocommunications $\mathrm{K}$ and $\mathrm{Ka}$ bands are often designated by the single symbol $\mathrm{Ka}$. Frequency bands according to the recommendation ITU-R REC-V.431-7

In this context, constraints of access to spectrum and orbital resources for each new satellite system began to appear, first for the longitudes centered on the service areas which make them easier to cover, and then everywhere else (with the use of shaped beam antennas or of steerable antennas).

So the frequency coordination becomes more complex, operating margins will be reduced and sometimes become negatives till reducing the satellite capacity. More chances are taken by considering that some ITU satellite network declaration will not be brought into services, and cases of interference will increase inevitably.

Therefore, it is important to preserve the spectrum allocations to space services in the frequency bands below $6 \mathrm{GHz}$, to guarantee their protection from terrestrial mobile services emissions, and to maintain a crossborder geographical harmonization compatible with the scale of the satellite coverages in order to maximize the spectrum use efficiency.

\section{Regulatory debate and decisions}

On the one hand, each ITU Regions, and each country have its own needs and interests, its own analyses, and will make its own decision at the next WRC. The ITU recognizes the sovereignty of the states as an essential basis of international law.

On the other hand, there is a common interest in the global harmonization of the uses of satellites to match the wide covers radiocommunication service rendered from space, and ensure the most efficient use of spectrum. This is a basis of public law and good resource management.

So it is of common interest to find the best framework which meets the national interests and the economic and technologic rationality in the ITU regions. 


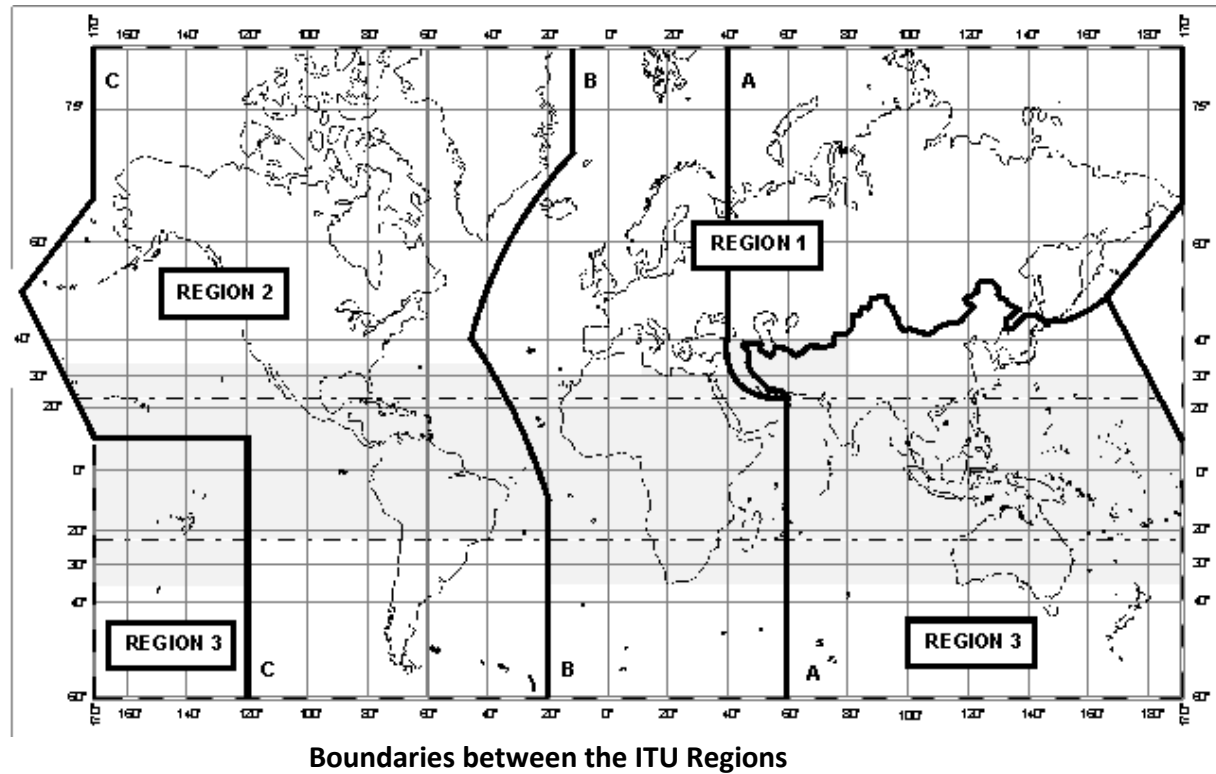

During the regulatory meetings dealing with the sharing of these bands below $6 \mathrm{GHz}$ between terrestrial and space services, and beyond a segmented approach, two distinct interpretations of general interest materialize.

- The use of spectrum by institutions or by the space sector, acting on behalf of the public interest;

- $\quad$ And the use of spectrum by a mass market of terrestrial radio.

However, the usable spectrum is not extensible, and the technical limitations of its sharing will inevitably be reached in some areas.

In order that operators, markets, institutions and innovation do not reduce their activity because of forecasted shortage of spectrum, we can try to identify criteria to arbitrate the allocation of spectrum between space services and terrestrial mobile services.

Shall we select them on the criterion of:

- $\quad$ the service provided to the users? ${ }^{65}$

- $\quad$ the societal changes enabled? ${ }^{66}$

- the induced economic activity ${ }^{67}$ among users, operators, handset providers, infrastructure providers, ${ }^{68}$ content providers, stakeholders from these contents? ${ }^{69}$

\footnotetext{
65 These are: 1) the essential services arising from obligations of states: freedom of moving and communication, the right to protection and assistance, etc.; 2) and non-essential services but able to provide some value added information: weather, traffic conditions and access to transportation services, directories and geolocalized information, access to dematerialized booking and ticket offices, etc.

${ }^{66}$ The mobility and flexibility of the "human resources" and the "customer resource" is promoted both at work and outside.

${ }^{67}$ Measured by: the number of jobs, the growth rate, the competitive advantage.

${ }^{68}$ Terrestrial versus satellite networks and associated ground stations.
} 
- the sectorial balance of foreign trade?

- the participation in the construction by the states of their national competitive advantage?

For example, within the EU, the Commission was seized of the request for land mobiles, and it saw the opportunity to put into practice the idea of a single telecoms market. In this context:

- How to differentiate between Northern countries that have less interest in GSO space-based services because of their latitude, and other countries, some of which are major space actors in Europe? The Lisbon Treaty includes a clause allowing the subsidiarity principle in each state. Each country, if it considers that this is contrary to its public interest, can derogate from the draft decision of the EC, at the risk of reducing the interest that the harmonization could represent for the space operations.

- How to consider the choices made by other continental space powers, the impact on their economies and their respective competitive and strategic advantages?

The EU countries involved in space operations participate in international cooperation (outside the $\mathrm{EU}$ ) in the spatial domain. In this case, how will the required frequencies be preserved to guarantee the commitments and interests of participating countries?

\footnotetext{
${ }^{69}$ Shops and services that make advertisements by these land mobile means.
} 


\title{
3/ Satellite Communications and Space Governance in the Coming Years
}

\section{1/ International Regulation of Frequencies and Satellite Orbits: Improving Rather than Revising ITU's Procedures}

\begin{abstract}
Victor Strelets, Member of the Radio Regulations Board (RRB) of the International Telecommunication Union (ITU), Counselor to the General Director of FSUE "Morsvyazsputnik," Moscow (Russia). The following is a personal view of a RRB member, not of RRB itself. Any view presented on behalf of $R R B$ has to be based on the consent of all twelve RRB members.
\end{abstract}

This article examines the issues related to the international regulation of limited geostationary orbit and associated radio-frequency spectrum resources. Today, national regulators, satellite communication system operators and equipment manufacturers are increasingly wondering whether the current international regulatory framework for the use of orbit/spectrum resources is sufficiently effective to meet the growing demand in satellite communication services and to resolve excessive occupancy of the geostationary orbit. Interference, which is intentional in nature in certain cases, is another pressing issue for satellite operators and broadcasters using satellite communications. What is the most appropriate international mechanism in this situation?

In this article, the author with over 30 years of experience in the field of effective use of the geostationary orbit seeks to give his view on the matter in question.

\section{Current international regulatory framework}

As it is known, the International Telecommunication Union (ITU) is involved in the regulation of limited resources of the geostationary orbit/radio-frequency spectrum used by satellite networks, at the international level. ITU, founded in Paris in 1865 as the International Telegraph Union, today is a specialized UN agency for information and communication technology. An organization of public-private partnership since its inception, ITU currently has a membership of 193 countries and some 700 private-sector entities. Every three to four years, ITU holds a World Radiocommunication Conference (WRC), where Member States address the issues of frequency spectrum regulation for various applications, both spatial (space, aeronautical, terrestrial, maritime), and targeted (communications, navigation, meteorology, Earth exploration, etc.). It should also be kept in mind that GSO is not only used for telecommunications and broadcasting, but also geostationary-satellite systems provide Earth exploration-satellite service, space scientific services, meteorological service, radio navigation service, etc. Thus, it would be prematurely to raise an issue of considering other organizations capable of facilitating more 
effective use of the geostationary orbit. It should be initially understood, what is not comfortable with the current principles for the allocation of the orbit/spectrum resources.

As it is known, ITU uses two principles for the allocation of the geostationary orbit and frequency spectrum resource: trough coordination procedure and on planned basis.

In the recent years, active consideration has been given to how fair the "firstcome, first-served" principle is. Indeed, when something is limited in quantity, there will always be disappointment of not being the first. However, no one suggests changing sales system for air and railway tickets, tickets for sports, theater, etc., while many people are not able to meet their needs in such tickets. Fortunately, no one suggests allocating limited resources on market relations internationally, as it is the case in the real estate market.

The question is whether the rights of states, satellite communication operators or service providers are impaired in implementing the "first-come, firstserved" principle. When talking about restricting countries access to the geostationary orbit resource, one should look at this issue from different perspectives. For example, in the mid-2000s the demand for satellite communication and broadcasting services has strongly overtook the supply in the African countries. Accordingly, in two years since 2009, 13 satellite operators launched and relocated two dozens of satellites with beams, covering the region, in order to provide services in Sub-Saharan countries alone. During this time, the increase in capacity accounted more than 200 transponders. Today, satellite operators face very strong competition in Africa, where market witnesses solid presence of all the giants of the global satellite operator industry, such as Intelsat, SES, Eutelsat, Telesat, as well as strong regional operators. So, another question emerges, i.e. loading of the GSO-satellite capacity. Every new or existing operator launching a satellite into a new orbital position faces real difficulties in looking for potential customers. It is therefore clear that implementation of the "first-come, first-served" principle does not impair the right of a state to "get real access to the limited orbit/spectrum resource." Indeed, countries have different economical and technical capabilities and, certainly different human capacity.

Another principle is based on the allocation of the GSO resources using FSS/BSS Plans. Could it be considered as using spectrum more effectively? No, unfortunately. The Plans were developed and adopted to provide all countries with guaranteed and equitable access to the GSO resource. However, the reality is that the use of this most valuable limited resource is highly restricted. Some experts believe that the GSO orbit tightness could be removed in the coming years by lifting regulatory barriers in the planned bands and applying the coordination procedure.

Therefore, the main question is whether we should look for new mechanisms or organizations to manage the allocation of limited resources, or increase the efficiency of the existing institutions.

If we take the first approach, the question that needs to be answered is how can equitable access of different countries or groups of countries to the limited natural resources (geostationary orbit and radio frequencies) be guaranteed, taking into account the special needs of the developing countries and the geographical situation of particular countries? Any review of existing mechanisms starts with this question. This is a delicate and complex issue, involving political, economic and strategic interests of countries, as well as strong economic interests of existing 
satellite operators. Furthermore, the UN system has no other specialized agency with practical experience in managing orbit/spectrum resource.

Therefore, the second approach calling for improvement and enhancement of existing regulatory principles might be considered the most effective solution.

The following course of action is proposed:

1. Improvement of the ITU rules and procedures for the allocation of the orbit/spectrum resource;

2. Adoption of the organizational and technical measures to eliminate interference, including interference to satellites;

3. Promoting the legal value and status of the decisions taken by the Radio Regulations Board.

\section{Improvement of the ITU rules and procedures \\ for the allocation of the orbit/spectrum resource}

WRC-12 has adopted a number of decisions enabling to improve procedures for the use of the orbit/spectrum resource.

- New wording for No.11.49 of the Radio Regulations (RR) was adopted, which clearly states a possibility to suspend the use of a recorded frequency assignment to a space station for the period of up to 3 years. In this case the notifying administration shall no later than six months from the date on which the use was suspended, inform the Bureau of this date.

- $\quad$ RR No. 13.6 authorized the Radio Regulations Board (RRB) to take decisions on cancellation or modification of an entry for a recorded frequency assignment to a space station where the assignment in question has not been brought into use, or is no longer in use, or continues to be in use but not in accordance with the notified characteristics.

- RR No. 11.44B set clear criteria to consider a frequency assignment to a space station in the geostationary-satellite orbit as having been brought into use.

- RRB is authorized to consider the force majeure cases related to satellite launch.

It should be noted that the RRB, as well as the ITU Radiocommunication Sector continuously focuses on improvement and simplification of the regulatory procedures for the GSO/spectrum resource in drafting proposals for the forthcoming 2015 World Radiocommunication Conference. Agenda item 7 of WRC-15 instructs the Conference "to consider possible changes, and other options, in response to Resolution 86 (Rev. Marrakesh, 2002) of the Plenipotentiary Conference, an advance publication, coordination, notification and recording procedures for frequency assignments pertaining to satellite networks, in accordance with Resolution 86 (Rev.WRC-07) to facilitate rational, efficient, and economical use of radio frequencies and any associated orbits, including the geostationary-satellite orbit." 


\section{Adoption of the organizational and technical measures to} eliminate interference, including interference to satellites

One of the main issues related to the international regulation of the radio-frequency spectrum is detection and elimination of interference source. Unfortunately, cases of intentional interference raised in number and duration recently. However, identification of a nature of interference (intentional or unintentional) is a complicated task since operators may configure their equipment improperly or maintenance errors may occur. Given the cross-border nature of radio propagation, the interference caused by stations on the territory of another state can be resolved only within international organization, i.e. International Telecommunication Union. Sometimes states pay insufficient attention to the ITU activities and do not always seek the solution through ITU, alleging that the satellite issues have reached very high political level, while ITU is responsible for technical issues. Nevertheless, no one can deny that only the application of the Radio Regulations procedures could resolve the issue of interference through their detection and interference source location. This is equally relevant to interference occurred in satellite communication systems.

Appeal to an administration causing interference may not always lead to success, since sometimes the administration seeks to delay addressing the issue by clarifying status of the methodology used, characteristics of equipment, nature of interference, etc. Thus, independent monitoring stations within the ITU international satellite monitoring system need to be used in order to resolve the issue. Now, Radiocommunication Bureau (BR) considers the establishment of agreements on cooperation with administrations that have the capacity to monitor the use of spectrum allocated to satellite services in order to assist the BR to perform measurements related to cases of harmful interference for which an administration is seeking the assistance of the BR. However, it has to be borne in mind that an agreement between ITU and a national administration affects interests of third countries; therefore such activity could be undertaken on the basis of international agreements adopted by Plenipotentiary Conference or on its behalf based on the appropriate ITU Council decision. Furthermore, an agreement between ITU and a national administration has financial implications related to maintenance and usage of monitoring stations belonging to the international satellite monitoring system, and therefore organizational, technical and financial interaction between BR and a national station belonging to the international satellite monitoring system should be determined.

Establishment, adoption and widespread use of the international monitoring independent stations could be tackled through the mechanism for discussing regional initiatives within ITU for their adoption by a World Telecommunication Development Conference (WTDC). Next WTDC will be held in 2014, and regional preparatory meetings considering various draft regional initiatives are held in 2013.

\section{Promoting the legal value and status of the decisions taken by the Radio Regulations Board}

Any international organization can work effectively only when all parties exercise their good will towards cooperation and the spirit of compromise prevails in addressing complicated tasks.

RRB treats requests of administrations for its assistance regarding harmful interference on a regular basis. These cases involve mostly terrestrial services, but increasingly also involve some space services. RRB and the BR had no difficulties acting in accordance with the procedures of RR Article 15 in addressing these cases. 
Nevertheless, the persistent character of the harmful interference in some situations is a concern and creates a situation that impedes fulfilment of the principles contained in Article 44 of the Constitution and No. 0.3 of the Preamble to the Radio Regulations. In some cases, the administrations involved have not responded to the RRB's recommendations or the BR's offers of assistance and appear to take no action to resolve the interference. ITU has always successfully relied upon Member States exercising goodwill and mutual assistance. Departing from this practice and adopting any type of sanction-based approach to resolving issues such as harmful interference would be a momentous step that would change the face of ITU and the relationship between $\mathrm{BR}, \mathrm{RRB}$ and administrations. Of course, all states shall exercise the utmost goodwill and mutual respect and adhere to the instruments of the Union. However, in case of violation of international treaties it is recommended to consider using RRB decisions as evidence in proceedings before the courts of different instances.

\section{Conclusion}

Currently, ITU is a leading UN agency for the global management of the radiofrequency spectrum and satellite orbits, so it is appropriate that problems considered above be treated and resolved within the ITU through the application of the Constitution, Convention and Radio Regulations and on the basis of the utmost goodwill and mutual assistance.

We need to further improve the ITU rules and procedures and implement the organizational and technical measures to eliminate interference between satellite communication systems. And, of course, all states should exercise the utmost goodwill and mutual respect and adhere to the instruments of the Union. 


\title{
3.2/ The ITU Regulatory System: a Self-Contained Regime or a Part of International Law?
}

\author{
Sergio Marchisio, Professor of International Law, University Sapienza of Rome \\ (Italia), Chairman of the European Centre for Space law (ECSL/ESA), Paris (France).
}

The competition for radiofrequency spectrum and orbital resources, which is the core issue of this IFRI Seminar, raises two main categories of concern. The first refers to the nature of the orbital slots as natural limited resources, whose availability should be open to all States in an equitable manner. In fact, the equitable distribution of orbital slots and associated radio frequencies still remains to be fully implemented.

The second area deals with the harmful interference, whose prevention is one of the statutory objectives of the International Telecommunications Union (ITU). The issue is twofold: on the one side, there is a problem of coordination, both at the universal as well as the regional levels; on the other side, there is a lack of efficient international monitoring systems. Overall, in the absence of a global authority endowed with coercive powers, the key role is still played by the responsible administrations.

\section{The ITU legal system: between specialty and international law}

The main focus for a lawyer is on ITU, which is the sole global agency charged with managing the world's shared radio spectrum and orbital resources. It maintains the Master International Frequency Register (MIFR), coordinates planned new satellite networks, and ensures that systems operate according to its provisions (Constitution, Convention and Radio Regulations). The satellite systems - with some 400 geostationary satellites currently in operation - deliver services both for commercial interests and for governments. About forty more satellites are launched each year, either for replacement or for additional capacity. The ITU processes over 300 GSO satellite networks every year and over 2300 are recorded in the MIFR.

ITU satellite coordination is mandatory for ITU Member States and the inclusion in ITU's MIFR confers the international rights and obligations to national administrations, in particular the international recognition and protection of individual satellite systems. The ITU focuses also on ensuring that the essential services delivered over satellite systems can function without risk of "harmful interference," term which includes also intentional and illicit interference between two operating radio frequencies that seriously degrades, obstructs or repeatedly interrupts either or both services.

It should not be taken for granted that the ITU's core legal frame is widely known. The ITU legal instruments are often interpreted by engineers, who are tempted to utilize hermeneutic methods that are far from being the canonical legal criteria. Furthermore, there is a tendency of certain sectors of international law to consider themselves as fragmented self-contained regimes, where primary (substantive) and secondary norms (that attach legal consequences to the breach of primary obligations) exclude once for all the application of norms of general nature. This specialist approach means that the scope of the legal rules is defined by reference to a close system of values without any connection with the general 
system of law within which they are supposed to function. In this perspective, also the ITU legal order is often presented as a self-contained and self-sufficient order, as an island floating in a vacuum. Outside the Union, the nihil.

This way of thinking confuses the specialty of the ITU rules within international law with their self-sufficiency. On the contrary, the ITU legal framework does not work in isolation from the overall system of international law, and does not present the character of a self-contained regime, where substantive and procedural obligations pretend to be applied in an exclusive way. We are faced indeed with a legal system that constitutes a special part of international law and functions in conjunction with the other parts of the same legal order in a cohesive mode. It is a harmonized picture, or, if you like music more than painting, a symphony rather than a set of clashing colors or sing flats.

Conceptual arguments for ITU as a so-called self-contained regime are unconvincing. The chimera of self-contained regimes should be dispelled, because in the field of space telecommunication law tout se tient. The ITU specialized legal setting implies a strongest institutional framework and an ability to set new international norms adapted to emerging needs. However, the rules on distribution of orbital slots and associated radio frequencies should be interpreted and applied in close connection with the general principles of space law, which in its turn form part of international law at large, including the Charter of the United Nations (art. III 1697 OST).

Moreover, international telecommunication law, born with the chrism of specialty within the context of the ITU legal setting, has acquired for several aspects, and since long-time, the status of a part of general international law opposable to all States. This erga omnes scope of application is certainly an added value that settles longstanding quarrels about the legal nature of the geostationary orbit, the orbital slots and the associated radio frequencies.

If we look at the ITU basic legal instruments, we find that art. 44 CS is a key norm on the use of the radio-frequency spectrum and of the geostationary-satellite and other satellite orbits. It regards both the behaviour of Member States and the legal nature of these resources. For the first aspect, ITU Member States are requested to endeavour to limit the number of frequencies and the spectrum used to the minimum essential to provide in a satisfactory manner the necessary services, and to apply the latest technical advances as soon as possible. This provisions is clearly linked to the general principle of civiliter uti which goes together with the concept of common good (res communis omnium of roman law), and that we could also define as a duty of sustainable use. Second, and more important aspect, "radio frequencies and any associated orbits, including the geostationary-satellite orbit, are limited natural resources and ... must be used rationally, efficiently and economically ..., so that countries or groups of countries may have equitable access to those orbits and frequencies, taking into account the special needs of the developing countries and the geographical situation of particular countries."

Now, the legal concepts adopted by art. 44 of the ITU CS, which are indeed in line with the provisions of the 1967 Outer Space Treaty (freedom of exploration and use, benefit of all countries, province of humankind, non appropriation), are now also reflected in and form part of general international law. Evidence is given by the agreement on the geostationary orbit status reached in 2000 within the UN Committee on the peaceful uses of outer space (COPUOS), which has been "noted" with satisfaction in paragraph 4 of UNGA resolution 55/122 of 8 December 2000. This agreement, reached in simplified form during the work of the UNCOPUOS by the specially affected States members of the Committee and then, through the GA, 
by all States Member of the UN without any objections or protests, corresponds to the norms of general international law regarding the character and utilization of the geostationary orbit, norms which have the same content and are binding erga omnes. ${ }^{1}$ At the time, the 2000 Agreement settled the dispute concerning the legal status of the geostationary orbit raised by the Bogotá Declaration of December 3, 1976; the States traversed by the Equator (Brazil, Colombia, Congo, Ecuador, Indonesia, Kenya, Uganda, Zaire) claimed the right to exercise their national sovereignty over the segments of geostationary synchronous orbit corresponding to their territories. After lengthy discussions at the UNCOPUOS Legal Subcommittee, in 1999 art. 44 of the ITU CS was recognized as the applicable norm. Furthermore, it was agreed that, in order to facilitate equitable access to the orbit/spectrum resource according to the ITU system based on the principle of "first come, first served," in the case of comparable requests for access to the spectrum/orbit resource by a country already having access to the orbit/spectrum resource and a developing country or another country seeking it, the country already having such access should take all practicable steps to enable the developing country or other country to have equitable access to the requested orbit/spectrum resource.

Efficient use of spectrum and orbital resources remains therefore one of the most crucial challenges facing the international community. ITU made progress through the outcomes of the WRC-12, where one of the main issue was the apparent congestion of spectrum/orbit resources that results from the existence of rights which are not being used in practice. WRC-12 established a minimum period of three months of operation to consider that a satellite network has been brought in service and that its rights are confirmed; and requested the Radio-communication Bureau to enquire on situations where the same satellite may have been used to maintain the rights of inactive networks at various orbital locations, by "jumping" from one location to another.

So said, a key role within this process is played by national administrations, to whom pertains the task to assign frequencies and orbital positions, to apply the appropriate procedures (international coordination and recording) for the space segment and earth stations of their networks (governmental, public and private) and to assure continuing responsibility for the networks.

In the end, if we look at the core substantial norms determining the legal status of orbital slots and associated radio frequencies, there are no arguments supporting the view that the ITU legal system is a self-contained regime.

\section{The harmful interference: ITU's role and general international law}

The same conclusion is reachable if we shift to the second area of concern regarding the harmful interference issue, and to the procedures put in place in order to settle the related disputes. In recent years an increasing number of cases of harmful interferences have emerged including deliberate ones with the intention of disturbing or preventing receptions of signals, which particularly affect telecommunication satellites. However, once again, there are no reasons for considering the ITU legal system as a self-contained regime.

The main ITU provision on harmful interference is art. 45 CS, which sets out the obligation for Member States to ensure that all transmitters or receivers (or a

\footnotetext{
${ }^{1}$ As detailed in the document paper by the Legal Subcommittee at its thirty-ninth session under the title "Some aspects concerning the use of the geostationary orbit" (A/AC.105/738, annex III).
} 
combination of both) necessary at one location for carrying on a radiocommunication service, are established and operated in such a manner as not to cause harmful interference to the radio services or communications of other Member States. Further, the Member States should take all practicable steps to prevent the operation of electrical apparatus and installations of all kinds from causing harmful interference to the radio services or communications.

Moreover, the ITU Radio Regulations, which have the legal nature of a treaty and are regularly updated by the World Radio communication conferences (WRC), have as objective to ensure the availability and protection from harmful interference of the frequencies, and to assist in the prevention and resolution of cases of harmful interference between the radio services of different administrations.

These provisions do not amount to "an independent legal system" according to the theory of the self-contained regimes. More simply, they are special rules applying within the ITU legal system, which do not exclude the possibility, for Member States, to resort to other agreed modes of settlement if they so wish. The 2006 Adriatic Agreement adopted at the RRCO6 Geneva Conference to make a new plan for TV channels using digital divide broadcasting DVB-T, contained a final clause stating that all disagreements between Contracting Administrations should be settled according to the provisions of the UN Convention on the Law of treaties signed on Vienna, 23 of May 1969. However, when a dispute among the Parties arose for harmful interferences in the region, the role of the ITU was central in solving the matter and no recourse to other methods based on international law was considered. In fact, the procedures available under the ITU legal instruments in case of harmful interference are more adequate and, whenever a case of interference occurs, ITU works with all parties involved to try and find a mutually acceptable solution.

In case of illicit interference into an assignment recorder in the ITU Master International Frequencies Register, the first obligation of the State under whose jurisdiction is located the station which is causing the problem is to take immediate steps to cease and not to repeat it. This corresponds to a principle of general international law concerning the responsibility for wrongful acts, that necessarily is also applicable in the ITU legal system.

Then, the ITU system contains a sort of non-compliance procedure, but lacks specific enforcement means. The notion of compliance is distinct from related terms, such as "effectiveness," "enforcement" and "implementation." Implementation refers, in a neutral way, to the actions undertaken by the parties to the ITU legal instruments in fulfilling their commitments, mainly at the internal level. Even in cases where the parties are in full compliance to agreement provisions, the ITU conventional instruments may not be implemented, or fully implemented or correctly implemented, because the actions do not achieve the aims established by the same instruments. Enforcement focuses on ensuring the observance of a legal norm through legal means, including coercive means. Effectiveness has to do with the factual degree of application of a legal norm, by all possible means.

Compliance is a narrower concept, focusing on the fulfilment of legal commitments through cooperative mechanisms which involve the community of States Parties to a treaty. More often, non compliance depends on the behaviours of the States parties to a treaty, when a State, for instance, consciously decides not to respect a conventional obligation. But more often non compliance is due to the financial or technological incapacity of States to meet the obligations established by a treaty, as in the case of developing countries. Finally, States may inadvertently fail to comply. 
Now, the ITU procedures in case of harmful interference are not properly working as a classical "non-compliance mechanism," but can nevertheless be included in this category. In fact, if the interference is not ceased, then ITU intervenes mainly as a mediator: it can appeal to the parties concerned to exercise the utmost goodwill and, if those parties cannot reach a satisfactory result, the administration victim of the interference can seek the assistance of the Radiocommunication Bureau. The RB shall, as appropriate, help in identifying the source of the interference and seek the cooperation of the responsible administration in order to resolve the matter, together with a request for prompt action. The procedure ends with a non legally binding report for consideration by the ITU Board, including draft recommendations to the administrations concerned, which shall ascertain the facts and take the necessary actions (WRC-12).

At this point, the key principle, shared with the systems of many other international organizations, is again that the enforcement of the obligations assumed by Member States, such as the obligation to avoid harmful interference, rest fundamentally with the national regulatory authorities of each individual Member State. They can resort in the last instance to the means offered by general international law on State responsibility for wrongful acts. The ITU has in fact no coercive powers to enforce the report of the Bureau.

WRC-12 reaffirmed that recent and repeated cases of intentional harmful interference represent infringements and that member States under the jurisdiction of which the signals causing harmful interference are transmitted have the obligation to take the necessary action. This bring us to consider that compliance within ITU system could be improved through enhanced organizational co-ordination, strengthened national implementation and enforcement mechanisms, capacity building and training. Furthermore, there is room for improving the system mainly through international independent monitoring to localize the sources of harmful interference. Some steps in this direction have already been realized.

In conclusion, in the ITU legal order unity and multiplicity, stability and change mutually condition each other. On the one hand, the ITU special regime has evolved as a response to insufficiencies of the general system. On the other hand, the very same regime remains dependent on international law in a number of ways, including, as a measure of last resort, the enforcement of substantive obligations. 


\title{
3.3/ From GEO and Spectrum Crowding to the Threat of Space Debris: Is our Present Use of Outer Space Sustainable?
}

\author{
Gérard Brachet, Space Policy Consultant, former Chairman of the UN Committee on \\ the Peaceful Uses of Outer Space (2006-2008), French expert on the UN Group of \\ Governmental Experts on Outer Space TCBMs (2012-2013).
}

\section{Setting the scene}

The safety and sustainability of space activities in earth orbit over the long term is increasingly a matter of concern for space faring nations and regional space organizations as well as for commercial satellite operators. The ever increasing number of actors in outer space, both government and private, the increasingly difficult task of managing the finite radio-electric spectrum available and the geostationary orbit slots, the effect of space weather on space operations and the proliferation of space debris produced by an increasing use of outer space, all call into question the ability to continue operating safely and without interference, at least in the low earth orbits (LEO) and in the geostationary earth orbit (GEO).

The legal background for the safety and sustainability of space activities can be found in several instruments and provisions of international law as well as national legislations which deal with the concerns relevant to the sustainable future of space activities, namely the rational use of outer space, the responsibility of States for space activities, international liability in case of damage and the transparency in the utilisation and the exploitation of outer space, in particular Earth's orbits.

A first set of relevant principles is made of the principles stated by the 1967 Outer Space Treaty. Those principles feature the freedom of access to and use of Outer Space, the non-appropriation under national sovereignty of Outer Space, the respect of the space environment, including Earth's orbits, the sharing of information on space activities and their outcome.

Another major legal instrument is the Constitution of the International Telecommunications Union, complemented by the ITU Radio-regulations which have both the status of an international convention.

Other important set of principles are related to States' international responsibilities for space activities. States are responsible for their own governmental activities and for private activities performed under their jurisdiction. This requires States to authorize and supervise such activities. Furthermore, according to the 1967 UN Outer Space Treaty as complemented by the 1972 UN Liability Convention, States which launch or procure a launching or from whose territory or facility an object is launched are internationally liable for any damage caused by this space object on the Earth's surface and to aircraft in flight as well as for damage caused by their fault to another space object in flight. It must be noted that the definition of a "space object" includes the object as well as any of its parts. In connection to the international responsibilities principle, the space object registration mechanism is set up by the 1967 UN Outer Space Treaty as complemented by the 1975 UN Registration Convention. This set of provisions requires that any object 
launched in Outer Space be registered by (one of) the launching State(s). This State thereby exercises its jurisdiction and control on and onboard the space object.

Besides the UN treaties and conventions, the United Nations General Assembly has adopted several resolutions related to various specific aspects of space activities. Those resolutions have no binding effect per se, although some of them have generated constant practice from space faring nations and contain important principles and recommendations. ${ }^{2}$

An important text has been adopted within the UN COPUOS Legal SubCommittee at its $39^{\text {th }}$ session, as inserted in the Main Committee's report adopted by the United Nations General Assembly (December 8, 2000). This text features the consensus achieved amongst UN COPUOS' Member States on the access to and the use of the geostationary orbit, considering the interests and needs of developing countries.

Finally, one should also keep in mind the United Nations General Assembly Resolutions adopted through its First Committee on "Transparency and ConfidenceBuilding Measures," which relate more specifically to the risks associated with potentially aggressive behaviour in Outer Space. ${ }^{3}$ In particular Resolution 65/68 of December 2010 which calls for the establishment of a Government Group of Experts to develop and submit to the UN General Assembly a set of TCBMs for Outer Space activities. More on this GGE later in this article.

\section{Initiatives in the UN context}

The issue of sustainability of space activities has already been addressed by many sectors of the space community, for example the Inter-Agency Space Debris Coordination Committee (IADC) which focused on the proliferation of space debris, by the International Academy of Astronautics which published a report on space traffic management in $2006^{4}$ or by the International Association for the Advancement of Space Safety (IAASS), which published a report called "An ICAO for Space?" in 2007.

It was also raised by the chairman of the United Nations Committee on the Peaceful Uses of Outer Space (UN COPUOS), the committee mandated by the UN General Assembly to elaborate appropriate resolutions, principles or international conventions relative to the peaceful uses of outer space, in his paper "Future role and activities of the UN COPUOS" 5 presented to member states' delegations at the plenary session of UN COPUOS in June 2007. Following this initiative, at its 52nd session, in June 2009, the French delegation to UN COPUOS formally proposed the

\footnotetext{
${ }^{2}$ The most relevant resolutions with respect to the issue of long-term sustainability of space activities are the following: Resolution 47/68 of 14 December 1992, on the Use of Nuclear Power Sources in Outer Space; Resolution 51/122 of 13 December 1996, featuring the Declaration on international cooperation in Outer Space. Two other technical resolutions are relevant as far as the improvement of the transparency and the reliability of space activities is concerned: Resolution 59/115 of 10 December 2004 on the Concept of "Launching State"; Resolution 62/101 of 17 December 2007 on the States' registration practices. Two resolutions of December 1961 (Res. $1721 \mathrm{~A}$ and B) must also be noted since they provide the legal basis to some States for communicating information and data about space objects and activities to the UN Secretary General.

3 Those are resolutions on Transparency and Confidence-Building Measures in Outer Space Activities (i.e. A/Res/61/75 of 6 December 2006, A/62/43 of 5 December 2007, A/Res/63/68 of 2 December 2008, A/Res/64/49 of 2 December 2009 and A/Res/65/68 of 8 December 2010).

${ }^{4}$ Cosmic Study on Space Traffic Management, IAA, 2006.

${ }^{5}$ A/AC.105/L268 of 10 May 2007(section D).
} 
topic of "Long-Term Sustainability of Outer Space Activities" as a new agenda item of COPUOS in 2010.

COPUOS agreed to include this item as a new agenda item of its Scientific and Technical Sub-Committee in 2010 and beyond. The COPUOS/STSC then decided to set up a formal Working Group to address this issue, as it had done in 2003 for the space debris issue. Dr. Peter Martinez (South Africa) was selected to be the chairman of this new dedicated Working Group and its first meeting took place in conjunction with the 53rd session of COPUOS in Vienna in June 2010. The Terms of Reference of the Working Group were approved during the 48th session of COPUOS/STSC in 2011. ${ }^{6}$

Four Expert Groups were set up, each addressing different aspects of the sustainability issue:

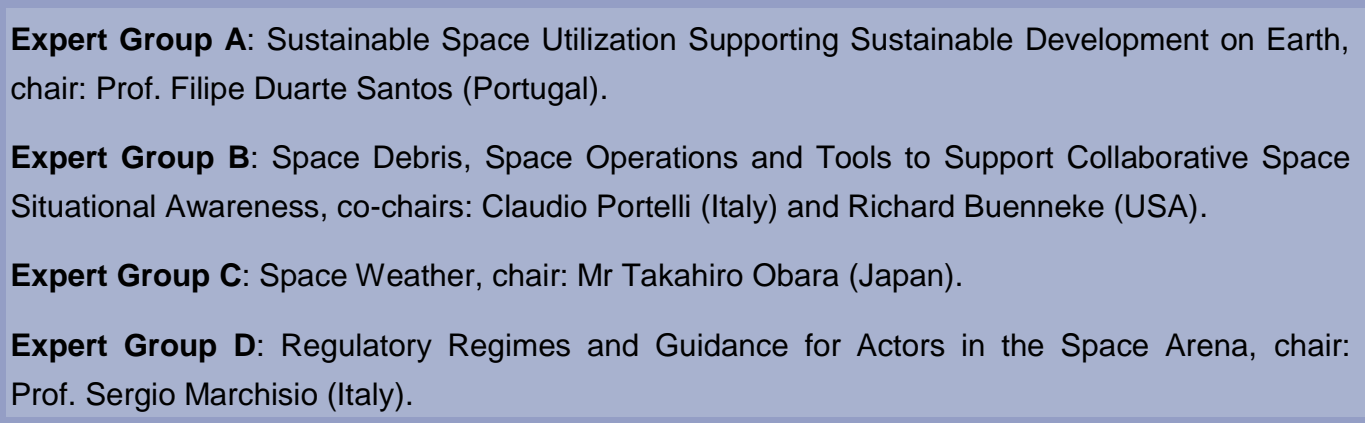

Ensuring an active interaction of the Working Group on Long-Term Sustainability of Outer Space Activities with the community of commercial satellite operators, not formally represented in UN COPUOS, was deemed essential. Ad hoc workshops, such as the one that took place in February 2013, were organized for this purpose. In parallel, continuing interaction with the International Telecommunication Union (ITU), with the Inter Agency Debris Committee, with space weather organizations and with other interested parties such as the International Academy of Astronautics, the International Astronautical Federation (IAF) and the Association for the Advancement of Space Safety (IAASS), is essential in order to benefit from their work and avoid any unnecessary duplication.

The expected output from this COPUOS Working Group are a set of "Best practice" guidelines for space operations and recommendations to establish new data exchange mechanisms, both aimed at improving the safety of launch and inorbit operations.

\section{The European Union proposal for an International Code of Conduct for Outer Space Activities}

In parallel to the COPUOS activities on Long-Term Sustainability of Outer Space Activities, the discussions on the Prevention of an Arms Race in Outer Space (PAROS) at the Conference on Disarmament in Geneva are not making any progress because the CD could not agree on a work plan. As a consequence, the Council of the European Union has taken in 2007 an initiative to propose an

\footnotetext{
${ }^{6}$ Annex II to A/66/20. ${ }^{7}$ See Resolution $68 / 50$ on "Transparency and confidence-building measures in outer space activities," adopted by the General Assembly on December 5, 2013, http://www.un.org/fr/documents/view_doc.asp?symbol=A/RES/68/50\&TYPE=\&referer=http://www.un.or $\mathrm{g} / \mathrm{fr} / \mathrm{ga} / 68 /$ resolutions.shtml\&Lang=E
} 
"International Code of Conduct" for Outer Space Activities. A first version of the EU draft Code of Conduct was approved by the EU Council in Dec. 2008 and widely circulated.

Bilateral consultations with major space-faring nations were conducted by the EU in 2009-2010, leading to a new version of the EU-proposed International Code of Conduct circulated in September 2010. A first multilateral meeting took place on June 5, 2012 in Vienna, where an updated version of the draft Code was presented by the EU External Action Service and a second multilateral forum took place in Kiev, Ukraine, on 15th and 16th May 2013. Further multilateral consultation meetings are planned, eventually leading to a Conference of adhesion to finalize and sign this International Code of Conduct provided that a sufficient number of States have declared their willingness to sign in.

\section{The UN Group of Governmental Experts}

As noted earlier, the first Committee of the UN General Assembly has adopted in 2010 Resolution 65/68 on Transparency and Confidence Building Measures (TCBMs) in outer space activities. This resolution requests the UN Secretary General to set up a Governmental Group of Experts (GGE) to conduct a study on outer space transparency and confidence measures and report to the UNGA by the end of 2013.

The Group of Governmental Experts has been formally set up at the beginning of 2012 and includes representatives from 15 countries: Brazil, Chile, China, France, Italy, Kazakhstan, Nigeria, Romania, Russian Federation (Chair), Rep. of Korea, South Africa, Sri Lanka, Ukraine, United Kingdom, United States.

It held its inaugural meeting in New York on July 23 to 27, 2012 and two working meetings in 2013, one from 1 to 5 April in Geneva and one from 8 to 12 July in New York. The GGE worked very efficiently under the chairmanship of Victor Vassiliev, Deputy Chief of the Russian permanent mission to the United Nations and the Conference on Disarmament in Geneva and was able to finalize its report, adopted by consensus, during its meeting in July in New York. It was submitted for endorsement to the first Committee of UN General Assembly in December 2013. ${ }^{7}$ Some recommendations extracted from the GGE report are worth mentioning here:

In section VI (Consultative mechanisms):

"Timely and routine consultations through bilateral and multilateral diplomatic exchanges and other government-to-government mechanisms including bilateral, military-to-military, scientific, and other channels can contribute to preventing mishaps, misperceptions and mistrust. They may also be useful in:

a. clarifying information regarding exploration and use of space, including for national security purposes.

b. clarifying information provided on space research and space applications programmes

c. clarifying ambiguous situations.

d. discussing the implementation of agreed transparency and confidencebuilding measures in outer space activities.

\footnotetext{
7 See Resolution 68/50 on "Transparency and confidence-building measures in outer space activities," adopted by the General Assembly on December 5, 2013, http://www.un.org/fr/documents/view_doc.asp?symbol=A/RES/68/50\&TYPE=\&referer=http://www.un.or $\mathrm{g} / \mathrm{fr} / \mathrm{ga} / 68 /$ resolutions.shtml\&Lang=E
} 
e. Discussing the modalities and appropriate international mechanisms to address practical aspects of outer space uses.

f. Preventing or minimizing potential risks of physical damage or harmful interference.

States are encouraged to consider using existing consultative mechanisms, for example as provided for in Article IX of the Outer Space Treaty of 1967 and the relevant provisions of the ITU Constitution and the Radio Regulations."

Also, in its concluding section:

"The GGE endorses efforts to pursue political commitments, for example, in the form of unilateral declarations, bilateral commitments or a multilateral code of conduct to encourage responsible actions in, and the peaceful use of, outer space. The GGE concludes that voluntary political measures can form the basis for considerations of concepts and proposals for legally binding obligations."

\section{Conclusions}

The converging initiatives described above of UN Committee on the Peaceful Uses of Outer Space (COPUOS), of the European Union for an international Code of Conduct for Outer Space activities and the recent work of the UN Governmental Group of Experts on Outer Space TCBMs illustrate the concern of both space-faring nations and non space-faring nations for the future safety and sustainability of the uses of Outer Space for government-sponsored as well as commercial applications.

However, much remains to be done to transform these recommendations into actions or, in some cases, legally binding obligations.

The complementary work done within the ITU to reinforce its ability to regulate the use of the radio-electric spectrum and the GEO orbital slots should eventually complete a whole new set of principles and guidelines which will provide for a better governance of the uses of Outer Space. Hopefully this new governance will lead to a safer and more sustainable outer space environment in the future. 


\title{
Conclusion: Governance Without Politics?
}

\author{
Guilhem Penent, Research Associate at Institut Français des Relations \\ Internationales (IFRI), Paris (France).
}

This book has presented a series of views and analysis on the issue of the distribution and use of the orbit/frequency resource (OSR) in an era of increasing interference. The views have come from a vast range of recognized space policy experts, academics, high level representatives from various public institution (European External Action Service) and international organization (International Telecommunication Union), as well as representatives from the private telecommunication sector (ESOA, Eutelsat, Intelsat, SES). Following the seminar of April 2013 in which most of the contributors participated, the book is an outreach effort toward creating awareness and assigning significance and meaning to actual developments taking place in satellite communications.

Such an effort is deemed necessary for the radio spectrum and geostationary orbit may often appear to the nonspecialist to be very technical and obscure topics. Suffice to say for that matter that, while playing a pivotal role in fostering cooperation in telecommunication as one of the most important of the UN specialized agencies, the International Telecommunication Union (ITU) has always maintained a low profile. Unlike the World Trade Organization (WTO), International Monetary Fund (IMF) or even the International Civil Aviation Organization (ICAO), the Union rarely makes the headlines. The management of the parking slots and associated frequency bands in the geostationary-satellite orbit, however, is a crucial and timely issue in its own right. Its critical importance to the rapidly expanding use of telecommunications and its vulnerability to increasing harmful interference are at the heart of this study. As a result, the objective of this project, both modest and ambitious at the same time, has been to diagnose and identify key bottlenecks and points of concern behind the current situation; it has been to recognize what the main issues at stake are rather than to search for any hypothetical solutions.

On the whole, the contributors are in agreement with the idea that, though there certainly is room for improvement, the world is better off with the ITU than without. The ITU provides an invaluable global forum that even the most recalcitrant members of the organization have learnt to respect and appreciate; a forum which since its inception has allowed discussions and fruitful exchanges for the development and progress of international telecommunications. Not only does it set the rules of the road by which all the countries and users must abide, it is also one of the sole avenues through which developing countries can address their broader needs and concerns without being entirely circumvented. Monitoring may not provide a definitive answer to issues such as harmful interference, but it is still an important step in the right direction. Opinions differ more widely as regards the departure from the current status quo toward any sanction-based approach that would radically change the face of the Union as we know it. For many, the ITU exists as a technical broker to address technical means of facilitating international telecommunications. As such, politically motivated issues are beyond its scope for the ITU must be 
apolitical if it is to be effective and accepted by all. For others, as the number of players increases and as ever more demand by satellite systems for orbits and frequencies may soon exceed availability, ITU decision-making is forced to become more and more complex and difficult. The Union may well be a gentlemen's club depending on the goodwill of its members, not all of them are gentlemen. Should the unconditional acceptance of the word of a sovereign nation, no matter how dubious it is, be conducive to continued abuses and illegal practices, confidence in the sustainability of the use of the OSR and therefore incentive for other space actors to cooperate will be in jeopardy. As noted by many contributors, one way to reconciliation might actually be to resort to other legal instruments, which may be both available and better suited than the ITU regime itself to address the problem of harmful interference and its political intricacies.

It is worth recalling that the Union is an intergovernmental structure and that its evolution remains therefore the responsibility of national states. In the absence of any central authority with coercive power, the key role is still played by the administrations which are the only actors capable of enforcing agreements, that is, of controlling signals coming from within their own territory. Yet, despite the fact that many if not all recent controversies and difficulties related to satellite communications have been triggered by changes in the interests and relative capabilities of the actors, knowingly absent from this study has been any discussion related to power. The distribution of power, however, has been a key variable in explaining the emergence or absence of international telecommunication regimes; ${ }^{1}$ it is likely to remain so with geopolitical changes looming at the horizon. All the more the reason to keep in mind that there is no such thing as governance without politics. $^{2}$

Regarding the issue at hand, power can be understood through three considerations: first, membership in a universal international organization such as ITU, which is based on the principle of sovereign equality: one-country, one-vote; second, the degree of control over territorial access as provided by sovereignty and notably the ability to regulate and block transnational information flow; and third, technology and market size, which can influence the relative opportunity costs of change and therefore the ability to make credible threat. ${ }^{3}$ The conclusion which follows is three-fold. It is openly state-centric, as a first cut aiming at hypothesis generation rather than hypothesis testing.

1) The more than ever timely problem of the ITU is that it was established to solve pure issues of coordination in which actors had a common interest in avoiding the mutually undesirable outcomes of radio interference and incompatible national communications systems and in ensuring that their satellites could operate through clear radio communications. Because of greater congestion, it has been in pain in recent years to adapt itself to a situation which requires a more collaborative ("a priori") allocation of an increasingly scarce twin resource. Indeed, the worst outcome for an actor is now to fail to get on the radio spectrum and relevant orbital slots at all. The fact that most OSR is still allocated on a first-come, first-served basis that benefits the world's most economically and technologically advanced nations mirrors the existing distribution of power capabilities. Accordingly, it is telling that the main

\footnotetext{
${ }^{1}$ Stephen D. Krasner, "Global Communications and National Power: Life on the Pareto Frontier," World Politics, Vol. 43, No. 3 (Apr., 1991), 336-366.

2 John Vogler, "Studying the global commons: governance without politics?," in Peter Dauvergne (ed.), Handbook of Global Environmental Politics (Cheltenham, UK: Edward Elgar, 2005), 51-63.

${ }^{3}$ Krasner (fn. 1), 363.
} 
tendency is to consider the "dilemma of common interests" - as opposed with the "dilemma of common aversions" that characterized the previous era ${ }^{4}$ - as a manifestation of collective irrationality leading to the so-called "tragedy of the commons," whose corrective can only be technical. This vision of political neutrality neglects what some have referred to as the "tragedy of dispossession." ${ }^{5}$ And in effect, no longer willing to accept what is in practice a form of coordination between developed countries, new entrants have begun to challenge rules of the game based on the present needs for communications through their votes in the ITU and their ability to interfere more or less candidly with broadcasts from other states. Difficulty will be to balance each group's interests without undermining the efficiency and universality of the system.

2) In the second issue area considered in this study - i.e. information flow -, there is no international regime per se. Or, to be more exact, if a regime is to be found, it is entirely permissive, allowing complete freedom to direct broadcasts across frontiers. Such an outcome was rendered possible because more powerful states, notably Western market-oriented democracies, have been able to secure their best solution which was to act unilaterally. Given the inability of states to regulate access to their own territory completely as it is easier to transmit than to block radio and television transmissions, the advocates of open dissemination have prevailed. Not to say that governments have stopped to seek to control the flow of information. Restrictions favorable to the principle of prior consent do exist; but those agreements have in fact been limited to areas where states have shared the same preferences and relatively equal power as manifested by their mutual ability to interfere with each other's broadcasts. This explains why countries of the European Union could coordinate while Cuba and the United States could not. For this reason, rather than looking for a global governance structure, one needs to focus on a more informal pattern figuring different regional themes and forms of state interventions that turn on particular satellites, particular footprints, or particular content. ${ }^{7}$ Assuming no agreement on principles involving the prior consent approach will ever be, the future of state control will depend on power derived from new technologies: fiber or, in the meantime, new particularly harmful jamming techniques. The issue of intentional interference directly affecting the uplink transmission of satellites, i.e. the sources of the signal, is proof that the distribution of power is not set in stone; a development with inevitable linkages with the ITU which reminds us that the leasing of transponders is much more than mere economic transactions.

3) The last dimension that needs to be considered, though being non-spatial, conveys important implications for both previous issue areas. Much has been said about the technological and economic competition between transmission systems on the ground and satellite communications in orbit; one important yet mostly unheardof part of the story, however, remains to be told. As more terrestrial networks are being put in place, bands of the spectrum now used by satellites for transmission notably in the developing world are quietly but steadily coveted by terrestrial

\footnotetext{
4 Arthur A. Stein, "Coordination and Collaboration: Regimes in an Anarchic World," International Organization, Vol. 36, No. 2 (Spring, 1982), 299-324, esp. 315-316.

${ }^{5}$ Vogler (fn. 2), 59.

6 To date, another challenge has been the almost universal practice of the registration of so-called "paper or virtual satellites," that companies use to warehouse orbital slots and frequencies, thus preventing others from developing them, but with no real intention of using them with operational satellites. See Ram Jakhu, "Legal Issues of Satellite Telecommunications, The Geostationary Orbit, and Space Debris," Astropolitics, Vol. 5, No. 2, (2007), esp. 181-184.

7 Monroe E. Price, "Satellite Transponders and Free Expression," Cardozo Arts \& Entertainment Law Journal, Vol. 27, No. 1 (2009-2010), 1-35.
} 
providers looking for a greater slice of limited radio spectrum, resulting in the fact that interference with satellite signals is becoming a common occurrence. While the battle over the status of C-band regulatory allocations has been put on stand-by, threats to other frequencies traditionally reserved for satellites systems may already be on the horizon. ${ }^{8}$ The issue is primarily determined by the weighting of the two industries within each state. Still, this development is equally important as part of the broader reform of the Union and its continued relevance in the future. Should the future be terrestrial in majority, the whole scene will be rather different from today. Contrary to the space common which has been ITU's historical preserve and a global transborder issue which needs some sort of international coordination by definition, the Union's intervention on the ground is limited so long as terrestrial broadcasts are contained within one's own territory. With very large countries characterized by a huge domestic market, the result would be like having powerful autonomous structures running in parallel without any buffer to serve as an equalizer during bilateral and international negotiations. As witnessed by the Internet governance controversy in 2012, the ITU-R in charge of coordinating the OSR in the common interest of all is certainly one of the few elements that might be holding some countries from threats of defection or unilateral action.

\footnotetext{
${ }^{8}$ Editorial, “Facing Down the Next Spectrum Challenge," Space News, Jan. 13, 2014.
} 


\section{List of Authors and Contributing Entities}

Philippe Achilleas

Frank Asbeck

Alain Austruy

Astrid Bonté

Gérard Brachet

Ron Busch

Yvon Henri

Claire Jolly

Ethan Lavan

Sergio Marchisio

Tanja Masson-Zwaan

Xavier Pasco

Guilhem Penent

Laurence Ravillon

SES

Victor Strelets 